\title{
100 Jahre Geographisch-Ethnographische Gesellschaft Zürich
}

\section{Einleitung}

Die Geographisch-Ethnographische Gesellschaft Zürich feiert in diesem Jahr ihr hundertjähriges Bestehen, obwohl sie dieses Alter noch gar nicht erreicht hat. Dem kleinen Schönheitsfehler zum Trotz - die reichlich komplizierte Entstehungsgeschichte wird sich aus den folgenden Seiten erhellen - erfüllt uns dieses Ereignis natürlich mit großer Freude und berechtigtem Stolz, vor allem auch deshalb, weil die greise Jubilarin in einer bis anhin unerreichten Blüte steht und ihre Lebenskraft zu einem kleinen Teil nur aus rückwärtsgewandter Traditionsschau bezieht, in unvergleichlich höherem Maß hingegen aus der Perspektive eines zukunftsgerichteten Tatendrangs. Das Jubiläum bietet uns Anlaß, der Geschichte der Gesellschaft etwas genauer nachzugehen, einen kurzen Blick in die reichen, in ihren Annalen verborgenen Schätze zu tun, aber auch einmal allgemein Rückschau auf die Entwicklung der geographischen Wissenschaften in dieser Stadt zu halten. Am Übergang zum zweiten Jahrhundert des Bestehens der Geographisch-Ethnographischen Gesellschaft Zürich empfiehlt sich ein solcher Überblick zur Standortbestimmung ganz besonders, kann und soll er uns doch auf dem weiter zu beschreitenden Weg orientierend behilflich sein.

\section{Die Anfänge der Schweizer Hochschulgeographie}

Es wäre wohl verfehlt, Zürich als jahrhundertealtes Geographen-Zentrum zu betrachten; die Wissenschaft der Erdkunde hat sich erst zu Ende des vergangenen Jahrhunderts in dieser Stadt fest etabliert und ihre spezifischen Vertreter hervorgebracht. Allgemein bekannt ist hingegen, daß die Limmatstadt immer wieder bedeutende Naturforscher und Universalgelehrte zu ihren Bewohnern zählte. Wir wollen hier nur Conrad Gessner und Johann Jacob Scheuchzer nennen, die natürlich in ihren Werken häufig auch geographische Sachverhalte beschrieben und erdkundliches Wissen zusammengetragen haben. Bei all diesen wichtigen Persönlichkeiten aus der Zeit der Renaissance und der Aufklärung können wir jedoch nicht von eigentlichen Geographen sprechen, auch kaum bei ihren vereinzelten Nachfolgern bis ins 19. Jahrhundert hinein.
Auf Julius Fröbel (1805-1893) trifft als Ausnahme die Bezeichnung «Geograph» noch am ehesten zu, obwohl ein großer Teil seines Lebenswerks verlegerische Tätigkeit und politische Publizistik umfaßt. Fröbel, der aus Thüringen stammte, kam durch Empfehlung Alexander von Humboldts nach Zürich und hielt an der neugegründeten Universität Zürich während des ersten Jahrzehnts ihres Bestehens geographische Vorlesungen. Somit fällt dem jungen Deutschen die Ehre zu, allem Anschein nach als erster die moderne, auf Alexander von Humboldt (1779-1859) und Carl Ritter (1769-1859) zurückführende wissenschaftliche Geographie in der Schweiz gelehrt zu haben. Auch war er wahrscheinlich der erste Lehrbeauftragte für Geographie an einer schweizerischen Hochschule überhaupt - kümmerlich entlöhnt notabene wie damals die meisten anderen, zum Großteil aus Deutschland stammenden Dozenten der 1833 errichteten Zürcher Universität. Bemerkenswert ist im weiteren, daß Fröbel in der Mitte der dreißiger Jahre zusammen mit dem berühmten Erforscher urweltlichen Lebens Oswald Heer (1809-1883) als Herausgeber der interessanten «Mittheilungen aus dem Gebiete der theoretischen Erdkunde» in Erscheinung trat, die allerdings bereits nach dem ersten Band wieder eingestellt wurden. Die in Zürich edierte Zeitschrift war «dem Herrn Freiherrn Alexander von Humboldt gewidmet», «dem Ersten, welcher den großen Zusammenhang der Naturerscheinungen an der Erde als besondere Aufgabe einer eigenen Wissenschaft aufgefaßt hat», und enthält einen interessanten, von Fröbel verfaßten «Entwurf eines Systemes der geographischen Wissenschaften».

Fröbels Rücktritt 1843 öffnete eine bedauerliche Lücke, die vorerst niemand auszufüllen in der Lage war. Wir bedauern von unserem Standpunkt aus natürlich, daß er durch seine Hinwendung zu Politik und Publizistik der Geographie verloren ging und darüber hinaus die Tatsache, daß sich in Zürich für ihn kein Nachfolger gefunden hat, der auf seinem

Peter Jud, Dr. phil., Geograph, Eidmattstr. 49, 8032 Zürich 


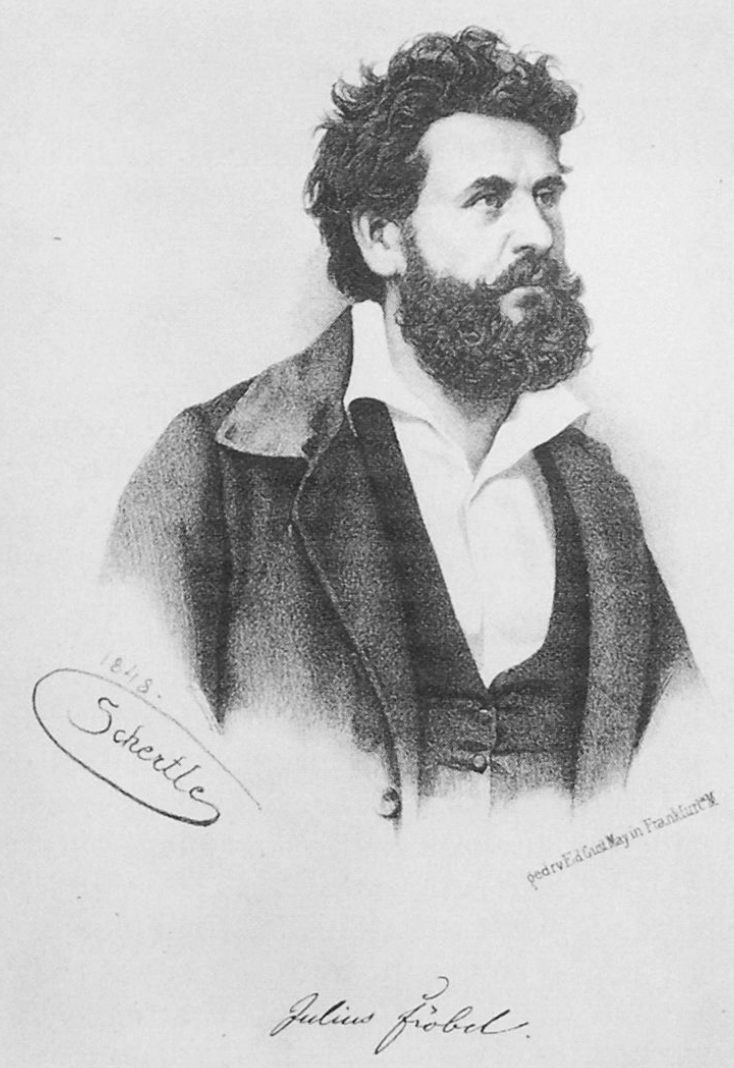

Abb. 1 Julius Fröbel (1805-1893), geboren in Griesheim (Thüringen), war der erste Dozent für Geographie an der Universität Zürich. Nach den Reisen und literarischen Versuchen seiner Jugendzeit betrieb er naturwissenschaftliche Studien in München. Bekanntschaften mit Karl Andree, Carl Ritter und den Brüdern Humboldt sowie das Angebot zu geographischer Schriftstellerei führten inn während seiner Aufenthalte in Weimar, Jena und Berlin (1828-1833) auf das Gebiet der wissenschaftlichen Erdkunde. Ab 1833 wirkte er als Lehrer für Geschichte und Geographie an der Zürcher Industrieschule (heute mathematisch-naturwissenschaftliches Gymnasium), zwischen 1833-1843 auch als Dozent (PD 1833, AO 1836-1843) für Mineralogie und Geographie an der hiesigen Universität. Er hielt Vorlesungen über "Oryktognosie" (Mineralogie und Gesteinskunde), "Physische Geographie", "Geographie von Afrika", "Geographie von Asien, nach Ritter", "Geographie von Amerika", "Allgemeine geographische und ethnographische Übersicht der Erde" usw.

Bereits diese Titel geben einen Hinweis auf Fröbels Orientierung an Carl Ritter, dessen geographisches Konzept er mit gewissen Einschränkungen übernommen hat. Fröbels Lehre besaß einen "originellen, der Zeit vorauseilenden Charakter. Sie hätte den Geographie-Unterricht an der Hochschule in aussichtsvolle Bahnen gelenkt” (Gagliardi und Strohl, 1938: 314), doch sein freiheitlicher Geist wandte sich nach dem "Züri-Putsch" und dem Sturz der radikalen Regierung mehr und mehr der Politik zu. Durch seine Verlegertätigkeit für das "Litterarische Comptoir in Zürich und Winterthur" in finanzielle Bedrängnis geraten, in politische Prozesse verwickelt und schließlich zu Gefängnisstrafen verurteilt, legte Fröbel sein Zürcher Lehramt 1843 nieder. Nach wechselvollen Jahren als Journalist und Diplomat in Amerika, Kleinasien und Nordafrika kehrte er 1892 in unsere Stadt zurück, wo er ein Jahr später verstarb.
Fundament aufbauend eine zürcherische geographische Schule hätte begründen können. Die späteren Geographie-Lehrbeauftragten der Universität vermochten nicht an die Arbeit des Deutschen anzuknüpfen - ein im germanischen Raum allgemein feststellbares Merkmal für die fehlende Kontinuität der Geographie in der Ära nach Ritter und Humboldt.

Die nachfolgenden Zürcher Dozenten waren Carl von Fritsch (1838-1906), der vom Sommersemester 1864 an bis 1867 hier lehrte - also rund zwanzig Jahre nach Fröbel -, Jakob Egli (1825-1896), Otto Stoll (1849-1922) und Jakob Früh (1852-1938). Egli hatte von 1883 bis 1891 die außerordentliche Professur für Geographie inne, die damals noch der Philosophischen Fakultät I der Universität Zürich angehörte. Er wurde abgelöst von Stoll, der an der Philosophischen Fakultät II zuerst Extraordinarius, ab 1895 ordentlicher Professor für Geographie war. Damit hatte die wissenschaftliche Erdkunde an der Universität Zürich den ersten Vertreter auf ihrem Lehrstuhl erhalten, vier Jahre nach der Errichtung des von Prof. Brückner gehaltenen Ordinariats an der Universität Bern, des ersten in der Schweiz.

Die Situation an der 1855 geschaffenen Eidgenössischen Technischen Hochschule war derjenigen an der hiesigen Universität hinsichtlich Dozenten und Vorlesungsangebot ähnlich. Die ersten «rein geographischen» Vorlesungen - wenn wir von thematisch verwandten Veranstaltungen für die damaligen Forstwissenschafts- und Geologiestudenten absehen - wurden in den frühen sechziger Jahren gehalten, und der erste Dozent war mit Carl von Fritsch mit demjenigen an der Universität identisch. 1866 begann auch der bereits erwähnte Jakob Egli seine Unterrichtstätigkeit am Polytechnikum, die er bis 1886 ausübte, assistiert von den Privatdozenten Weilenmann, Bodmer, Stoll und Früh. Seit den achtziger Jahren gab es an der ETH auch noch eine Professur für allgemeine Geschichte und Geographie in französischer Sprache. Das erste Ordinariat für Geographie wurde 1899 errichtet, und sein erster Inhaber hieß Jakob Früh.

Mit Otto Stoll an der Universität und Jakob Früh an der ETH war in den Anfangsjahren der zürcherischen akademischen Geographie das breite Spektrum dieser Wissenschaft an den beiden Hochschulen gut abgedeckt. Wie nachstehend noch genauer ausgeführt wird, war Stoll ein Vertreter der ethnologisch-anthropologischen Richtung der Geographie, während Früh entschieden der physisch-geographischen Seite zuneigte. In diesem Zusammenhang sei erwähnt, daß Stolls Wahl an die Universität fakultätsintern insbesondere vom Geologen Albert Heim angefochten wurde, der gerne einem Vertreter der physischen Geographie, beispielsweise Jakob Früh, den Vorzug gegeben hätte (scHMUTz, 1983: 170). 
Das schleppende Voranschreiten bei der Installierung der Geographie auf der akademischen Stufe über mehr als ein halbes Jahrhundert hinweg ist glücklicherweise kein spezifisch zürcherisches, sondern leider ein internationales Phänomen gewesen. Der Tod der beiden Väter der modernen Geographie, Carl Ritters und Alexander von Humboldts, im selben Jahr 1859 brachte für die wissenschaftliche Erdkunde den Abschluß der ersten, klassischen Periode. Die nächsten Jahrzehnte führten die international wichtige deutsche Geographie in eine Phase des Neuanfangs und der Neuorientierung. Die Entwicklung mündete in eine allmähliche «Geologisierung» der Geographie; «die Geomorphologie entwickelte sich zum Hauptstrang der Geographie in Deutschland» (BECK, 1982: 206). Was sich an Deutschlands Universitäten abzeichnete, blieb natürlich nicht ohne Auswirkungen auf andere akademische Zentren des deutschsprachigen Raumes, und in der Tat können wir in Zürich ähnliche, wenn auch zeitlich verschobene Phänomene und Entwicklungen erkennen: Die Lücke, welche sich nach Ritter und Humboldt auftat, die Versuche, der noch jungen Wissenschaft eine der Geologie zuneigende Richtung zu geben, sowie die Abgrenzungsschwierigkeiten der Geographie gegenüber anderen Wissenschaftszweigen natur- oder geisteswissenschaftlicher Art. Mit Identifikationsproblemen und Methodenstreit sieht sich die Erdkunde übrigens bis auf den heutigen Tag konfrontiert. In der Vielfalt und Breite der Geographie und in der Komplexität ihrer Fragestellungen liegt ein besonders schöner und faszinierender Zug dieser Wissenschaft, aber auch eine nicht zu übersehende Schwierigkeit.

Es liegt auf der Hand, daß die Geographen der ersten Stunde sich gewissermaßen Neuland erarbeiten und autodidaktisch auf ein eigenes Tätigkeitsfeld vortasten mußten, da sie von Hause aus eine andere Ausbildung - zum Mediziner, Geologen, Botaniker, Historiker - mitbrachten. Es überrascht aus diesem Blickwinkel nicht, daß diese neu aufkeimende Disziplin lange im Schatten anderer, etablierter Wissenschaften stand und sich nur langsam ihren Platz erobern konnte. Fridolin Becker, ein bedeutender Topographie- und Kartographieprofessor an der ETH, der sich immer mit Nachdruck für die Geographie eingesetzt hat, stellte 1897 bedauernd fest: "Die Schweizergeschichte wurde in unserem Lande immer in hervorragender Weise, die Geographie der Schweiz aber daneben eher als Stiefkind behandelt. Haben wir doch am eidgenössischen Polytechnikum in Zürich selbst neben zwei Professoren für $\mathrm{Na}$ tionalökonomie zwei für allgemeine Geschichte, einen für spezielle Schweizerische Geschichte, einen für Kunstgeschichte, einen für Philosophie und Geschichte der Philosophie, aber keinen für Geographie. Ein Privatdozent liest abwechselnd allgemeine und spezielle Schweizergeographie; daneben wird an der kriegswissenschaftlichen Abteilung noch Militärtopo- graphie vortragen, aber auch nicht in gesetzlich oder sonst definitiv geregelter Organisation» (BECKER, 1897: 53).

Solche Verhältnisse bestanden - was Becker vielleicht zu wenig berücksichtigt hat - nicht nur in der Schweiz, sondern nahezu in ganz Europa. In den USA war die Geographie zu diesem Zeitpunkt an den Hochschulen ebenfalls nur schwach vertreten. Auch wenn Zürich im internationalen Vergleich damals also kaum abgefallen ist, weil eben die Entwicklung weltweit noch zu wenig fortgeschritten war und es allenthalben an geeigneten Dozentenund Forscherpersönlichkeiten mangelte, gibt es doch noch eine Reihe weiterer Gründe, die für das Abseitsstehen der Limmatstadt bei der Entwicklung der Geographie verantwortlich gewesen sein dürften. Anführen können wir in dieser Hinsicht die geringe Größe der Stadt - so zählte Zürich zur Zeit der Gründung der Universität bloß rund 15000 Einwohner -, die Überschaubarkeit der Landschaft und außerdem natürlich die Binnenlage; Verhältnisse dieser Art tragen wohl kaum dazu bei, die Bewohner der betreffenden Region zur Erforschung und Gestaltung des näheren und weiteren Lebensraumes besonders anzustacheln. Im weiteren mag eine Rolle gespielt haben, daß sich im Gegensatz zu anderen Schweizer Städten im entscheidenden letzten Viertel des vergangenen Jahrhunderts keine ausländischen Geographen in Zürich niedergelassen haben, welche - wie die Deutschen E. Petri und E. Brückner in Bern, der Russe L. Metchnikoff in Neuenburg und der Franzose E. Reclus in der Region Genf - dem einheimischen Wissenschaftsbetrieb Anregung gebracht hätten. (Es ist übrigens bemerkenswert, daß mit Ausnahme Brückners alle hier Genannten nicht aus wissenschaftlichen Gründen in die Schweiz gekommen waren, sondern aus politischen Motiven hier Zuflucht gesucht hatten. Der wegen seiner Teilnahme an der Pariser Kommune in Frankreich inhaftierte und 1872 aus seiner Heimat zwangsexilierte Reclus trug sich während einer gewissen Zeit ernsthaft mit dem Gedanken, in Zürich Bleibe und Brot zu suchen. Die «germanische Atmosphäre» dieser Stadt, wie er sich ausdrückte, hielt ihn jedoch von diesem Schritt ab.) Schließlich wollen wir aber auch nicht übersehen, daß die geographischen Wissenschaften in Zürich während Jahrhunderten in gewissen Spezialdisziplinen, insbesondere der Topographie und Kartographie, seit Jos Murer und Hans Konrad Gyger, in großer Blüte standen und zu hohem Ansehen gelangt waren, und dieser Tradition blieb sich die Limmatstadt bis in die jüngste Zeit hinein treu. Auch die Geologie als benachbartes Wissenschaftsgebiet besaß in Zürich bereits vor Albert Heim, dem Vater der modernen Schweizer Geologie - in Hans Conrad Escher von der Linth, seinem Sohn Arnold und anderen hervorragende Vertreter. 


\section{Die ersten Geographischen Gesellschaften der Schweiz}

Wie bereits angedeutet, waren die letzten Jahrzehnte des vergangenen Jahrhunderts für die Geographie eine außerordentlich wichtige und fruchtbare Zeit. Die Entstehung Geographischer Gesellschaften und der Eingang der Geographie in Lehre und Forschung vollzogen sich vor dem Hintergrund und als Folge kultureller, wirtschaftlicher und politischer Strömungen. Das folgende Zitat, das einem 1879 zuhanden des Eidgenössischen Handels- und Landwirtschaftsdepartements erstellten Bericht der Schweizer Delegation am Brüsseler Internationalen Kongreß für Handelsgeographie entnommen ist, veranschaulicht die damaligen Verhältnisse recht deutlich:

"Die Anstrengungen aller Handel und Industrie treibenden Völker concentriren sich gegenwärtig in einem $\mathrm{Maaße}$, wie es kaum je vorgekommen ist, auf das Bestreben, neue und ergiebige Absatzwege zu finden; es organisirt sich ein förmlicher Wettlauf unter den Nationen, worin allerdings die durch eine kräftige Marine unterstützten Länder überall den Vorsprung vor anderen behalten, welche diesen Vortheil nicht besitzen.

Vor Allem gab die schon seit Jahren andauernde Krise den Hauptansto $\beta$ dazu; die Anstrengungen früherer Jahre der Prosperität, welche nur zu ausschließlich eine in's Ungeheure gehende Vermehrung der Production im Auge behielten, schufen einen Überflu $\beta$ an Waaren, den die bisherigen Absatzgebiete nicht mehr $z u$ absorbiren fähig waren. Es ist daher nicht zu verwundern, daß die neuen großartigen Entdeckungen, namentlich im Centrum des afrikanischen Continents, eine Aufregung in der industriellen Welt hervorriefen, die, wenn auch hie und da zu abenteuerlichen Projecten treibend, doch im Allgemeinen die glücklichsten Folgen verspricht. Namentlich hat dadurch das Studium der Geographie in letzter Zeit bei allen Völkern einen wirklich überraschenden Aufschwung genommen; geographische Gesellschaften schossen überall wie Pilze aus dem Boden, und es ist in der That erstaunlich, mit welchem Eifer jede Etappe der geographischen Forschungen aufgegriffen und verwerthet wird. Ganz besonders erfreulich ist dabei die Wahrnehmung, daß durch diesen Wetteifer nicht nur das Wissen gefördert wird, sondern daß mit der Bereicherung an Kenntnissen auch zugleich das Gefühl der Solidarität aller civilisirten Völker in der Erstrebung gemeinsamer Ziele unverkennbar zum Durchbruch gelangt» (AMREIN und KÜNZLE-STEGER, 1879: 44).

Der Bericht beleuchtet die - wer wollte sich darüber wundern - enorme Bedeutung, welche die wirtschaftlichen und kolonialpolitischen Gegebenheiten bei der Errichtung Geographischer Gesellschaften sowie bei der Einführung der Erdkunde an den Schulen und Universitäten in Europa und Nordamerika hatten. Man würde es sich nun allerdings zu einfach machen, wenn man aus dem Auftreten ökono- mischer Notwendigkeiten gleich auf ihre zwangsläufige Befriedigung schließen wollte: Individuelle Handlungen oder Unterlassungen konkretisieren bzw. verzögern - wie noch zu zeigen sein wird - was die Zeitgeschichte erlaubt oder fordert.

Wie wir gesehen haben, waren die Universitäten hinsichtlich der Förderung der Geographie im allgemeinen sehr zurückhaltend. Sie haben keine Vorreiterrolle bei der Entwicklung dieses neuen Wissenschaftszweiges gespielt. Der Erdkunde den Weg gebahnt haben in der Regel vielmehr private Organisatoren, eben die Geographischen Gesellschaften, die, wie es im vorstehend zitierten Bericht heißt, «überall wie Pilze aus dem Boden schossen». Normalerweise ging der Errichtung eines akademischen Lehrstuhls für Geographie an einer bestimmten Universität die Gründung eines Geographischen Vereins am selben Ort voraus. Allmählich übernahm dann die staatliche Institution Universität einen Teil der privaten Gesellschaftsfunktionen, belegte eventuell gar den wissenschaftlichen Lehrund Forschungsbetrieb mit ihrem Monopol. Natürlich ist nicht nur die Geographie von diesem Phänomen staatlicher «Kulturexpansion» betroffen; die Feststellung gilt auch für andere Disziplinen.

In der zweiten Hälfte des 19. Jahrhunderts war auch in der kleinen, meerfernen und kolonielosen Schweiz die Zeit für die Gründung Geographischer Gesellschaften gekommen. Den Anfang machte Genf im März 1858. Die «Société de Géographie de Genève» war nach Paris (1821, mit der «Société de Géographie» schlechthin), Berlin (1828), London (1830), Frankfurt (1836), Rio de Janeiro (1838), Mexico (1839), Darmstadt und St. Petersburg (1845), Tiflis (1850), Irkutsk (1851), New York (1852), Wien und Buenos Aires (1856) erst die vierzehnte ihrer Art. Ihre Anfänge waren nach den Worten ihres späteren langjährigen Präsidenten und verdienten Förderers Arthur de Claparède «sehr bescheiden»; zu Beginn handelte es sich um einfache Versammlungen im Haus des einen oder anderen ihrer fünfzehn Gründungsmitglieder, die «sich gegenseitig über ihre Lektüre auf dem laufenden halten oder in einem kleinen, persönlichen Kreis einen Bericht über ihre eigenen Reisen geben» wollten (DE CLAPARÈDE, 1908: 14-5). Es waren vor allem wissenschaftliche Interessen, geographische Neugier, laufend genährt durch die damaligen grandiosen und atemberaubenden Entdeckungen zu Wasser und zu Land, im Polargebiet, in Afrika, Asien und Australien, welche diese gebildeten Männer zusammengeführt hatten. Praktische Gründe, der Nutzen der Geographie für Handel, Verkehr und Kommunikation zwischen den verschiedenen Erdteilen, waren für den Genfer Verein immer von zweitrangiger Bedeutung. Für das hohe Ansehen der Gesellschaft war nicht zuletzt das sorgfältig redigierte und auf solider finanzieller Basis stehende Vereinsorgan «Le Globe» verantwortlich. 
Es verstrichen in der Folge fünfzehn Jahre, bis die «Société de Géographie de Genève» in der Schweiz eine Nachahmerin fand. Dabei handelte es sich um die «Geographische Gesellschaft in Bern», die im Mai 1873 ins Leben gerufen wurde. Gemäß Statuten war deren Ziel demjenigen des Genfer Vereins durchaus vergleichbar, betrachtete sie sich doch als «Vereinigungspunkt der Freunde der Erdkunde zum Zweck der thätigen Belebung des Studiums und der Verbreitung der geographischen Wissenschaft in allen Zweigen».

Eine etwas andere Richtung verfolgte die 1878 gegründete «Ostschweizerische Geographisch-commerzielle Gesellschaft» mit Sitz in St. Gallen. Zur Hauptsache bestand ihr Ziel darin, dem ostschweizerischen Kaufmannsstand beim Auslandsgeschäft behilflich zu sein, sei dies durch Informationsbeschaffung, Bereitstellung ethnographischen Anschauungsmaterials, in einzelnen Fällen sogar durch die Finanzierung wirtschaftlicher Auslandsunternehmungen, wie beispielsweise Werbereisen zur Anbahnung von Geschäftskontakten. Die Mitglieder der Ostschweizer Gesellschaft waren in der Mehrzahl Kaufleute und Firmen. Es ist klar, daß neben diesen Aktivitäten praktischer Art die Beschäftigung mit der wissenschaftlichen Geographie etwas in den Hintergrund trat.

Auf dem nächsten Platz in der Gründungschronologie unserer einheimischen geographischen Gesellschaften folgt mit dem Jahr 1885 die "Société neuchâteloise de Géographie». Sie strebte nach einer Verbesserung der geographischen Heimatkunde und des Geographieunterrichts, nach der Popularisierung geographischen Wissens sowie der Schaffung eines auf die Bedürfnisse von Handel, Industrie und der Schweizer Emigranten ausgerichteten Dokumentations- und Auskunftszentrums. Einem ihrer Gründungsmitglieder lag ganz besonders die Hilfeleistung am Herzen, welche die Geographischen Gesellschaften den damaligen Schweizer Emigrantenscharen hätten zuteil werden lassen können, führte doch der Exodus dieser meist wenig gebildeten und notleidenden Menschen oft nur allzu leicht nicht in ein Paradies der Neuen Welt, sondern in ein auswegloses Verderben. Obwohl die Eidgenossenschaft damals eine gewisse Kontrolle über die Emigration ausübte und Unterstützungsfunktionen wahrnahm, hätte für die Geographischen Gesellschaften in diesem Bereich ein weites Tätigkeitsfeld vorgelegen; rückblickend sind allerdings von dieser Seit kaum konkrete Schritte auszumachen.

\section{Die Gründung der Geographisch-Ethnographi- schen Gesellschaft Zürich}

Im Herbst 1897 ist schließlich auch in Zürich eine Geographische Gesellschaft aus der Taufe gehoben worden. Sie steht ihrem Gründungstermin nach an fünfter Stelle der einschlägigen Vereinigungen, wenn wir von nur kurzzeitig bestehenden Gesellschaften in Aarau und Herisau absehen. In der Festschrift zur 50-Jahr-Feier der «Geographisch-Ethnographischen Gesellschaft Zürich» hat Hans J. Wehrli 1939 bereits einen Überblick über die Vorgänge bei dieser Vereinsgründung gegeben, die ihn zu einer Rückblende bis in die siebziger Jahre des letzten Jahrhunderts veranlaßten. Wehrli schreibt: «Schon vor der Rückkehr Stanleys von seiner ersten Reise [Ost-West-Durchquerung Zentralafrikas 1874-77] hatte König Leopold von Belgien - im September 1876 - einen freien europäischen Kongreß in Brüssel veranstaltet, zu dem die Geographischen Gesellschaften Europas und die zur Zeit in Europa weilenden Afrikaforscher eingeladen waren. [...] Die Versammlung beschloß einstimmig, zur Erforschung und Gesittung von Zentralafrika im besondern des Kongogebietes - eine internationale Kommission zu gründen mit nationalen Unterkommissionen, denen die Aufgabe zukäme, die Kräfte in den verschiedenen Ländern zu sammeln und in stetigem Kontakte mit der Zentralkommission zu arbeiten. Diese Zentralkommission sollte aus den Präsidenten der Geographischen Gesellschaften der verschiedenen Nationen bestehen, die bei der Tagung in Brüssel vertreten waren [. . . ] sowie aus je zwei Mitgliedern von jeder nationalen Kommission. So kommt Prof. Alb. Mousson, der als Vertreter von Zürich an dieser Tagung in Brüssel teilgenommen hatte, in seinem ausführlichen Bericht [...] zum Schluß, die Schweiz könne dieser schönen, großartigen Bestrebung nicht fern bleiben. Die Geographische Gesellschaft in Genf übernahm die Führung. In verschiedenen Städten wurden Gesellschaften gegründet sowie ein Initiativkomitee, das die Interessen der Schweiz vertreten sollte $[\ldots]$.

Prof. A. Mousson hat damals die Frage erörtert, ob auch in Zürich ein solches Lokalkomitee geschaffen werden sollte, etwa in der Form einer Geographischen Gesellschaft, wie sie in Bern schon seit 1873 bestand. Er kam zu einem ablehnenden Ergebnis: Vorerst besäße die Stadt- und Naturforschende Bibliothek - besonders letztere - eine schöne Reihe der wichtigsten Reisewerke, welche jährlich erweitert werde, dann bestehe seit vielen Jahren ein Kartenverein mit dem Zwecke, durch jährliche Beiträge seiner Mitglieder die Anschaffung jener großen Kartenwerke verschiedener Länder zu ermöglichen, welche die Kräfte des einzelnen übersteige. Seine Sammlung gelte bereits als eine der bedeutendsten der Schweiz. Endlich sei Zürich in diesem Jahre (1877) von einer geographischen Ausstellung überrascht worden, welche durch J.J. Egli, Lehrer für Geographie an der Industrieschule, zusammengebracht worden war. Prof. Mousson hielt es nicht für zweckmäßig, alle diese verschiedenen Bestre- 
bungen unter einer Leitung zu vereinigen. Vorläufig schien auch die Gründung eines eigenen Geographischen Vereins, außer etwa als bescheidene Sektion der Naturforschenden Gesellschaft, den lokalen Verhältnissen nicht entsprechend, da geographische Vorträge weitgehend vom Alpenklub besorgt wurden.

Es fehlte Zürich zu dieser Zeit eine Persönlichkeit, die sich - mit dem nötigen Verständnis für Geographie - voll Begeisterung für ein solch wissenschaftliches Unternehmen eingesetzt hätte [. . . ].

So ist die Anregung zur Gründung der Ethnographischen Gesellschaft in Zürich einige Jahre später von zwei Gelehrten ausgegangen, die sich während längerer Zeit im Auslande aufgehalten und auf Forschungsreisen Kenntnisse von überseeischen Ländern und Völkern erworben hatten: vom Zoologen Dr. Conrad Keller und seinem Freunde Dr. med. Otto Stoll $[\ldots]$. .

In einem Zirkular vom November 1887 wurde zur Gründung einer Ethnographischen Gesellschaft eingeladen, deren Hauptaufgabe die Schaffung eines Museums sein sollte und dessen zukünftige Bedeutung für Wissenschaft und Bildung mit folgenden Worten umschrieben ist: "Als Sitz zweier Hochschulen ist die wissenschaftliche Pflege der Ethnologie und Anthropologie (in Zürich) ein stets wachsendes Bedürfnis, welchem nur an Hand größerer Sammlungen Genüge geleistet werden kann. Die Mittelschulen und Volksschulen in Zürich würden in einer derartigen Schöpfung ein wertvolles Hilfsmittel zur Belebung des geographischen Unterrichts gewinnen. Auch die kommerziellen Kreise haben an derselben ein nicht zu unterschätzendes Bildungsmittel zu erwarten. Der junge Kaufmann wird je länger je mehr genötigt sein, eine tüchtige Schulung des Geistes und einen weiten Blick mitzubringen, wenn er in seiner Laufbahn prosperieren will. Da er vielfach nach überseeischen Plätzen auswandert, so kann es für ihn von Nutzen sein, wenn er frühzeitig die Kulturzustände anderer Völker beurteilen lernt.»

Diese Aufforderung zum Beitritt in die Ethnographische Gesellschaft von Mitte November 1887 ist unterzeichnet von den Herren:

C. Abegg-Arter

A. Koller, Stadtrat

H. Angst, engl. Konsul Carl Krüse

Dr. A. Bürkli-Ziegler, Ing. A. Ramsauer

Prof. Dr. Carl Cramer Fritz Rieter-Bodmer

Cramer-Frey, Nationalrat Prof. Dr. E. Schär

C. Fierz-Landis

C. Schindler-Escher

Emil Frey, Redaktor

Prof. Dr. A. Heim

Prof. Dr. C. Schröter

Dr. Otto Stoll

Dr. Conrad Keller

Diese Namen führender Persönlichkeiten zeigten das große Interesse, das die Anregungen von Keller und Stoll in den Kreisen von Handel, Industrie und Wissenschaft der Stadt gefunden hatten. Am 23. Fe-

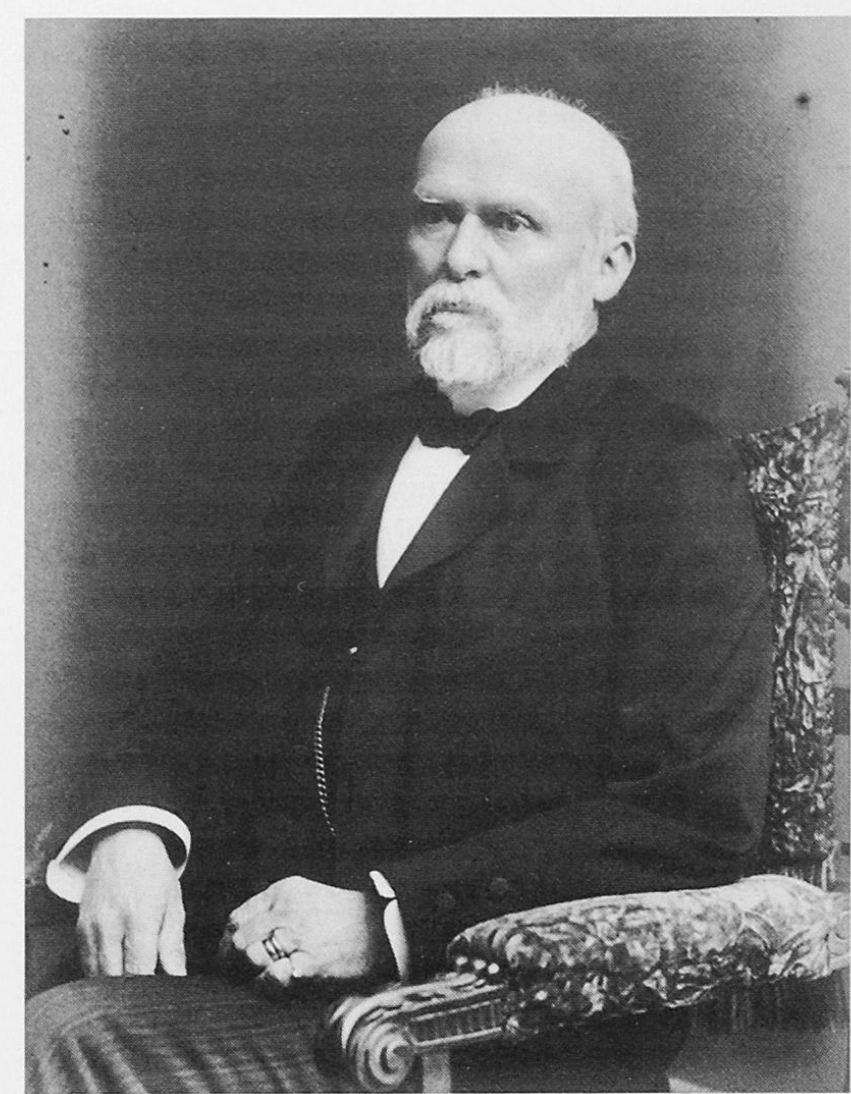

Abb. 2 Otto Stoll (1849-1922), geboren in Frauenfeld als Sohn eines Postkreis- und späteren Bankdirektors, verbrachte den größten Teil seiner Jugend in Zürich. 1873 legte er die eidgenössische Staatsprüfung für Medizin an der Universität $a b$. Nach Aufenthalten in Wien, Leipzig und Prag praktizierte er als Arzt in einer Zürcher Landgemeinde. 1878 verliess er Zürich und reiste nach Guatemala. Neben seiner ärztlichen Tätigkeit arbeitete er dort an vielfältigen zoologischen und linguistischen Studien. Das tropische Land Mittelamerikas bot seinen breiten Interessen reiche Nahrung; der fünfjährige Auslandaufenthalt bis 1883 übte einen nachhaltigen Einfluß auf seine späteren Arbeiten aus. Zu Stolls Eigenart gehörten eine "seltene Vereinigung natur- und geisteswissenschaftlicher Fähigkeiten, außergewöhnliche Sprach- und Literaturkenntnisse und ein klarer Geist” (Wehrli, 1925: 24). Die Frage nach der Erklärung gewisser Erscheinungen des Völkerlebens führte inn zur Auseinandersetzung mit Suggestion und Hypnotismus. 1884 habilitierte er sich an der Universität Zürich für Ethnographie und Anthropologie. Im Wintersemester 1891 wurde er Extraordinarius für Geographie. Im Sommer 1893 benützte er einen Urlaub, um an der Wiener Universität die Einrichtungen zur Ausgestaltung des geographischen Unterrichts zu studieren. Er hörte Vorlesungen bei Albrecht Penck, Eduard Süeß und Julius Hann. 1895 erfolgte die Beförderung zum Ordinarius an der Universität Zürich. Unter Leitung dieses bedeutenden, enzyklopädisch gebildeten Gelehrten sind vierzehn Dissertationen aus den verschiedensten Zweigen der Geographie entstanden. 1912 trat er von seinem Amt zurück. Nach langem und schwerem Leiden verstarb Otto Stoll im August 1922.

bruar 1888 konnte die konstituierende Sitzung stattfinden und der Vorstand gewählt werden. [ . . . ]. Mit der stattlichen Zahl von 80 Mitgliedern trat die Ethnographische Gesellschaft ins Leben» (WEHRLI, 1939: 6-10). 
Die Hauptaufgabe der Gesellschaft war also die Schaffung und der Ausbau einer völkerkundlichen Sammlung als Informations- und Studienobjekt für exportorientierte Zürcher Handels- und Kaufmannskreise. Angehörige der Zürcher Kaufmännischen Gesellschaft haben denn auch als Initianten und tatkräftige Mitarbeiter im Vorstand gewirkt. Daneben gehörte die Veranstaltung von Vorträgen und Demonstrationen zu den Aufgaben der Ethnographischen Gesellschaft. (Ein erster Vortragszyklus hatte bereits im Winter 1887/88 im Rahmen der Rathausvorträge des Allgemeinen Dozentenvereins stattgefunden.) Die Erträge dieser Veranstaltungen wurden für den Ausbau der ethnographischen Sammlung verwendet.

Offenbar vermochten aber die Aktivitäten der Ethnographischen Gesellschaft nicht alle Bedürfnisse der geographisch interessierten Kreise Zürichs zu befriedigen, und man schritt endlich zur Schaffung eines weiteren Forums. Hans Wehrli fährt fort:

«Im Herbst 1897 ist als zweite Wurzel der heutigen Geographisch-Ethnographischen Gesellschaft Zürich die Geographische Gesellschaft gegründet worden. Da keine Protokolle oder andere Akten vorhanden sind, mußte versucht werden, aus Zeitungsberichten und Bemerkungen in den Protokollen der Ethnographischen Gesellschaft ein Bild über die Entstehung und die Ziele der Geographischen Gesellschaft zu skizzieren.

Ihre Gründung ist von Vertretern der physischen Geographie, von Kartographen und höhern Militärs ausgegangen. Die konstituierende Versammlung vom 23. November 1897 wählte zum Präsidenten Oberst $U$. Meister, zum Vizepräsidenten Prof. Dr. J. Früh, zum Aktuar Hauptmann H. Bauer, als weitere Vorstandsmitglieder E. Kollbrunner, Chef. des Kant. Statist. Büros, und Prof. F. Becker. Nach Mitteilungen in der zweiten Sitzung, vom Dezember 1897, gehörten zirka 100 Mitglieder der Gesellschaft an, besonders viele höhere Militärs und Professoren des Eidg. Polytechnikums. In seinem Vortrag „Ausblicke auf die verschiedenen Gebiete der Geographie" in der konstituierenden Sitzung entwarf Früh ein Arbeitsprogramm für die neugegründete Gesellschaft. „Diese solle vor allem Vaterlandskunde treiben und das Werk der großen Zürcher Gyger, Scheuchzer, Ebel, Fäsi, Meyer von Knonau, Wolf, Wild u. a. fortsetzen. Sie solle aber neben den Monographien kleiner Gebiete auch die Probleme der allgemeinen Geographie nicht vergessen. Sie solle ferner das Studium der Geographie auch draußen in der Natur treiben, d. h. Exkursionen machen, um die Dinge an Ort und Stelle zu sehen"» (WEHRLI, 1939: 12-3).

Die «Neue Zürcher Zeitung» brachte zu diesem Anlaß am darauffolgenden Tag die nachstehende Meldung: "Die konstituierende Sitzung der Geographischen Gesellschaft Zürich auf der Waag war etwa von einem halben Hundert Freunden der Erdwissenschaft besucht. Einstimmig und ohne Diskussion wurden die vom Initiativkomitee entworfenen Statuten, die einen Jahresbeitrag von 3-5 Franken und den Eintritt der Gesellschaft in den allgemeinen schweizerischen Verband vorsehen, genehmigt [...]. In einem ungemein anregenden Vortrag entwickelte Herr Dr. Früh in gedrängten Zügen die Geschichte der geographischen Wissenschaft, die in der Neuzeit durch kühne Forschungen in allen Erdteilen befruchtet worden ist, durch eine Menge geographischer Gesellschaften zum Gemeingut der Gebildeten gemacht wird und an der die Schweiz im Verhältnis zu ihrer Größe ehrenvollen Anteil nimmt. Indem er die Vielseitigkeit des geographischen Interesses darlegte, zeigte er, welch reiches Gebiet eine geographische Gesellschaft bebauen kann [...]. An diesen Programm-Vortrag [...] knüpfte Herr Prof. F. Becker einen solchen über eine Serie württembergischer Spezialkarten [...]. Mit regster Teilnahme folgte man auch diesen Ausführungen, und man bekam den bestimmten Eindruck, daß die jüngste unserer wissenschaftlichen Gesellschaften, die bereits über sechzig eingeschriebene Mitglieder zählt, ihre Arbeit unter den günstigsten Auspizien eröffnet hat» («NZZ», 24.11.1897).

Ebenfalls nach Mitteilung der «NZZ» zählte die Geographische Gesellschaft ein Jahr später, im November 1898, 125 Mitglieder («NZZ», 25.11.1898).

Wehrli schreibt weiter: «Bald nach der Gründung der Geographischen Gesellschaft wurde indes in den Kreisen beider Zürcher Gesellschaften die Frage eines Zusammenschlusses erwogen, hatte doch Oberst Meister schon 1898 in der ersten Sitzung [des zweiten Lebensjahres (22.11.1898)] der Geographischen Gesellschaft diesem Wunsch Ausdruck verliehen. Bei den Verhandlungen des $\mathrm{Zu}$ sammenschlusses hat vor allem die Sicherung der Erhaltung und Mehrung der ethnographischen Sammlung Schwierigkeiten verursacht, doch konnte schließlich eine Vereinbarung getroffen werden, die den Interessen der Sammlung gerecht wurde. Zur Erinnerung an die Vereinigung beider Gesellschaften zur Geographisch-Ethnographischen Gesellschaft im April 1899 wurden in der Eröffnungssitzung sechs Ehrenmitglieder ernannt:

Staatsrat Dr. Hch. von Wild, langjähriger Direktor des Kaiserl. Meteorologischen Central-Observatoriums in Petersburg, mit Rücksicht auf seine wissenschaftlichen Verdienste um die Klimatologie und Meteorologie.

Dr. Paul und Dr. Fritz Sarasin, in Basel, in Anerkennung ihrer Forschungsreisen und ihrer hervorragenden Leistungen auf dem Gebiete der Anthropologie Ceylons und Südasiens überhaupt.

Alfred Ilg, dessen Verdienste um die Kulturentwicklung Äthiopiens allgemein gewürdigt sind und der durch Unterstützung wissenschaftlicher Expeditionen die geographische Forschung gefördert hat. 
$J$. Randegger wegen seiner Verdienste um die schweizerische Kartographie.

Pittier de Fabrega in Costa Rica, der sich durch wertvolle naturhistorische und ethnographische Veröffentlichungen große Verdienste erwarb.

Die Zahl der Mitglieder der vereinigten Gesellschaften betrug 222. Der Zusammenschluß hat sich als eine glückliche Tat erwiesen. Das Interessengebiet ist durch die Verschmelzung wesentlich erweitert worden, so daß in der Geographisch-Ethnographischen Gesellschaft sich alle Geographen und Ethnographen sowie die dem Gebiete nahestehenden Kreise Zürichs sammelten, in erster Linie die Dozenten beider Hochschulen und eine große Zahl von Lehrern der Mittel- und Volksschule» (weHRLI, 1939: 13-4).

Von ihrem Charakter her ist die Zürcher Gesellschaft jener Gruppe Geographischer Gesellschaften zuzuordnen, welche sich einer primär theoretisch-wissenschaftlichen Tätigkeit verschrieben hatte. Der erste Paragraph ihrer Statuten lautete (Fassung 1905): «Die Geographisch-Ethnographische Gesellschaft Zürich bezweckt die Förderung und Verbreitung geographischer Kenntnisse, deren angemessene Verwertung sowie die wissenschaftliche Pflege der verschiedenen Disziplinen der gesamten Erd- und Völkerkunde mit tunlichster Berücksichtigung der Schweiz.»Zur Erreichung dieser Ziele veranstaltete die Gesellschaft «für die Dauer des Winterhalbjahres monatliche Versammlungen, in welchen durch Vorträge, Vorweisungen und Mitteilungen ein gegenseitiger Gedankenaustausch erzielt werden soll.» Für den Sommer waren «zweckentsprechende Exkursionen» vorgesehen $(\$ 2)$. Im weiteren dienten «eigene Publikationen für die Verbreitung der Kenntnisse in der Erd- und Völkerkunde» (\$3).

Bei der Gründung der Zürcherischen Geographischen Gesellschaft 1897 betrug die Zahl ihrer Schwestervereinigungen in aller Welt bereits mehr als 150. Einer bedeutenden Schweizer Stadt - Basel - fehlte jedoch zu diesem Zeitpunkt nach wie vor eine solche Institution. Erst nach dem Ersten Weltkrieg, im Dezember 1923, wurde hier eine Geographische Gesellschaft aus der Taufe gehoben, obwohl sich auch in der Stadt am Rheinknie das Bedürfnis nach einer derartigen Vereinigung «schon lange fühlbar gemacht» hatte. Verschiedene Umstände, vor allem wohl die fehlende Initiative der dazu prädestinierten Persönlichkeiten, hatten, wie in Zürich, die Gründung immer wieder hinausgezögert. Das Beispiel Basel stellt, zusammen mit Neuenburg, insofern einen Ausnahmefall dar, als hier vor der Gründung der Geographischen Gesellschaften bereits Lehrstühle an den Universitäten errichtet worden waren. Auffällig bleibt natürlich, daß gerade Zürich und Basel, «die Schweizer Städte mit besonders großen Übersee-Beziehungen», am Schluß unserer Gesellschaftschronologie stehen, worauf bereits Hans Wehrli 1939 hingewiesen hat. Für dieses Phänomen verantwortlich ist seit Albert Mousson, der 1876 von der Gründung einer Geographischen Gesellschaft in Zürich abriet, der Mangel an Weitblick und Tatkraft bei denjenigen Persönlichkeiten gewesen, von denen am ehesten die Impulse zur Schaffung solcher Vereine hätten ausgehen können. Die Beispiele der Zürcher und Basler Gesellschaft verdeutlichen - wenn auch im negativen Sinn -, welche Bedeutung der Privatinitiative auch auf wissenschaftlichem Gebiet zukommt.

\section{Organisation und Tätigkeit der GEGZ im Überblick}

Werfen wir nun einen kurzen Blick auf die Tätigkeit der Geographisch-Ethnographischen Gesellschaft Zürich (GEGZ) während den ersten hundert Jahren ihrer Geschichte. Allerdings müssen wir hier vorausschicken, daß es natürlich ein außerordentlich schwieriges Unterfangen ist, aus der überreichen Fülle an Material, insbesondere den Vorträgen, Aufsätzen und Exkursionen, einen repräsentativen Querschnitt auszuwählen und dabei auch die zahlreichen Glanzlichter gebührend zu würdigen. Es muß leider erwähnt werden, daß aus den ersten anderthalb Jahren des unabhängigen Bestehens der Geographischen Gesellschaft, wie von Hans Wehrli bereits angedeutet, keine Sitzungsprotokolle oder andere Dokumente vorliegen, von einigen wenigen Zeitungsmitteilungen abgesehen. Wir kennen nur die Titel der damals gehaltenen Vorträge, wissen im übrigen aber nicht, womit sich der frischgebackene Geographenverein auseinandergesetzt hat. Seit dem Zeitpunkt der Vereinigung der Geographischen und der Ethnographischen Gesellschaft sind hingegen recht vollständige Sitzungsprotokolle vorhanden. Aus ihnen, aus dem Verzeichnis und den Rezensionen der Vorträge, die bei den Zusammenkünften gehalten wurden, sowie aus den Beiträgen im Publikationsorgan der Gesellschaft läßt sich ein Bild der früher aktuellen geographischen Forschung gewinnen.

Die Tätigkeit der GEGZ ist auch heute noch grundsätzlich gleich organisiert wie früher: Während des Winterhalbjahres werden regelmäßige Versammlungen durchgeführt (bis 1905 in monatlichem, später in vierzehntäglichem Turnus), auf welchen Referenten aus dem In- und Ausland zu Wort kommen sowie kürzere Mitteilungen wissenschaftlicher und geschäftlicher Art gemacht werden. Nach wie vor findet jeweils im Mai die sogenannte Hauptversammlung statt, anläßlich derer die Vereinsgeschäfte (Abnahme des Jahresberichts und der Jahresrechnung) erledigt und Wahlen durchgeführt werden. An der Spitze der Gesellschaft stand und steht ein von der Hauptversammlung auf die Dauer von zwei Jahren 


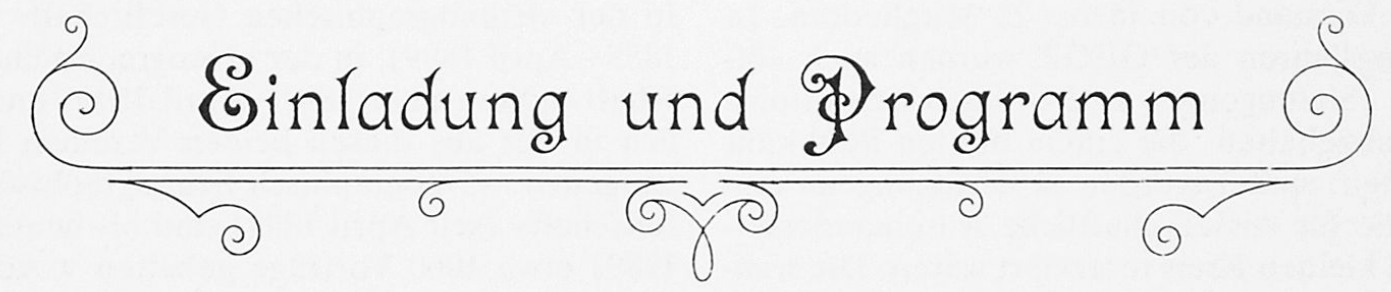

\section{Kongress}

der

\section{Schweizepischen Geographischen Gegsellschaften in ZÜRICH}

vom 22. bis 24. September 1901.

लริन

Sonntag den 22. September.

7 UHR ABENDS: Empfang der Gäste in der Tonhalle. - Einlösung der Festkarten und Festzeichen. -- Abendunterhaltung.

Montag den 23. September.

81/2 Uhr vorm.: Sitzung der Delegierten im Gesellschaftszimmer.

$10 \%$, Eröffnung des Kongresses im kleinen Saale der Tonhalle. Eröffinungsrede des Vorortspräsidenten, Herrn Nationalrat Oberst Meister.

Mitteilung von den Beschlüssen der Delegiertenversammlung. M. le prof. E. Naville-Genève: Les relations des anciens Egyptiens avec l'étranger, surtout avec l'Asie occidentale. Herr Staatsrat von Wild-Zürich: Zur Föhnfrage.

$12^{1 / 2}$ n MitTags: Lunch im Tonhalle-Restaurant.

3 n Nachm.: M. Gauthiot, secrétaire de la société de Géographic commercialc à Paris (event.): L'état économique de Madagascar. M. Ie Dr Arth. de Claparède-Genève: Le prof. Paul Chaix, Esquisse biographique.
Herr Prof. Dr. Otto Stoll-Zürich: Medizinische Geographic von Guatemala.

Herr Prof. Dr. Eberh. Fraas-Stuttgart: Ueber die Badlands und Prairien von Nordamerika.

Von 7 Uhr abends an: Freie Vereinigung im Waldhaus Dolder.

Dienstag den 24. September.

9 Uhr vorm.: Herr Prof. Dr. Brückner-Bern: Ueber die Volksdichte, besonders in der Schweiz.

M. le Dr Arth. de Claparède-Genève: Le canal de Suez.

Herr Prof. Dr. Rud. Burckhardt-Basel: Das Problem der Antarktis.

Herr Prof. Dr. Rud. Martin-Zürich: Ueber den neolithischen Menschen der Schweiz.

Herr Major Held, Chef des Eidg. topogr. Bureaus, Bern: Die neue schweizerische Schulwandkarte in ihrer $\mathrm{Be}$ deutung für die Landeskunde.

1 UнR маснм. Bankett in der Tonhalle, offeriert von der GeographischEthnographischen Gesellschaft Zürich.

Fahrt auf Uto-Kulm.

\section{\&chluss des Kongresses.}

Abb. 3 Einladung zum 13. Kongreß der Schweizerischen Geographischen Gesellschaften vom 22. bis 24. September 1901 in Zürich 
gewählter Vorstand von 15 bis 25 Mitgliedern. In den Anfangsjahren der GEGZ wurden auch «öffentliche Sitzungen» und «DemonstrationsAbende» abgehalten, die einem breiten Publikum offenstanden; später wurden «Fachsitzungen» eingeführt, die für wissenschaftliche Auseinandersetzungen im kleinen Kreis reserviert waren. Die sommerlichen Aktivitäten der Gesellschaft beschränken sich bis heute auf die Durchführung von Exkursionen und Führungen. Von der Mehrzahl der Veranstaltungen früherer Jahre bestehen handschriftliche Protokolle und Zusammenfassungen sowie Rezensionen in der «NZZ». In den ersten Jahrzehnten wurden fast alle diese Beiträge von Ulrich Ritter, Professor für Geographie an der Töchterschule der Stadt Zürich, verfaßt, der sich damit ein großes Verdienst als Historiograph der GEGZ erworben hat. Sein wichtigster Nachfolger im Amt des Protokollführers und Berichterstatters war der spätere ETHDozent Ernst Winkler. Das von diesen beiden und anderen Autoren hinterlassene wertvolle Material erlaubt es uns heute, einen genaueren Blick in die interessanten geographischen Fragestellungen verflossener Jahre zu tun. Eine weitere wichtige Tätigkeit des Vereins stellt die Herausgabe einer Zeitschrift dar, welche die Gesellschaft nach außen hin repräsentiert. Von diesem Vereinsorgan wird weiter unten noch die Rede sein.
In der «Ethnographischen Gesellschaft» (Februar 1888-April 1899), in der "Geographischen Gesellschaft» (November 1897-April 1899) und schließlich in der aus diesen beiden Vereinen hervorgegangenen "Geographisch-Ethnographischen Gesellschaft» (seit April 1899) sind bis heute (August 1989) etwa 1060 Vorträge gehalten worden. Eine thematische Gruppierung dieser Referate läßt folgendes erkennen: Rund zwei Fünftel aller Darbietungen betrafen länderkundliche Themen, etwa ein Sechstel entstammte dem Gebiet der Ethnographie und je ein Zehntel behandelte wirtschafts- bzw. physisch-geographische Problemstellungen (vgl. Tab. $1)$. Es ist auffällig, daß sich diese Verteilung bis heute grundsätzlich nicht verändert hat. Eine anteilmäßig leicht sinkende Tendenz weisen vor allem die Länderkunde und die historische Geographie auf; demgegenüber erstaunt es nicht, daß anthropogeographische Themen und Fragestellungen aus Wirtschaft und Verkehr an Raum gewinnen. Die Ethnographie besitzt nach wie vor einen recht groBen Stellenwert. Die Stabilität der Themenanteile stellt den für die Auswahl der Referenten zuständigen Präsidenten und Vorstandsmitgliedern ein gutes Zeugnis bezüglich ihres Bemühens um eine ausgeglichene und breitgefächerte Programmgestaltung aus. Allerdings ließe sich hier die Frage nach dem Ursprung und dem Sinn dieses Verteilschlüssels stel-

Tab. 1 Thematische Zuordnung der Vorträge der GEGZ (in Prozent)

\begin{tabular}{|c|c|c|c|}
\hline $\begin{array}{l}\text { 1. Quartal * } \\
\text { (Feb. 1888- } \\
\text { Mai 1913) }\end{array}$ & $\begin{array}{l}\text { 2. Quartal } \\
\text { (Nov. 1913- } \\
\text { Aug. 1939) }\end{array}$ & $\begin{array}{l}\text { 3. Quartal } \\
\text { (Nov. 1939- } \\
\text { Mai 1964) }\end{array}$ & $\begin{array}{l}\text { 4. Quartal - } \\
\text { (Nov. 1964- } \\
\text { Mai 1989) }\end{array}$ \\
\hline
\end{tabular}

Länderkunde, allg. Geographie

Anthropogeographie (Bevölkerung,

Besiedlung, Politik usw.)

Wirtschaft und Verkehr

Physische Geographie (inkl. Geologie,

Klimatologie usw.)

Kartographie

Theoretische Geographie, Geschichte der Gg. 2

Historische Geographie, Geschichte

Angewandte Geographie (Planung,

Fernerkundung usw.)

Ethnographie (inkl. Kunst, Kultur usw.) 15

Anderes (Biogeographie, Astronomie, usw.) 4
40

1

10

9

4

11

3

4

Aug. 1939)

Mai 1989)

\footnotetext{
* Vorträge der Ethnographischen Gesellschaft (Feb. 1888-April 1899), der Geographischen Gesellschaft (Nov. 1897-April 1899) und der Geographisch-Ethnographischen Gesellschaft (April 1899-Mai 1913).
} 


$\begin{array}{lllll}\text { 1. Quartal * } & \text { 2. Quartal } & \text { 3. Quartal } & \text { 4. Quartal } & \text { Total } \\ \text { (Feb. 1888- } & \text { (Nov. 1913- } & \text { (Nov. 1939- } & \text { (Nov. 1964- } & \\ \text { Mai 1913) } & \text { Aug. 1939) } & \text { Mai 1964) } & \text { Mai 1989) } & \end{array}$

\begin{tabular}{lrrrrr} 
Global & 3 & 3 & 3 & 5 & 4 \\
Europa & 13 & 18 & 19 & 15 & 17 \\
Schweiz & 15 & 20 & 17 & 10 & 16 \\
Asien & 19 & 24 & 17 & 30 & 23 \\
Afrika & 21 & 13 & 12 & 14 & 14 \\
Amerika & 10 & 13 & 16 & 15 & 14 \\
Australien und Ozeanien & 5 & 3 & 5 & 7 & 5 \\
Polargebiete (inkl. Grönland) & 3 & 2 & 2 & 1 & 2 \\
& & & & & \\
\hline
\end{tabular}

Nur räumlich zuordnungsfähige Themen berücksichtigt.

* Vorträge der Ethnographischen Gesellschaft (Feb. 1888-April 1899), der Geographischen Gesellschaft (Nov. 1897-April 1899) und der Geographisch-Ethnographischen Gesellschaft (April 1899-Mai 1913).

len. Entspricht er dem Interessenspektrum der Vereinsmitglieder und konkretisiert er deshalb den Vereinszweck in optimaler Weise oder handelt es sich dabei um eine in langer Tradition verfestigte Form, gewissermaßen um den Ausdruck eines Normprofils durch die geographischen Wissenschaften?

Die Betrachtung der räumlichen Gruppierung der Themen führt zu folgendem Resultat (vgl. Tab. 2): Die meisten geographischen Fragestellungen betrafen den Kontinent Asien (rund ein Viertel aller Referate, mit einem auffallend hohen Anteil im letzten Quartal), gefolgt von Vorträgen zur Geographie Europas und der Schweiz (je etwa ein Sechstel). Erstaunlich wenig kamen amerikanische Themen zur Sprache, wenn man bedenkt, daß in der Tabelle die drei Regionen Nord-, Mittel- und Südamerika zu einer Position zusammengefaßt sind. In der räumlichen Gruppierung der Vorträge sind ebenfalls nur geringe Schwankungen und Gewichtsverlagerungen erkennbar. Diese Aufteilung der Vortragsthemen auf die verschiedenen Großregionen der Erde weist uns auf eine etwas einseitige Ausrichtung der Arbeitsgebiete der Vortragenden hin: Da die überwiegende Mehrheit der Referenten aus deutschsprachigen Ländern stammt, können wir aufgrund der Tabelle schließen, daß die Geographen dieses Raumes sich offenbar am häufigsten mit Asien beschäftigen.

Etwas mehr als die Hälfte aller Referenten waren Schweizer; selbstverständlich war ihr Anteil während gewisser Phasen, in Kriegs- und Krisenzeiten, überdurchschnittlich hoch. Es liegt auf der Hand, daß diejenigen Redner, die in Zürich am häufigsten gesprochen haben, aus dem Inland stammten. Mit 21(!) Referaten, gehalten zwischen 1914 und 1960, führt Arnold Heim die Liste der Mehrfachreferenten mit Abstand an. Er berichtete in den Vorträgen von seinen Reisen und Expeditionen in die verschiedensten Regionen und Landschaften der Erde. Als wissenschaftlich geschulter Reisender war er zum Redner in einem Geographischen Verein geradezu prädestiniert. Sein Vater Albert Heim brachte es «nur» auf 5 Veranstaltungen, spielte aber besonders während der Gründungszeit in der Gesellschaftsgeschichte eine wichtige Rolle. Eduard Imhof, der weltberühmte Kartograph, bestritt 15 Sitzungen, gefolgt von Otto Flückiger und Martin Rikli (je 12), Fridolin Becker (11), Otto Stoll, Jakob Früh und Hans Boesch (je 10), Jakob Heierli (9) u. a. Unter den ausländischen Referenten, die mehrfach in Zürich gesprochen haben, finden wir so illustre Persönlichkeiten wie Julius Büdel mit 6 und Carl Troll mit 5 Vorträgen. Aus der Durchsicht der Jahresprogramme ergibt sich als Auswahl die umstehende beeindruckende Liste bedeutender Wissenschaftler und Reisender, welche der GEGZ ihre Untersuchungen und Forschungen präsentiert haben (Tab. 3). Es fällt auf, daß sich der Kreis der Redner im Laufe der Jahre stark vergrößert hat, insbesondere vermutlich deshalb, weil infolge des starken Wachstums der wissenschaftlichen Zentren und Institute heute immer mehr Fachleute aus dem In- und Aus- 


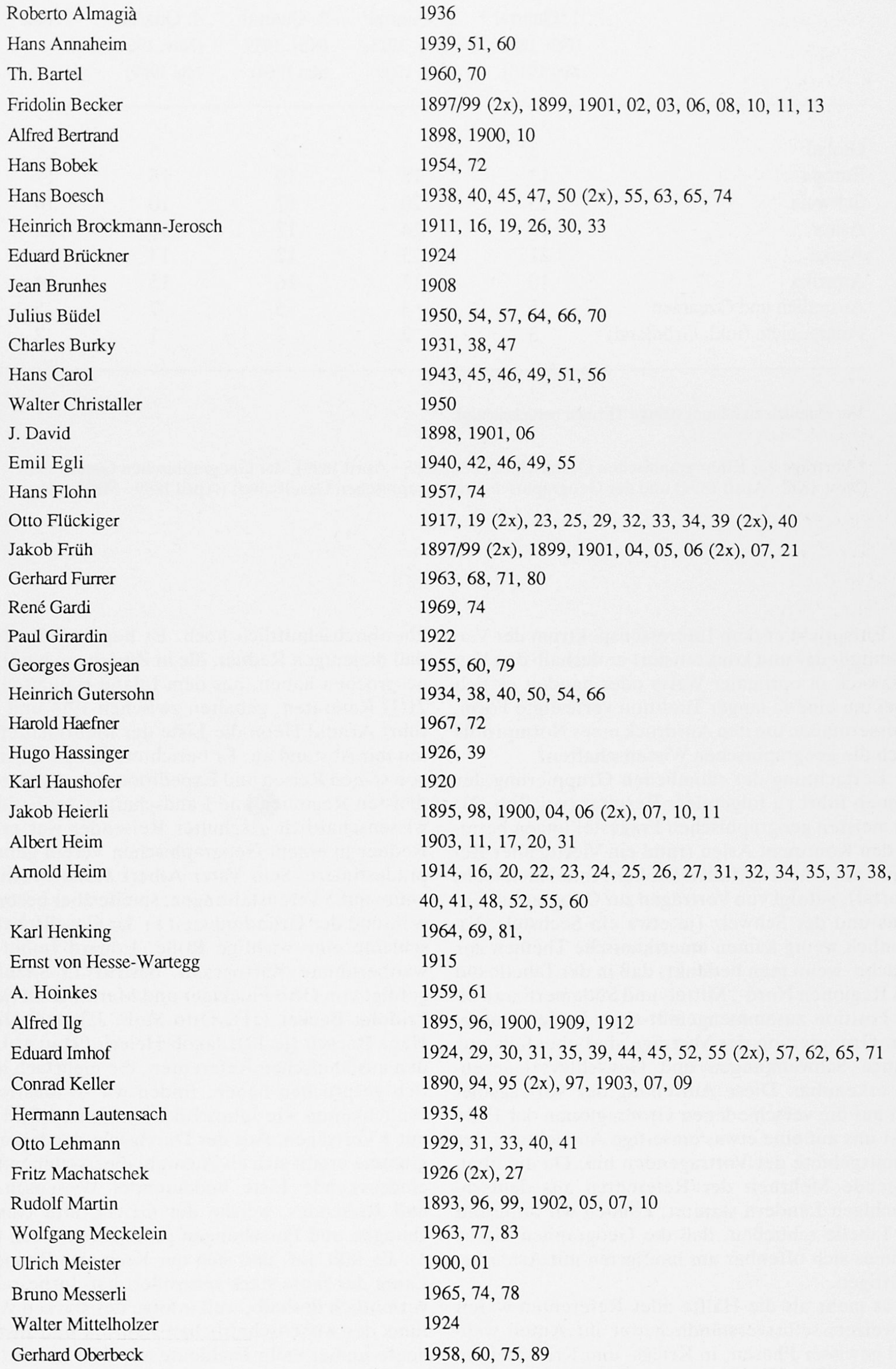




\begin{tabular}{|c|c|}
\hline Alfred de Quervain & $1908,09,12$ \\
\hline Carl Rathjens & $1951,58,73$ \\
\hline Walter Raunig & $1968,70,76,84$ \\
\hline Martin Rikli & $1900,1905,09(2 x), 13,14(2 x), 21,22,28,29(2 x)$ \\
\hline Karl Sapper & 1921,25 \\
\hline Fritz Sarasin & $1897,1904,1907,13$ \\
\hline Paul Sarasin & 1910 \\
\hline Otto Schlaginhaufen & $1910,40,48$ \\
\hline Josef Schmithüsen & 1955 \\
\hline Carl Schröter & $1894,97,99,1908,11,14,28$ \\
\hline Emil Schulthess & 1965,70 \\
\hline Walter Staub & $1924,29,30,43,58$ \\
\hline Alfred Steinmann & $1925,36,39,44(2 x)$ \\
\hline Otto Stoll & $1889,91,93,94,96,97,1902(2 x), 04,07$ \\
\hline Karl Suter & $1933,35,41,42,47$ \\
\hline Carl Troll & $1932,48,49,64,70$ \\
\hline Friedrich Traugott Wahlen & 1946 \\
\hline Leo Waibel & 1938 \\
\hline Heinrich Walter & 1959 \\
\hline Alfred Wegener & 1899 \\
\hline Hans Wehrli & $1905,09,29,31,39$ \\
\hline Leo Wehrli & $1930,37,39,42,44$ \\
\hline Richard Weiss & 1943 \\
\hline Heinrich von Wild & 1899 \\
\hline Herbert Wilhelmy & 1958,67 \\
\hline Ernst Winkler & $1942,44,49,66$ \\
\hline
\end{tabular}

land zur Verfügung stehen. Es ist unwahrscheinlich, daß ein Redner in Zukunft derart häufig zum Zuge kommen wird, wie das noch vor wenigen Jahrzehnten der Fall war. Mit der sich ausbreitenden Gemeinde der Wissenschaftler wächst natürlich auch ihr Drang zur Spezialisierung - bereits die Titel der Vorträge legen von diesem Phänomen Zeugnis ab -, und entsprechend nehmen die Anforderungen, die ein geographischer Vortrag an den Redner und die Zuhörer stellt, allmählich zu. Jedoch liegt jedem Geographen, ob er sich nun berufsmäßig oder aus Liebhaberei mit dieser Wissenschaft befasse, zum Glück eine hohe Bereitschaft zur synthetisierenden Gesamtschau im Blut, auch wenn die Zeit der klassischen Geographen, die noch alle Zweige dieser Wissenschaft beherrschten, natürlich längst vorbei ist. Die Zukunft wird zeigen, bis zu welchem Grad auch nichtprofessionelle Geographen - die in der Geographischen Gesellschaft eine Mehrheit bilden - der wachsenden Spezialisierung zu folgen vermögen.
Um dem Leser einen genaueren Einblick in die Veranstaltungen der GEGZ zu verschaffen, wurden in Tab. 4 die Titel der Referate aus fünf verschiedenen Vortragsreihen - im Jahr der Vereinsgründung 1899 sowie in den Jubiläumsjahren 1913, 1939, 1964 und 1989 - einander gegenübergestellt. Die Vorträge sind thematisch geordnet und stehen innerhalb ihrer Serie nicht in chronologisch richtiger Reihenfolge.

\section{Die Anfangsjahre der GEGZ (1899-1913)}

Das erste Lebensquartal der Gesellschaft stand stark im Zeichen der Entdeckungen und des Kolonialismus. Für diese Periode typische Versammlungsvorträge und Aufsätze in den «Jahresberichten» beschäftigten sich dementsprechend mit Reisen und Expeditionen in unerschlossene Regionen Afrikas, Asiens, des pazifischen Raumes oder zu 
unbekannten Völkern. Am Rande sei in diesem $\mathrm{Zu}$ sammenhang vermerkt, daß der Beitrag, den die Schweiz zu diesen Bestrebungen geliefert hat, bis heute wahrscheinlich noch zu wenig beachtet worden ist; Tatsache ist aber, daß eine ganze Reihe unserer Landsleute außergewöhnliche und wagemutige Erkundungsreisen, nicht selten sogar eigentliche Pionierfahrten unternommen haben. Wichtige Schweizer Forscher jener Zeit waren Fritz und Paul Sarasin aus Basel, die Celebes, Ceylon und Neukaledonien erforschten, der Genfer Missionar Alfred Bertrand und der Zürcher Botaniker Hans Schinz mit Reisen im südlichen Afrika, J. David mit Forschungen im Nilgebiet, A. de Quervain als Leiter einer gewagten Grönlanddurchquerung und manche andere. Sie alle hatten Gelegenheit, vor der GEGZ über ihre Fahrten zu berichten, die meisten von ihnen sogar mehrmals. Paul Sarasin hielt im Jahre 1910 auch ein vielbeachtetes Referat über den «Weltnaturschutz». Dem auch von der GEGZ unterstützten Westafrika-Forscher W. Volz blieb die Berichterstattung versagt; er wurde auf seiner Expedition zur Erforschung des Hinterlandes von Liberia ermordet. Erwähnung finden möge hier im weiteren der 1899 mit der Ehrenmitgliedschaft ausgezeichnete Ingenieur Alfred Ilg, der sich «als rechte Hand des Kaisers Menelik» um die kulturelle und verkehrstechnische Entwicklung Äthiopiens verdient gemacht hat. Ilg war als Redner und Gast in der GEGZ gern und häufig gesehen.

Die Vorträge und Aufsätze von Jakob Früh und anderen lassen die auf deutsche Einflüsse zurückführende physisch-geographische Ausrichtung der akademischen Erdkunde jener Zeit erkennen. Bereits 1891 hatte Früh in seinem an den Zürcher Erziehungsrat gerichteten Zulassungsgesuch als Geographiedozent an der Universität geschrieben: «Die Geographie, wie sie in den letzten zwei Dezennien namentlich in Deutschland und Österreich wieder zur wissenschaftlichen Blüte erhoben worden ist, baut sich auf naturwissenschaftlicher Grundlage auf» (Staatsarchiv, U 1108). Dieser Orientierung blieb sich Früh durch sein ganzes Werk hindurch treu, sowohl in seinen zahlreichen Werken und Schriften als auch in seinen Vorträgen. So sprach er in der GEGZ beispielsweie über «Winddruckerscheinungen an Pflanzen», «Windmotoren», «Erdbeben in der Schweiz», «Naturbrücken» usw., hinzu kommt noch sein Beitrag für die «Jahresberichte» zum Thema «Wasserhosen auf Schweizer Seen». Ein wissenschaftshistorisch interessantes Referat zur Anthropogeographie jener Zeit stammt aus dem berufenen Mund des Freiburgers Jean Brunhes. Er sprach zum Thema: "Qu'est-ce que la géographie humaine?» und behandelte wichtige Grundfragen derTheorie der geographischen Wissenschaften. Da er der französischen wissenschaftlichen Tradition verbunden war, die einen kontinuierlichen Entwicklungsgang aufweist und in ihrer Geschichte frei von

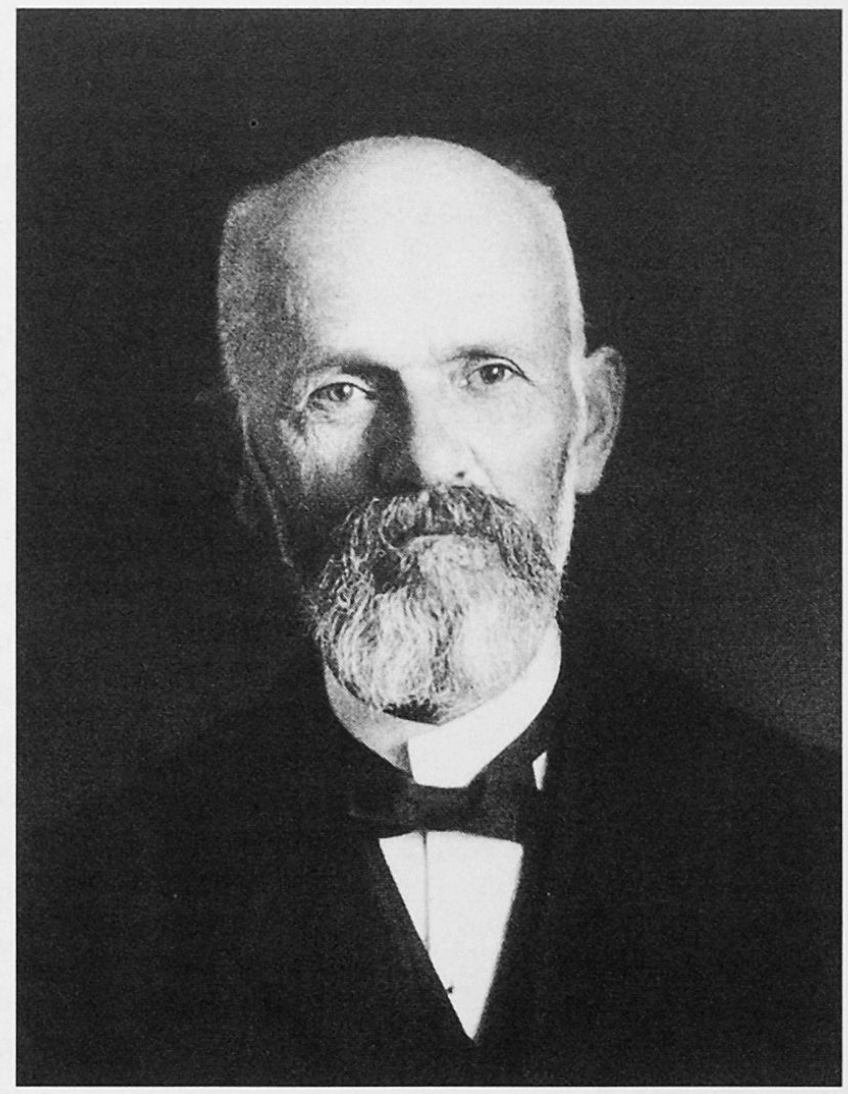

Abb. 4 Jakob Früh (1852-1938), aus dem Kanton Thurgau stammend und in einfachen ländlichen Verhältnissen aufgewachsen, gelangte nach der Ausbildung zum Primarlehrer (1869-1872) und kurzer Unterrichtstätigkeit an die naturwissenschaftliche Abteilung der ETH (Diplom 1876). Es folgten Studienaufenthalte in München und Lausanne. Von 1877 bis 1890 lehrte er Naturwissenschaften und Geographie an der Kantonsschule Trogen, mußte das Unterrichten jedoch aus gesundheitlichen Gründen aufgeben und kam als Assistent an die geologische Sammlung der ETH. Dank eines Studienaufenthalts bei Ferdinand von Richthofen in Berlin vollzog sich bei Früh ein beruflicher Richtungswechsel, der für die Entwicklung der (deutsch)schweizerischen Geographie von erheblicher Bedeutung gewesen ist. 1891 habilitierte er sich an der Universität und an der ETH Zürich, 1899 erfolgte seine Wahl zum ersten ordentlichen Professor für Geographie am Polytechnikum. In dieser Stellung, die er bis 1923 innehielt, entwickelte sich Früh zum wichtigsten Vertreter der zürcherischen akademischen Geographie in den ersten Jahrzehnten dieses Jahrhunderts. Früh kam «von der Geologie zur Geographie» (Aeppli, 1923: 7), und dementsprechend besteht sein umfangreiches Werk hauptsächlich aus Beiträgen zur physikalischen Geographie. Seine bedeutendste Arbeit stellt die dreibändige "Geographie der Schweiz" (St. Gallen 1930, 1932, 1938) dar, die eine von den geographisch interessierten Kreisen der Schweiz seit langem schmerzlich empfundene Lücke schloß. Frühs großartiges Werk setzte den Schlußpunkt hinter die mehr als fünfzigjährigen Bestrebungen zur Schaffung eines modernen wissenschaftlichen Handbuchs der Schweizer Geographie.

Jakob Früh war einer der Gründer der GEGZ. Obwohl er nie das Präsidentenamt innehatte, bekleidete er doch während langer Jahre wichtige Vorstandsfunktionen. 1922 wurde er wegen "seiner großen und vielseitigen Verdienste um die geographische Wissenschaft" zum Ehrenmitglied der Gesellschaft ernannt. 


\section{Vortragsserie 189911900 \\ C. Schröter: Mitteilungen über eine Weltreise, Präsentation von gesam-} melten Objekten

A. Wegener: Reise nach Spitzbergen, Begegnung mit Andree und Nansen

A. Bertrand: Reise in Südafrika

A. Ilg: Die moderne Entwicklung des Verkehrswesens in Aethiopien

A. Engeler: Die Verbreitung und die Geschichte der zahmen Kastanie in der Schweiz

J. Früh: Der internationale Geogragraphenkongress 1899 in Berlin

H. v. Wild: Uber die neuern klimatologischen Arbeiten in Russland

F. Becker: Fernöhren aus dem Atelier Zeiss in Jena

A. Aeppli: Der gegenwärtige Stand der schweizerischen Schulwandkart

C. Keller: Mitteilungen über altassyrische Haustierdarstellungen

Hoffmann-Krayer: Spuren von Haustierkult bei europäischen Völkern

J. Heierli: Der primitive Hausbau bei den verschiedensten Völkerschaften alter und neuer Zei 1912/13
A. de Quervain: Die schwei-
zerische Grönland-Expedition

Th. Herzog: Forschungen in der bolivianischen Ostkordil-

G. Montandon: Forschungsreise nach SW-Aethopien

M. Rikli: Studienreise durch die Kaukasusländer und Hocharmenien

C. Seelig: Hocharmenien und der Ararat

C. Täuber: Die Sarden und ihre Insel

F. Sarasin: Neukaledonien

F. Speiser: Die Neuen Hebriden

A. Ilg: Das Gerichtswesen und die mit diesem in Verbindung stehenalten Sitten und Gebräuche Aethopien Arabien, gestern, heute und in Zukunft

L. Waibel: Reisen und Forschungen in Mitteamerika

F. Metz: Das Tauberland

O. Flückiger: Aus der Bündner Alpwirtschaft

H. Gutersohn: Kolonisation in Mittelbrasilien

H. Brunner: Morphologisches aus dem Hochwan gisches

H. Annaheim: Holland gewinnt Land

C. Leden: 3 Jahre unter den kanadischen Eskimos

H. Kauffmann: Bergbauem H. Kauffmann: Bergbauern
und Kopfjäger. Meine Rei und Kopfjäger. Meine Rei-
se zu den Naga in Assam se zu den Naga in Assam G. Jöhrer: Aussterbende Saharastämme

H. Bernatzik: Auf der Suche nach unbekannten Völkern in Hinterindien

C. Rubi: Volkskunst und Volksleben im Emmental

H. Wehrli: Führung durch die Indonesien-Abteilun der völkerkundlichen Sammlung

\section{$1963 / 64$}

. Boesch: Südasien 1963 Beobachtungen und Gedanke eines Geographen

W. Kündig-Steiner: Kamerun heute

J. Büdel: Spitzbergen

A. Gansser: Eine Forschungsreise in den Bhutan-Himalaya

K. Helbig: Forschungen in Chiapas, Mexikos südlichstem Staat

C. Troll: Die Vegetation der Tropen im Lichte der pflanzlich Lebensformen

$1988 / 89$

W. Frentz: Die grosse Donaufahrt Vom Schwarzwald bis zum Schwarzen Meer

Stadelbauer: Sowjet-Kaukasien - landschaftliche Vielfalt und ihre touristische Erschliessung

K. Tauchmann: Mobile Meeres bewohner Südostasiens und ihre territoriale Integration

H. Elsasser: Der ländliche Raum in der Schweiz - Beiträge der Wirtschaftsgeographie zu seiner Erhaltung und Förderung

C. Hannss: Die Natur- und Kulturland( del der Zeiten

Pörensen: Urgeschichtliche For- G. Oberbeck: Die Hansestadt Hamburg schungen in Thailand Genese, Planung und aktuelle Probleme der norddeutschen Metropole

K. Henking: Marco Polo

A. Gerbrands: Kunst und Künstler glersherung in Tibet - Die Süd-Tibet-

H. Huber: Ackerbau-Riten be den Krobo (Westafrika) Mt

U. Köhler: Wirtschaftsleben und Festzy klus heutiger Hochland-Maya in Mexiko

P. Gerber, H. Lippuner: "Ich brauche keine Federn, um Indianer zu sein" - Identität und Selbstbestimmung der Indianer Nordamerikas 
Bruchstellen ist, wie sie die für uns wichtigere deutsche Geographie kennt, dürften seine Ausführungen für das Zürcher Publikum von besonderem Interesse gewesen sein.

Die Aufsätze in den «Jahresberichten» der GEGZ decken ein außerordentlich breites Spektrum von Themen ab. Neben den bereits erwähnten finden sich unter den 34 Arbeiten des ersten Quartals auch solche $\mathrm{zu}$ geschichtlichen und ethnographischen Themen, zu Problemen der angewandten Geographie und, gegen Ende der Periode, längere Aufsätze, die einer bestimmten geographischen Region gewidmet sind. Arbeiten dieser Art, sog. Landschaftsmonographien, haben in der folgenden Periode eine recht wichtige Rolle gespielt, weshalb von ihnen noch die Rede sein wird.

Insgesamt betrachtet befand sich die GEGZ im ersten Quartal ihrer Existenz in einer Phase schneller Konsolidierung und relativ starken Wachstums. Die Mitgliederzahl stieg von 222 im Jahre 1899 auf 321 im Jahre 1913 (vgl. Tafel 1). Die häufigen Appelle der Gesellschaftspräsidenten zur Werbung neuer Mitglieder trugen offenbar Früchte. Begründet wurden diese Aufrufe jeweils mit dem etwas unklaren Hinweis, daß mit steigender Mitgliederzahl «die Gesellschaft ihre Aufgaben um so besser erfüllen könne» (z. B. Sitzungsprotokoll vom 2.11.1910). Nicht ohne Stolz wurde schon bald festgehalten, daß die Geographische-Ethnographische Gesell- schaft «dazu berufen sei, einer der Sammelpunkte zur Pflege der großen Geistesfragen der Gegenwart in unserer Stadt zu werden». Mit Befriedigung konnte man feststellen, daß «diese Bestrebungen vom Stadtrat wie von der kantonalen Regierung gewürdigt und durch angemessene Beiträge unterstützt» wurden (Sitzungsprotokoll vom 25.5.1910). Die Versammlungen, die über lange Jahre hinweg im Saal des Zunfthauses zur Schmiden abgehalten wurden, erfreuten sich eines regen Publikumsinteresses, ja der Andrang war zeitweise derart gro $\beta$, daß an die Einführung einer Türkontrolle gedacht werden mußte, weil die Gesellschaftsmitglieder «infolge starken Zulaufs von der Gesellschaft fremden Personen nicht einmal Platz fanden» (Protokoll der Vorstandssitzung vom 30.9.1915). Besonders störend war für viele Mitglieder offenbar die Anwesenheit von «minderjährigen Knaben und Mädchen und strickenden Frauen» (30.9.1920). Eine besondere Anziehungskraft übten damals vor allem die eigentlichen Reisevorträge aus. Heutzutage, im Zeitalter des Films, des Fernsehens und einer grenzenlosen Mobilität, fällt es recht schwer, sich vorzustellen, was Vorträge über ferne Länder und fremde Völker für viele Zuhörer früher offenbar bedeuteten. Sicher hatten sie aber im Spektrum der städtischen Veranstaltungen jener Jahre einen besonderen Stellenwert - und dies gleich in mehrfacher Hinsicht. Ungewollt aufschlußreich protokollierte Ul-

Tafel 1: Totalbestand der Mitglieder (Ehrenmitglieder, lebenslängliche Mitglieder, Kollektivmitglieder, Einzelmitglieder) und Amtsdauer der Präsidenten der Geographisch-Ethnographischen Gesellschaft (1899-1989) und ihrer Vorläufer.

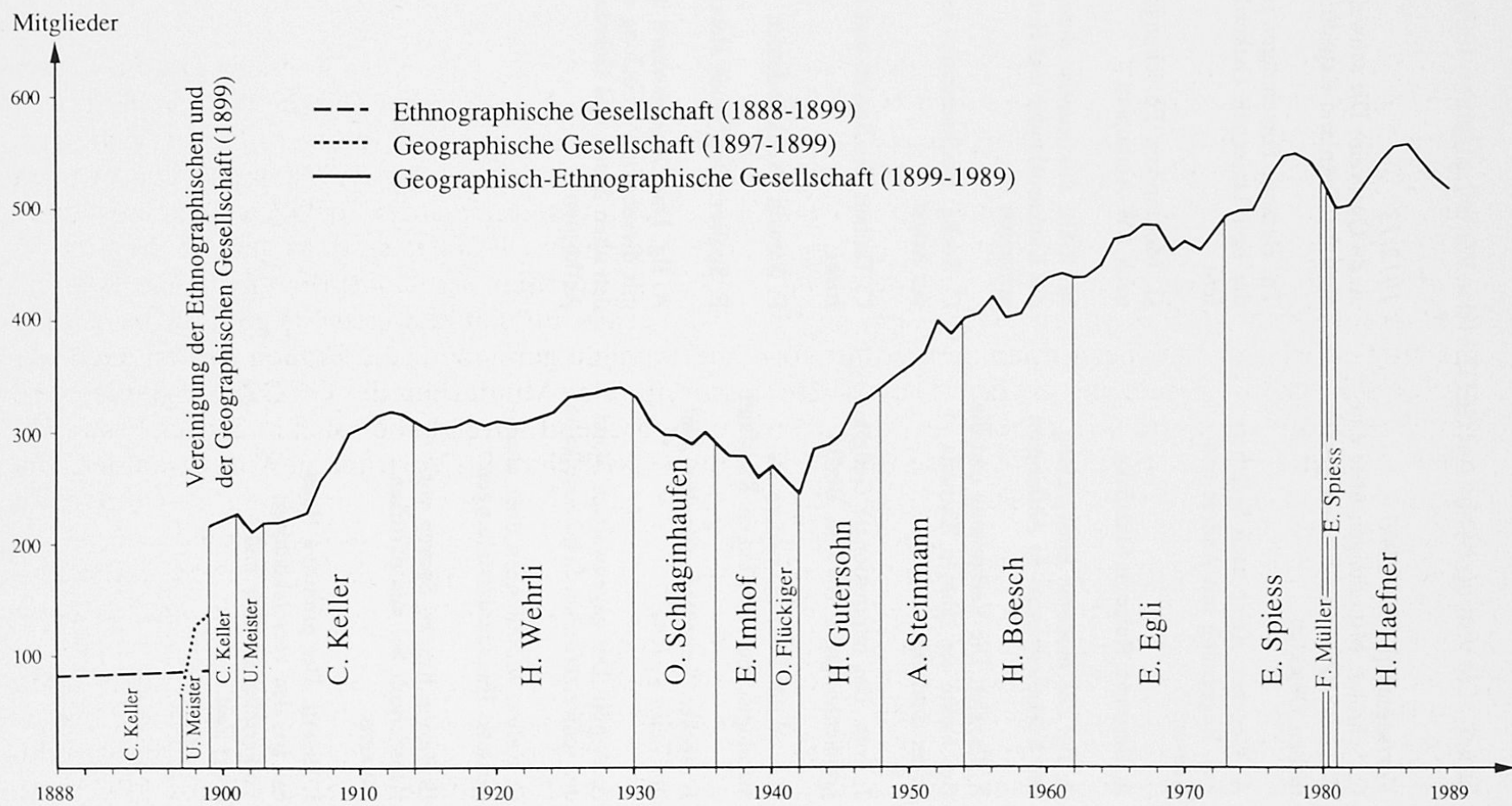




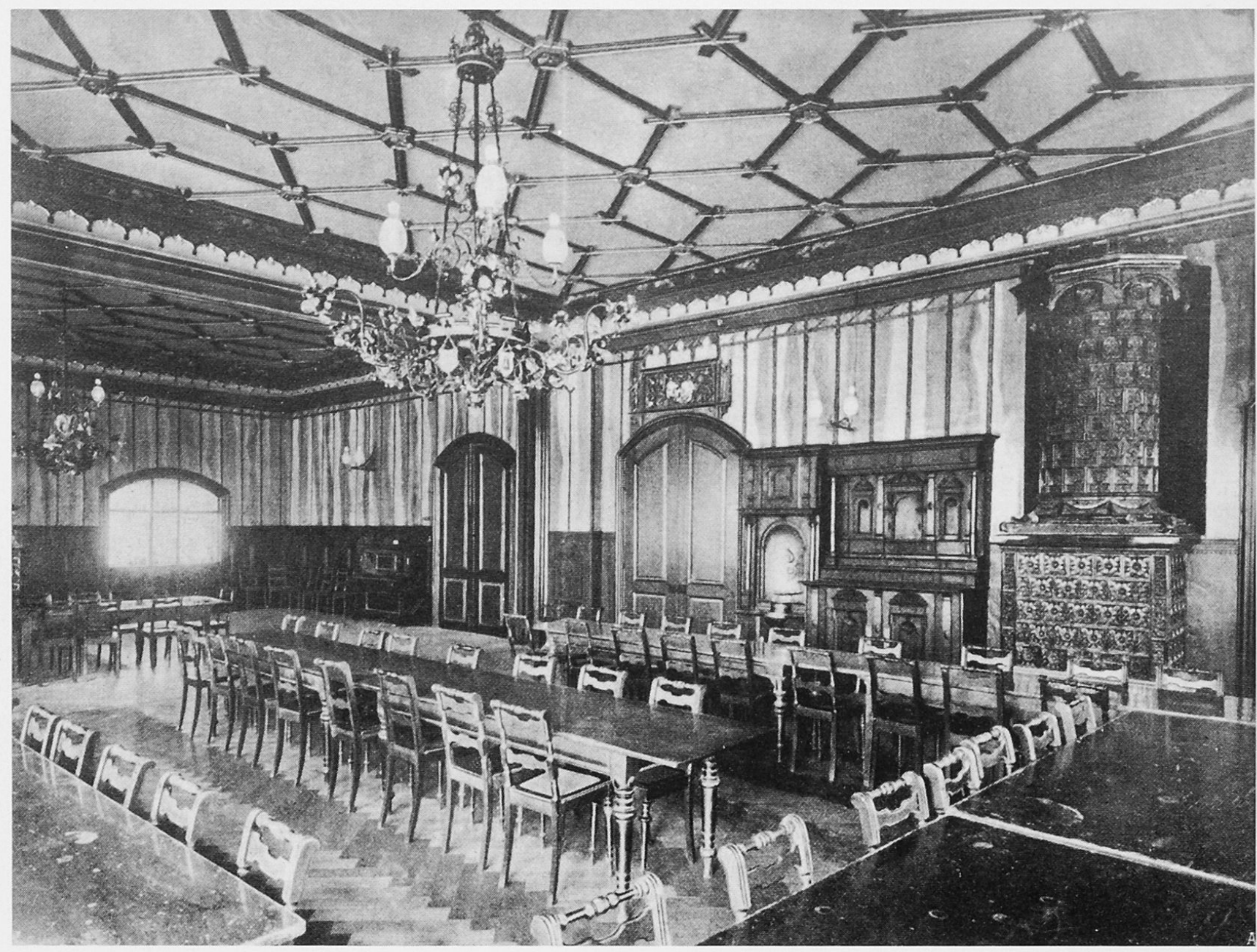

Abb. 5 Die «Schmidstube» im Zunfthaus zur Schmiden, Zürich, das Versammlungslokal der GEGZ von 1904 bis 1933.

rich Ritter 1915 eine Darbietung Professor KochGrünbergs, der über seine «Reise durch Nord-Brasilien zum Orinoco, 1911-13» berichtete: Es fanden «Projektionsbilder, phonographische und kinomatographische Aufnahmen» Verwendung, notierte Ritter im Protokollband, und weiter: Der Referent schilderte die «von europäischer Kultur noch fast ganz unbeeinflußt gebliebenen Bewohner, deren prächtig entwickelte Körperformen in ihrer fast völligen Nacktheit ausgezeichnet zu Tage traten». Der deutsche Professor hatte mit seinen Ausführungen «dem den letzten Platz füllenden Auditorium einen ebenso lehr- als genußreichen Abend bereitet» (Protokoll vom 13.1.1915).

In diesem Publikum saßen übrigens, wie ersichtlich, auch zahlreiche Frauen. Dieser Punkt ist geschichtlich betrachtet nicht unwesentlich, weil in gewissen ausländischen Geographischen Gesellschaften, beispielsweise in der berühmten «Royal Geographical Society» (London), noch in diesem Jahrhundert über die Zulassung von Frauen zur Mitgliedschaft gestritten wurde. Hingegen konnten Frauen in den schweizerischen Geographischen Gesellschaften von Anbeginn weg selbstverständlich und diskussionslos Mitglied werden. 1899 finden wir zwar im Mitgliederverzeichnis der GEGZ noch keine weiblichen Namen, 1938/39 sind es jedoch bereits 52 $(20 \%)$. Trotzdem steht natürlich fest: Die Geographie ist bis auf den heutigen Tag generell eine Männerdomäne geblieben, die Frauen stellen nach wie vor nur eine Minderheit der GEGZ-Mitglieder, und entsprechend selten haben sich in Zürich Frauen in der Gesellschaft für Vorträge zu Wort gemeldet. Um so bedauerlicher ist es deshalb, daß ausgerechnet die erste Referentin, Frau Leopoldine von Morawetz-Dierkes aus Wien, die 1904 über «Land und Leute in Finnland» sprach, eine schlechte Kritik erhalten hat.

Das Jubiläumsjahr 1913 und die folgenden Jahre brachten für die Gesellschaft eine gewichtige Veränderung, nämlich die Übernahme der Ethnographischen Sammlung durch den Staat. Schon 1898 hatte 
sich die Ethnographische Gesellschaft als Eigentümerin der Sammlung veranlaßt gesehen, die Kollektion wegen Raumproblemen dem Kanton Zürich anzubieten. Die Verhandlungen, die damals mit den Behörden geführt wurden, verliefen erfolgreich und schufen die Voraussetzung für den Einbezug der für die Sammlung benötigten Ausstellungsräumlichkeiten in das Bauprogramm der neuen Universität, die sich in jenen Jahren in Planung befand. Der Volksentscheid über den Bau der Universität ließ jedoch noch bis im April 1908 auf sich warten, und es verstrichen weitere sechs Jahre bis zu ihrer Einweihung am 18. April 1914. Gemäß Regierungsratsbeschluß vom 13. Dezember 1913 sollte «die von der geographisch-ethnographischen Gesellschaft schenkungsweise angebotene Sammlung ethnographischer Ausstellungsgegenstände auf den Zeitpunkt des Bezugs des neuen Universitätsgebäudes vom Staate übernommen» werden. Die Schenkung selber «wie auch die Zusicherung einer Beitragsleistung im Betrage von Fr. 8000.- für Anschaffung von Glasschränken» zur Aufbewahrung der Objekte wurden der Gesellschaft von Zürichs Regierung «angelegentlichst verdankt». Im Dezember 1916 erfolgte schließlich am neuen Standort die Eröffnung der Ethnographischen Sammlung, die von nun an die Bezeichnung «Sammlung für Völkerkunde der Universität Zürich» trug. Damit hatte die GEGZ eine ihrer zentralen Aufgaben, die Erhaltung und Mehrung dieser Sammlung, abgetreten; gleichzeitig markiert diese Episode einen Meilenstein in der auseinanderstrebenden Entwicklung der Ethnologie/Ethnographie und der Geographie.

\section{Das zweite Quartal (1913-1939)}

Der Erste Weltkrieg brachte unserer Gesellschaft wie natürlich dem kulturellen und wissenschaftlichen Leben ganzer Erdteile - Behinderungen und Rückschläge, die sich aber in unserem vom Krieg verschonten Land zum Glück in Grenzen hielten. Im Ersten wie später im Zweiten Weltkrieg war es immer das Bestreben des Vorstandes, einen einigermaßen normalen Gang der Gesellschaftsaktivitäten aufrechtzuerhalten, was auch bemerkenswert gut gelungen ist. In der Eröffnungssitzung zum Vortragszyklus während des ersten Kriegswinters 1914/ 15 betonte Präsident Hans Wehrli, «daß der Vorstand trotz der infolge der Kriegswirren so ungünstigen Zeitverhältnisse in gleicher Weise wie bisher ein unverkürztes Winterprogramm aufgestellt hat, von der Voraussetzung ausgehend, daß gerade auch diese schwere Zeit geeignet sei, das Interesse an geographischen Dingen zu wecken und zu fördern». 1918 konnte rückblickend konstatiert werden, daß sich trotz der schwierigen Zeitlage die Tätigkeit der
GEGZ im normalen Rahmen bewegt hatte. Die «NZZ» schrieb: «Die Aufstellung des Vortragsprogramms war allerdings für den Vorsitzenden keine leichte Aufgabe, aber dank dem Entgegenkommen inländischer Geographen und Forscher konnten die Wintersitzungen ebenso anziehend und lehrreich gestaltet werden als früher, da [. . . auch ausländische Vertreter der geographischen Wissenschaft zu Wort kommen [konnten]. Ein ungemein reger Besuch aller Veranstaltungen legte Zeugnis ab, wie hoch geographische Kenntnisse in den Kreisen der Gebildeten geschätzt und gewertet werden.»

Im zweiten Lebensquartal unserer Gesellschaft (1913-1939) begannen in der Geographie zum Teil neuartige Themen und Theorien in den Vordergrund zu treten. Nach dem Willen des Vereinsvorstandes sollte die Zahl der reinen Reisevorträge reduziert, die Heimat wieder stärker berücksichtigt und allgemein eine inhaltliche Vertiefung der Referate herbeigeführt werden. Auf der theoretischen Ebene entwickelte die internationale Geographie in dieser Periode unter dem Stichwort «Landschaft» nicht nur einen neuen, zentralen Begriff, sondern auch - vielleicht erstmalig in ihrer Geschichte - eine klare Konzeption ihres Forschens. Der Deutsche Alfred Hettner und andere führende Geographen verfolgten in ihren Arbeiten eine Richtung, welche die wissenschaftliche Erdkunde immer konsequenter zur ausschließlichen Erkenntnis der Erdoberfläche als Landschafts- und Länderkomplex führte. Eine Landschaft oder ein Land als geographische Grundeinheiten wurden nun unter allen möglichen Gesichtspunkten untersucht und beleuchtet. Deshalb tauchen der Begriff «Landschaft» oder die Wendung «Land und Leute» in den Titeln der Referate jener Zeit häufig auf, und entsprechend schlug sich dieses Konzept in den langen Landschaftsmonographien nieder, die als Dissertationen am Geographischen Institut der Universität Zürich in ansehnlicher Zahl entstanden sind. Diese Arbeiten, von denen bereits weiter oben die Rede war, entstammten der sogenannten «Wehrli-Schule», benannt nach ihrem Gründer Professor Hans J. Wehrli, einem wichtigen Zürcher Geographen der Zwischenkriegszeit. Einige dieser Landschaftsstudien gelangten in den «Mitteilungen» zum Abdruck.

Da auch die Städte einen Typus geographischer Grundeinheiten verkörpern, gerieten sie in jenen Jahren ebenfalls in den Brennpunkt geographischen Interesses und gewannen als Thema mündlicher und schriftlicher Auseinandersetzung seither stark an Bedeutung. Der internationale Methodenstreit zwischen den Vertretern der allgemeinen Geographie und der Länderkunde rief in Zürich übrigens nur eine schwache Resonanz hervor; trotzdem dürfen wir davon ausgehen, daß wohl nicht jeder Zürcher Geograph Ernst Winklers Behauptung aus dem Jahr 
1936 unterschrieben hätte, «daß nämlich die Geographie nur als Länderkunde Berechtigung habe», worüber sich seit Ritter und Richthofen alle Geographen einig seien (WINKLER, 1936).

Eine dritte Kategorie geographischer Arbeiten, die in dieser Periode wurzelt, kann der angewandten Erdkunde, d. h. der Planung, der Gewässerverbauung und -regulierung, der Wassernutzung, dem Meliorations- und Verkehrswesen sowie der Fernerkundung zugeordnet werden. Gerade in diesem Bereich wurden sehr gehaltvolle und zukunftsweisende Arbeiten mündlicher oder schriftlicher Art vorgelegt, so zum Beispiel von Hans Bernhard (1915, 1922, 1932, 1939), K. Bertschinger (1915), Flury (1917), Emil Klöti (1918), Otto Flückiger (1919, 1939) u. a. Bertschinger sprach 1915 zum Thema: «Die Verkehrsprobleme Zürichs», und das Protokoll hält fest: "Ganz besonders redete er das Wort der Spezialisierung des Verkehrs, d. h. der Trennung des Vorortverkehrs vom in- und ausländischen Fernverkehr, der günstigen Gestaltung der Verbindungen mit den zürcherischen Interessensphären, wie Engadin und Schwarzwald, der Hebung und Beschleunigung des Nordsüdverkehrs durch die Erbauung der Randenbahn und die Erstellung der durchgehenden Doppelspur, desgleichen der Arlberglinie zur besseren und rascheren Verbindung von Frankreich und Österreich durch unser Land» [. . . . In der an das Referat anschlieBenden Diskussion kam der ungebrochene Fortschrittsglaube jener Zeit noch verstärkt zum Ausdruck, als zum Beispiel Professor Früh «die Kurzsichtigkeit und den Mangel an Großzügigkeit derer geißelte, die die Geschicke unseres Landes in verkehrstechnischer Hinsicht in den Händen haben». Professor Becker hoffte gar, daß es «gelingen werde, Zürich zum Verkehrsherz des zentralen Mitteleuropa auszugestalten» (Sitzungsprotokoll vom 1.12.1915).

Wenn heute eben gerade die Verkehrsträger und die Siedlungen als wichtigste Kulturlandzerstörer gelten, so standen in dieser Hinsicht früher die neugeschaffenen Stauseen im Vordergrund. 1922 referierte Hans Bernhard zu diesem Thema unter dem Titel: «Die kulturlandzerstörende Wirkung einiger größerer schweizerischer Stauseeanlagen und deren Behebung durch Umsiedlungswerke». Das Postulat des Kulturlandschutzes war also damit bereits ausgesprochen, und doch sind wir auch heute von seiner konsequenten Verwirklichung noch weit entfernt.

Otto Flückigers Vortrag über «Fliegeraufnahmen und ihre geographische Verwertung» aus dem Jahre 1919 steht am Anfang einer für die zürcherische Geographie bedeutenden Forschungsrichtung. Erstmalig wurden hier die Prinzipien und die faszinierenden Möglichkeiten der Fliegerbildauswertung und der stereographischen Luftbildanalyse besprochen. Flückiger legte mit diesem Referat sowie dem 1924 erschienenen Band «Die Schweiz aus der Vogelschau», der Luftaufnahmen aus der Sammlung Walter Mittelholzers enthält, den Grundstein für die moderne Fernerkundung, die am Geographischen Institut der Universität Zürich in der Zeit nach dem Zweiten Weltkrieg stark ausgebaut worden ist und heute intensiv gepflegt wird.

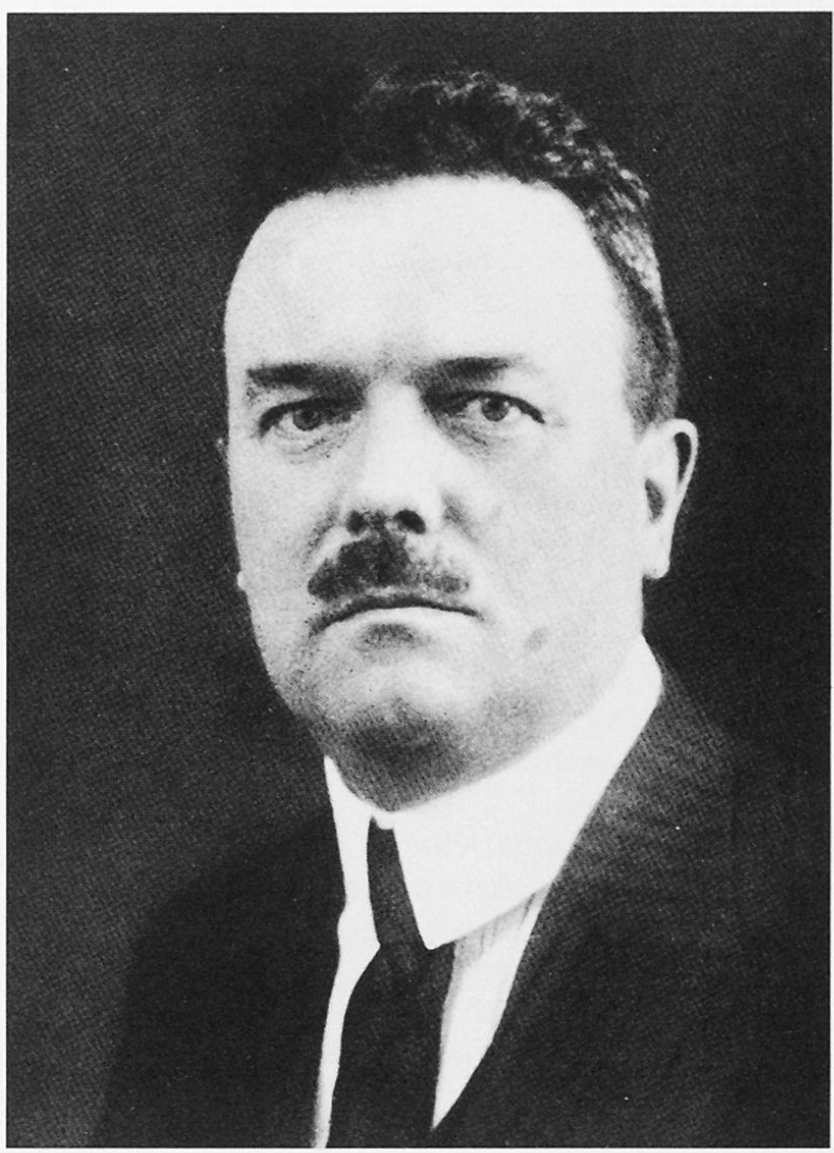

Abb. 6 Otto Flückiger (1881-1942), aus dem Kanton Bern stammend, schlug zunächst die Lehrerlaufbahn ein studierte anschließend bei E. Brückner in Bern, wo er als dessen letzter Berner Doktorand 1904 promovierte. Nach seiner Übersiedlung nach Zürich wirkte er als Geographielehrer an der Töchterschule. 1917 erhielt er die venia legendi aufgrund seiner Habilitationsarbeit "Morphologische Untersuchungen am Napf». 1925 wurde er zum Extraordinarius, 1940 zum Ordinarius und Direktor des geographischen Instituts der Universität gewählt. Seine wissenschaftlichen Interessen galten einerseits dem Studium der Nutzung der Kulturlandschaft durch den Menschen und der Frage «in welcher Art das Relief im Lebensraum des Menschen wegweisend und entscheidend gewirkt hat" (Gutersohn, 1942: 8). Als Hilfsmittel bediente er sich «insbesondere auch des Flugbildes, dessen didaktische Vorzüge er in unserem Land wohl als erster völlig erkannt und ausgewertet hat." Andererseits widmete er sich, angeregt durch Brückner, glazialmorphologischen Problemen.

Otto Flückiger gehörte seit 1920 dem Vorstand der GEGZ an und trat bei zahlreichen Gelegenheiten als Exkursionsleiter und Referent in Erscheinung. In seinen letzten beiden Lebensjahren hatte er das Präsidium der Gesellschaft inne. 
In die Periode von 1913-1939 fallen einige besondere Reiseunternehmungen von Mitgliedern der GEGZ, die es verdient haben, in Erinnerung gerufen zu werden. Der erwähnte Schweizer Flugpionier Walter Mittelholzer berichtete einmal selber («Flüge über Spitzbergen», 1924), und ein zweites Mal sprach Arnold Heim («Naturwissenschaftliche Skizzen vom Afrikaflug», 1927) über die wagemutige Luftreise, die er in Mittelholzers Maschine mitgemacht hatte. Martin Hürlimann trug über seinen Aufenthalt «Im verschlossenen Königreich Nepal» (1929) vor, das er als erster Schweizer besucht haben soll, und Eduard Imhof und Arnold Heim (s. Abb. 13) referierten über «Unsere Expedition nach chinesisch Tibet» (1931), die wohl wichtigste wissenschaftliche Reise von Schweizern in diesem Jahrhundert. Die Expedition, die mehr als zehn Monate dauerte, hatte in erster Linie zum Ziel, abzuklären, ob der Minya Konka in SW-China, das «chinesische Matterhorn», tatsächlich der höchste Berg der Erde sei, wie man damals vermutete. Die beste damalige Karte sparte den Riesen und seine Umgebung bis zur Reise von Heim und Imhof als «unsurveyed» weiß aus (HEIM, 1944: 41). Erwähnenswert sind auch «Die 2. schweizerische Angola-Expedition» (1935) und «Die schweizerische Himalaya-Expedition 1936» (1937) sowie eine Reihe von längeren Einzelreisen verschiedener Geographieprofessoren der Zürcher Hochschulen, die wir im einzelnen nicht aufzählen wollen.

Neben den Reiseberichten, Landschaftsmonographien und anderen Arbeiten nahmen im ersten und zweiten Jahrzehnt dieses Jahrhunderts auch ethnologische und anthropologische Beiträge in den «Jahresberichten» und «Mitteilungen» der Gesellschaft einen breiten Raum ein. Im selben Maß, wie diese Themen später zurücktraten, rückten geographische Arbeiten aus den Bereichen Länder- und Landschaftskunde, Wirtschaftsgeographie, Geomorphologie (z. B. Fritz Machatschek, 1924/25, 1925/26, 1926/27), angewandte Geographie (z. B. Hans Bernhard, 1929/30, Ernst Winkler, 1935/36, 1938/ 39) u. a. in den Vordergrund.

Die politischen Vorgänge in unserem nördlichen und südlichen Nachbarland, das Auftauchen des Nationalsozialismus und des Faschismus in den zwanziger und dreißiger Jahren als Auslöser eines nachhaltigen kulturellen Marasmus sowie der Pervertierung der Wissenschaft haben sich auf die GEGZ offenbar so schwach ausgewirkt, daß wir rückblickend nur noch wenige Spuren dieser Zeit zu entdecken vermögen. Mit Karl Haushofer, damals Dozent an der Universität München, sprach 1920 ein Mann in Zürich («Japans Weg von der sich selbst genügenden Kultur zum expansiven Industriestaat»), der sich später als Exponent einer der nationalsozialistischen Ideologie verpflichteten Geopolitik profilierte. Der seinerzeit bekannte Rassenforscher Egon Freiherr von Eickstedt referierte 1935

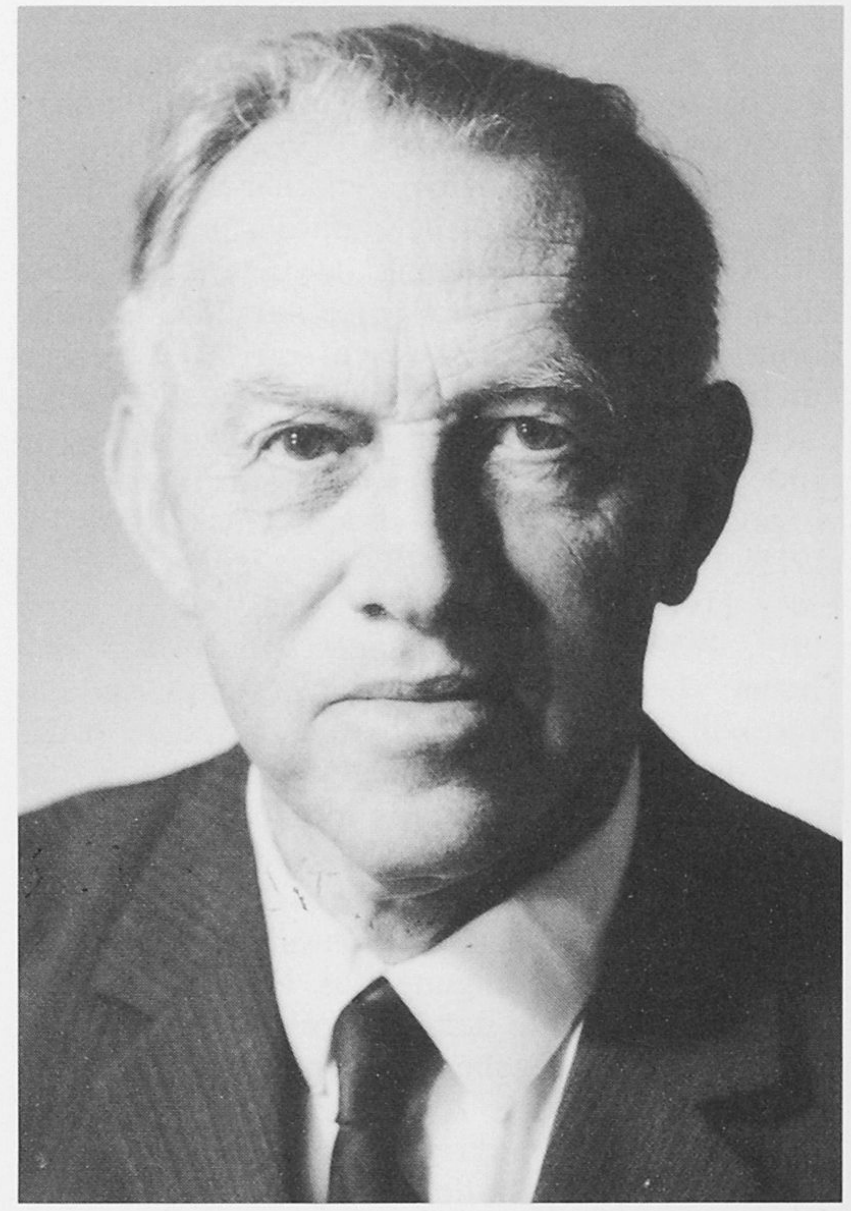

Abb. 7 Eduard Imhof (1895-1986), Sohn des gleichnamigen Geographen, absolvierte bei Fritz Baeschlin, Fridolin Becker, Jakob Früh u. a. ein Studium als Vermessungsingenieur an der Eidgenössischen Technischen Hochschule (Diplom 1919). Nach Assistenten-, Hilfslehrer- und erster Dozententätigkeit erfolgte 1925 seine Ernennung zum außerordentlichen Professor für Plan- und Kartenzeichnen, Topographie und verwandte Fächer an der ETH. «In Anerkennung seiner großen Leistungen auf dem Gebiet der Relief- und Kartenherstellung" verlieh inm die Universität Zürich 1949 die Würde eines Dr. h. c. Im darauffolgenden Jahr wurde er zum Ordinarius für Plan- und Kartenzeichnen, Topographie und Kartographie am Polytechnikum gewählt, 1965 trat er nach 46jähriger Lehrtätigkeit von diesem Amt zurück.

Imhofs Bedeutung als Kartenautor, Verfasser wissenschaftlicher Publikationen, Hochschullehrer, Landschaftsmaler und nicht zuletzt als Präsident und Förderer der GEGZ ist außergewöhnlich. Er brachte die lange Zürcher Kartographentradition zu einem vorläufigen Höhepunkt. Aus seinem umfangreichen Schaffen mögen hier lediglich die verschiedenen Schulatlanten und Schulwandkarten sowie der große "Atlas der Schweiz", dessen Redaktionskommission er präsidierte, Erwähnung finden. Von zahlreichen Fachgesellschaften in aller Welt wurden ihm Auszeichnungen verliehen. 


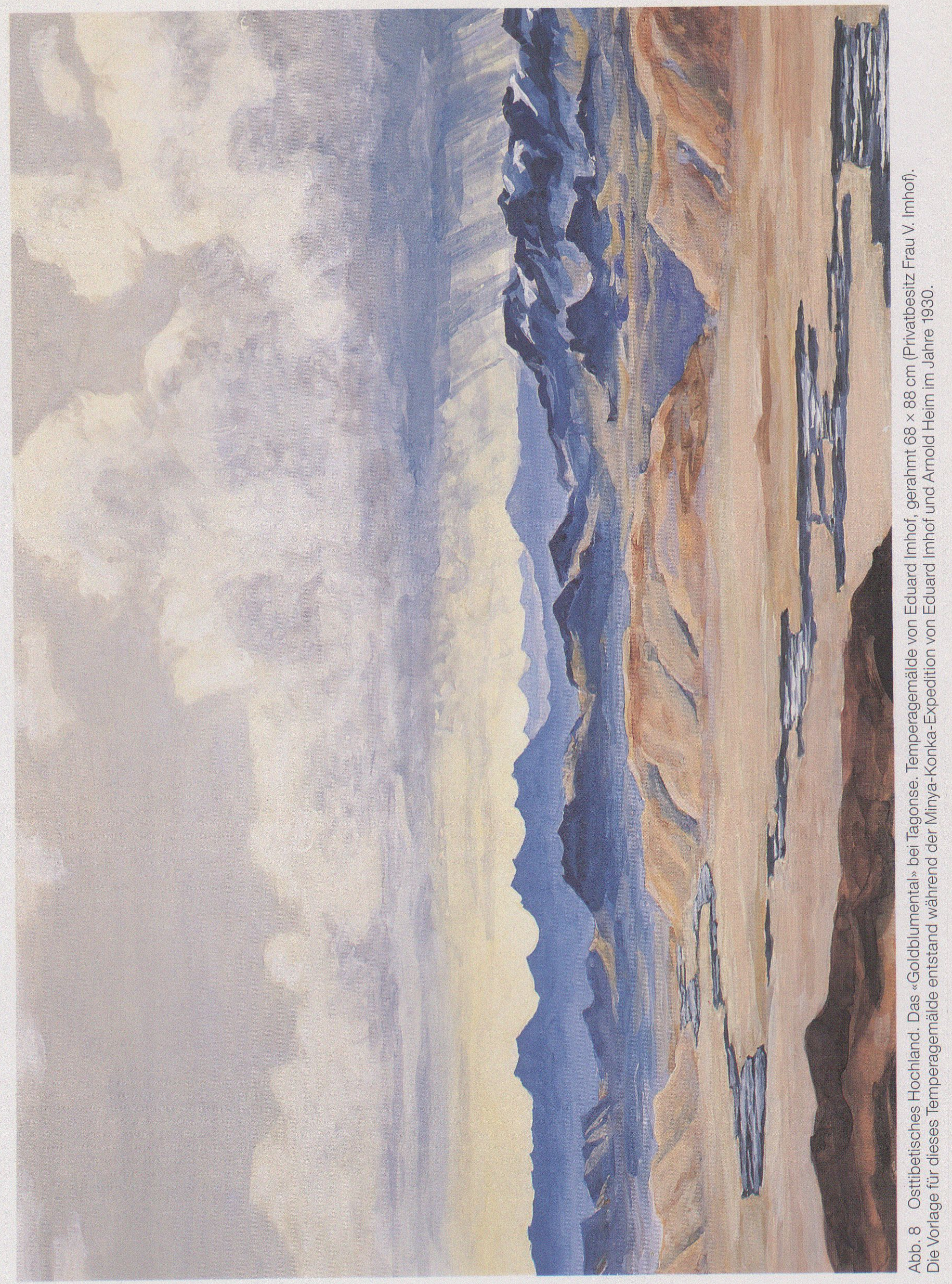


über «Forschungen und Fahrten in zentralindischen Dschungeln», und von verschiedenen Autoren, darunter auch Schweizern, wurde das Vorgehen Italiens in Libyen, Abessinien und anderswo («Italiens Kulturarbeit in Nordafrika») in einem schönfärberischen Licht gewürdigt. Als Zeichen der Zeit kạn sicher auch die damalige Betonung der Schweizergeographie gewertet werden. Der Umstand, daß gravierende politische Entwicklungen in nächster Nähe der Schweiz nur einen geringen Niederschlag in den Akten der GEGZ gefunden haben, spricht einerseits für das hohe Niveau und die wissenschaftliche Ausrichtung der Gesellschaft, andererseits aber vielleicht auch für eine teilweise in ihren Reihen verbreitete politische Indifferenz. Trotz der Tatsache, daß die GEGZ auch damals politisch dem bürgerlichen Lager zuzuordnen war, erstaunt uns ein Vorstandsbeschluß aus dem Jahre 1932, wonach auf «einer Liste von Tagesblättern, die Rezensionsexemplare der „Mitteilungen” bekommen sollten», das sozialdemokratische «Volksrecht» gestrichen wurde - ein Schritt, der mit den Grundsätzen einer universellen wissenschaftlichen Disziplin sicher im Widerspruch steht (Protokoll der Vorstandssitzung vom 24.10.1932).

Die Krise im Vorfeld des Zweiten Weltkriegs und der Krieg selber warfen noch dunklere Schatten über die GEGZ, als dies der Erste Weltkrieg ein Vierteljahrhundert zuvor getan hatte. Der damalige Gesellschaftspräsident Eduard Imhof stellte 1936 fest: «Infolge Krise häufen sich die Austritte. Die Gesellschaft braucht um die Aufgaben zu erfüllen und im Hinblick auf das 1938 stattfindende Jubiläum Geld» (Sitzungsprotokoll vom 28.10.1936) und im folgenden Jahr: «Dringend ist die Mitgliederwerbung, [weil die Mitgliederzahl] langsam aber stetig zurückgeht» (Protokoll vom 9.6.1937). Diese erreichte 1942 ein Minimum, stieg jedoch bereits in der zweiten Krieghälfte und in den darauffolgenden Jahren erfreulicherweise wieder stark an (vgl. Tafel 1). Die Jubiläumsfeier wurde auf das Landesausstellungsjahr 1939 verlegt, «um durch diese große nationale und heimatkundliche Schau unser Festprogramm zu bereichern» (Programm zur Fünfzigjahr-

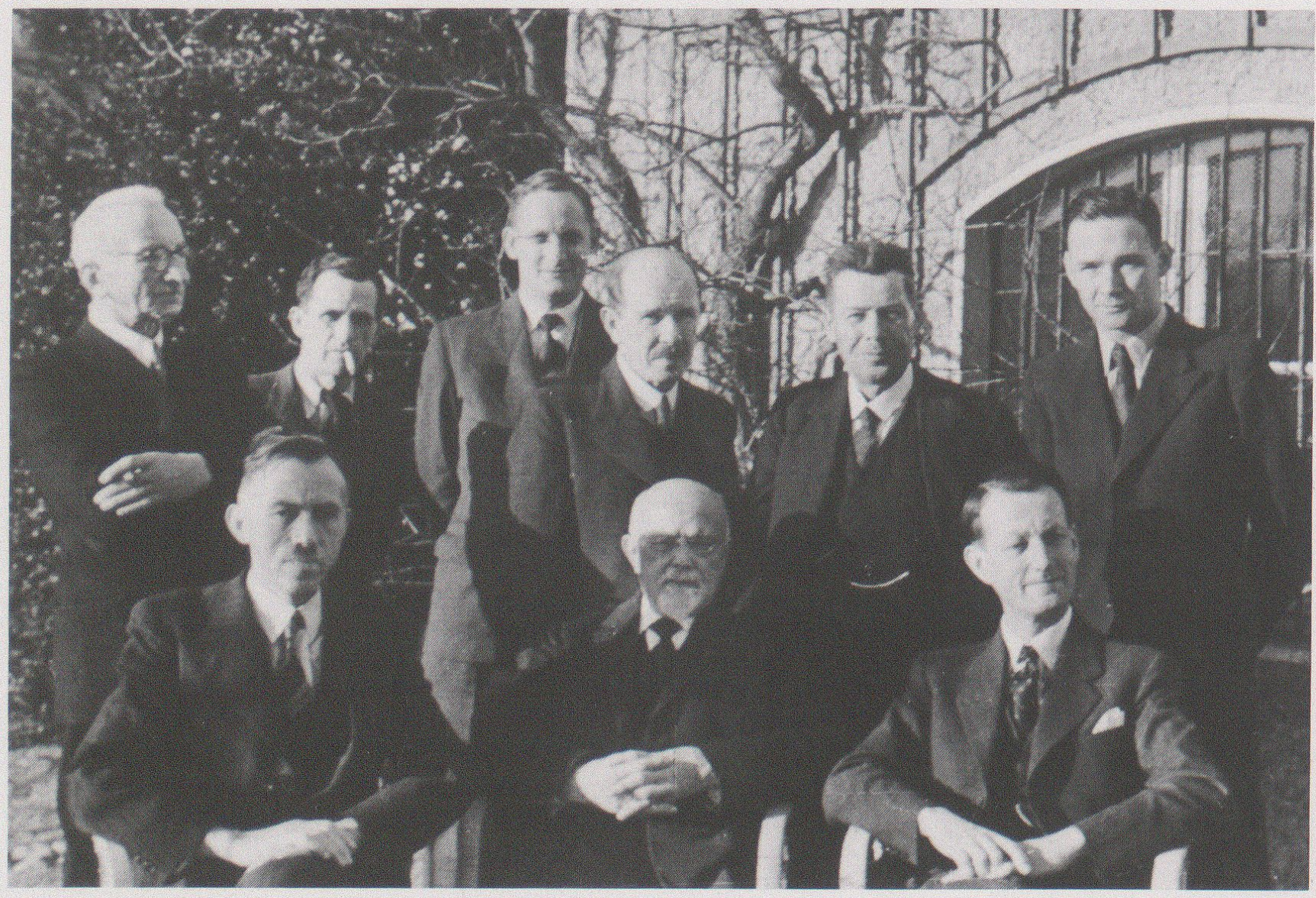

Abb. 9 Gruppenbild von Zürcher Geographen, aufgenommen an der Feier zum 80. Geburtstag von Prof. Dr. Emil Letsch (28. März 1944). Von links nach rechts, sitzend: Eduard Imhof, Emil Letsch, Heinrich Gutersohn; stehend: Paul Walther, Henri Rebsamen, Hans Boesch, Walter Wirth, Werner Manz, Hans Hofer. 
feier). Trotz der äußerst bedrückenden Weltlage unmittelbar vor Kriegsausbruch konnte eine würdige und gehaltvolle Feier durchgeführt werden.

Wegen der politischen Isolation der Schweiz während der Kriegsjahre konnten nur noch wenige ausländische Referenten in Zürich sprechen. Im ersten Kriegswinter war es ein einziger: Hugo Hassinger aus Wien. «Dies blieb auch durch die folgenden Jahre so, und der Vortragsdienst wäre in einzelnen Wintersemestern ausschließlich von schweizerischen Referenten bestritten worden, wenn nicht inzwischen bereits ausländische Gelehrte wie der Völkerkundler Koppers und der Prähistoriker Obermaier, um politischen Komplikationen zu entfliehen, in Fribourg Wohnsitz genommen hätten. Es war vor allem die Umsiedlung des Anthropos-Instituts von Mödling-Wien nạch Froideville-Fribourg, die wissenschaftlichen Zuzug brachte. Langsam nur öffneten sich nach dem Krieg die Grenzen wieder. 1946/47 war Prof. Wegener von Graz und Direktor Kunst von Amsterdam die Reise wieder möglich; 1947/48 waren von elf Referenten wiederum fünf Ausländer, und es zeigt das Bedürfnis nach Kontakt mit der wissenschaftlichen Umwelt, daß 1948/49 die Rekordzahl von sieben ausländischen Referenten erreicht wurde. Dann normalisierte sich das Verhältnis wieder auf in der Regel fünf nichtschweizerische Sprecher pro Wintersemester» (EGLI, 1964: 131).

\section{Die Entwicklung der GEGZ seit dem Zweiten Weltkrieg}

Schon zu Beginn der zweiten Lebenshälfte der GEGZ hatte der private Verein seine wissenschaftliche Führungsrolle längst an die staatliche Universität mit ihrem hochentwickelten Lehr- und Foschungsbetrieb, mit ihren Instituten, Prüfungen und Diplomen verloren. Die geographischen Institute der Universität und des Polytechnikums hatten seit der Jahrhundertwende wohl nur einen schwachen Aufschwung zu verzeichnen gehabt, stagnierten sogar während gewissen Epochen, wuchsen aber trotzdem zu festgefügten und auf solider Basis ruhenden wissenschaftlichen Zentren heran. Nachdem sich diese Schulen etabliert, wissenschaftliche Konzepte ihre Realisierung gefunden und die ersten Generationen von Geographen den Ausbildungsgang absolviert hatten, gingen die wesentlichen und zahlreicheren wissenschaftlichen Impulse von den Geographischen Instituten aus und nicht von der GEGZ. Der entscheidende, sich allmählich beschleunigende Aufschwung der akademischen Geographie hatte dabei noch gar nicht stattgefunden; er setzte erst in den fünfziger Jahren dieses Jahrhunderts ein. In relativ kurzer Folge wurden an den hiesigen Hochschulen weitere Lehrstühle eingerichtet (vgl. Tafel 2 und 3), und die Studentenzahlen erlebten eine beeindruckende Zunahme. Mit dem quantitativen Wachstum einhergegangen sind auch qualitative Veränderungen im Sinne einer Steigerung des wissenschaftlichen Niveaus sowie einer zunehmenden Spezialisierung. Die Folgen dieses Aufschwungs sind für die GEGZ, die natürlich von der Entwicklung der akademischen Geographie miterfaßt worden ist, mehrheitlich positiv gewesen; von gewissen negativen Aspekten soll weiter unten noch die Rede sein. Da die Geschichte der Hochschulgeographie und insbesondere der Geographischen Institute bereits von Walter Kyburz bzw. Hans Rudolf Brunner in den Festschriften der Universität (1983) und der ETH (1980) nachgezeichnet worden ist, können wir hier auf eine Darstellung verzichten. Kurz zusammengefaßt läßt sich festhalten, daß die Zürcher Geographischen Institute heute in folgenden Forschungsschwerpunkten engagiert sind:

Am Geographischen Institut der Universität werden «traditionsgemäß die Forschungsgebiete Physische Geographie, Anthropogeographie und Methoden der Geographie sowie deren gegenseitige Beeinflussungen und Abhängigkeiten in möglichst ausgewogener Form gepflegt» (Jahresbericht des Instituts 1988).

Im Fachbereich Physische Geographie bilden die Geomorphologie und die Klimatologie die Schwerpunkte (Untersuchungen zur Gletscher-, Klimaund Vegetationsgeschichte im Spät- und Postglazial; Zusammenhänge zwischen Böden und Umweltfaktoren).

Der Fachbereich Anthropogeographie stellt die Entwicklungsländerforschung (spez. in Südostasien), die Regionalforschung und Aspekte der Raumordnung, Raumnutzung und Raumplanung in den Vordergrund.

Schwerpunkte im Fachbereich Methoden der Geographie sind Fernerkundung und Kartographie/ Geographische Datenverarbeitung. Die geographische Fernerkundung entwickelt Verfahren zur Klassifikation von Luft- und Weltraumaufnahmen sowie für ihre Anwendung bei der Inventarisierung und Überwachung der natürlichen Ressourcen und der Umweltqualität. Die Kartographie/Geographische Datenverarbeitung befaßt sich vor allem mit der kartographischen Umsetzung von raumbezogenen Daten durch Computer.

Das Geographische Institut der ETH betreibt Forschungen auf vier Arbeitsgebieten (Jahresbericht des Instituts 1988):

Die Abteilung für Klimatologie befaßt sich mit der globalen Energiebilanz und der diesbezüglichen Rolle der Gletschergebiete sowie insbesondere mit klimatologischen Fragen, die das Gebiet der Stadt Zürich betreffen. 
Tafel 2: Geographie-Dozenten der Universität Zürich (1891-1989) (ohne übrige Privatdozenten und Titularprofessoren)

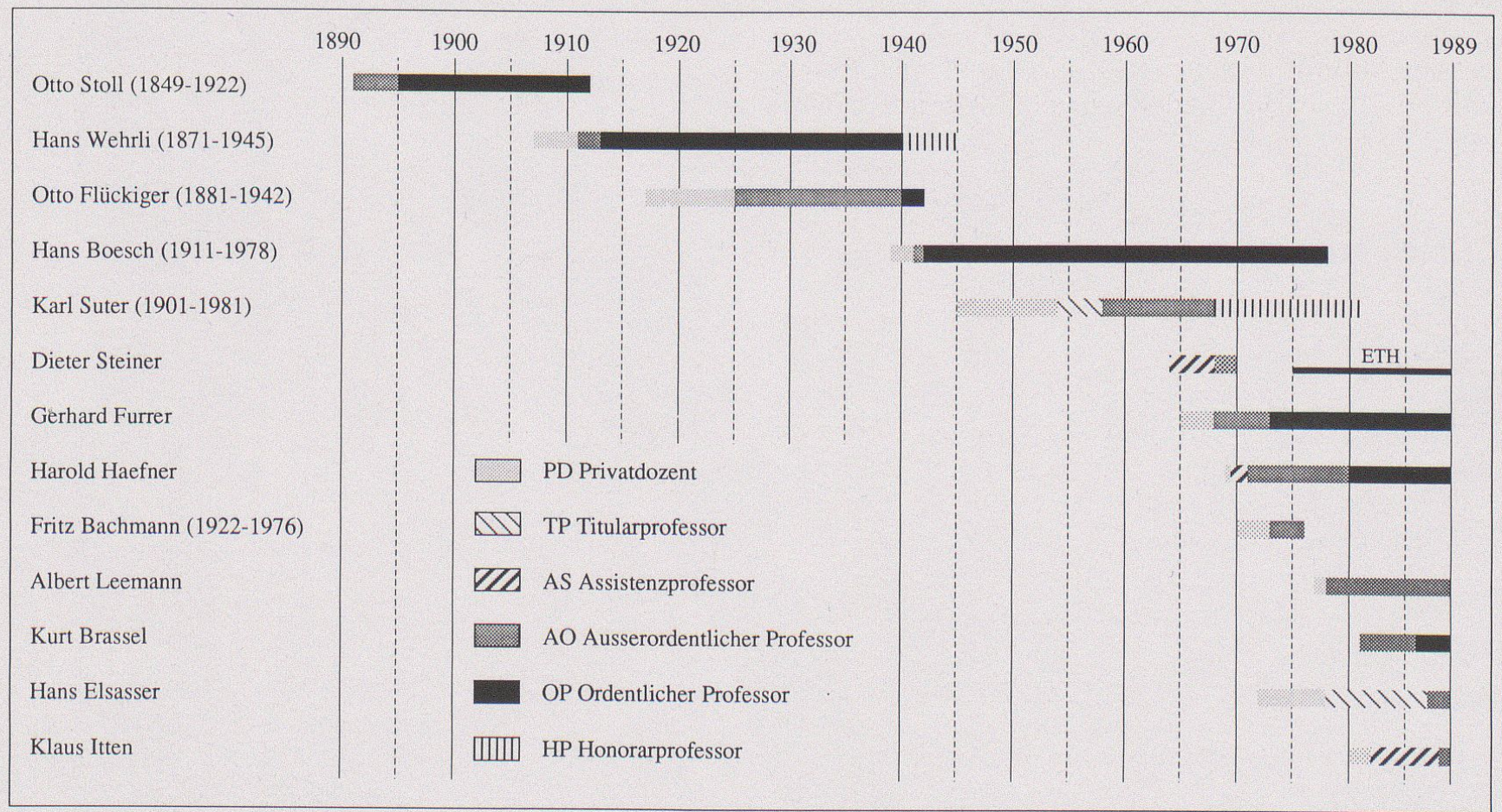

Tafel 3: Geographie-Dozenten der Eidgenössischen Technischen Hochschule (1899-1989) (ohne übrige Privatdozenten und Titularprofessoren)

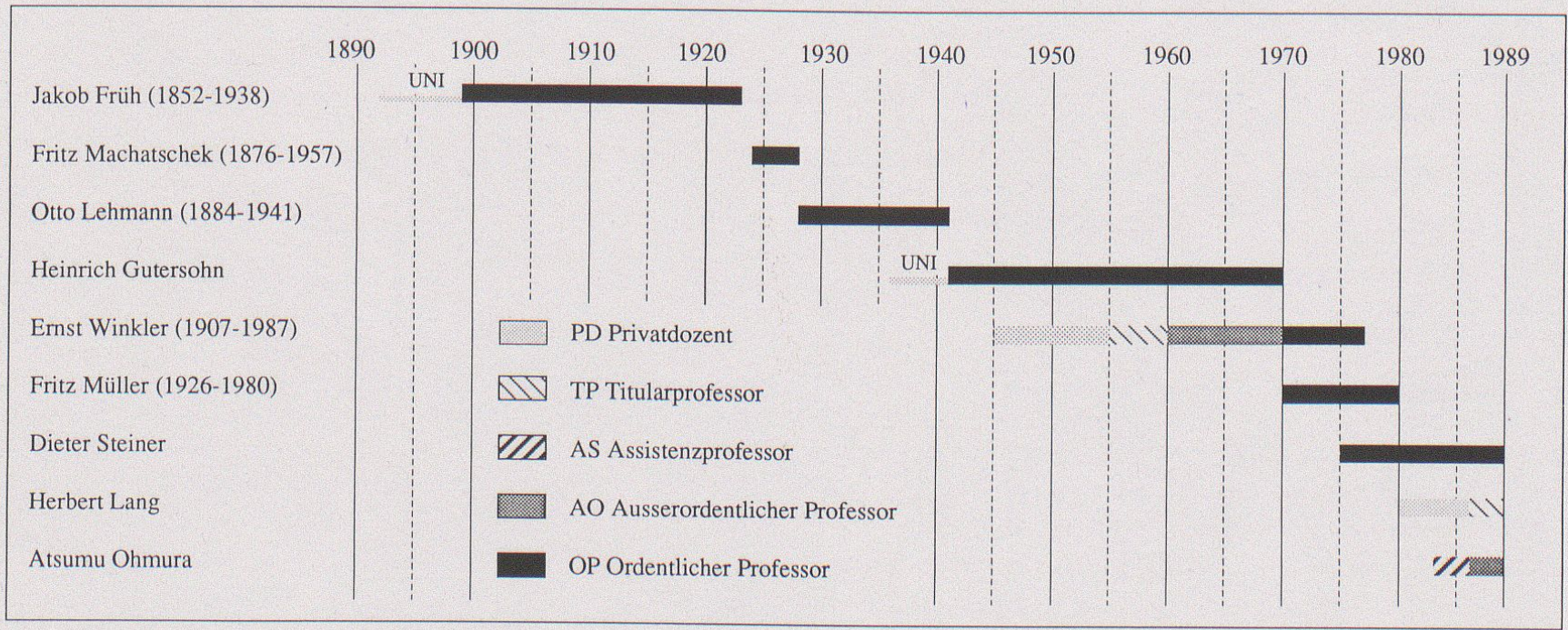


In der Abteilung Hydrologie ist die Grundlagenforschung traditionell durch praktische Fragestellungen geprägt. Aktuelle Schwerpunkte sind: Niederschlag-Abfluß-Modelle, Abflußvorhersagen, Starkniederschläge (bes. in der Schweiz), Klima und Wasserhaushalt usw.

Im Rahmen der Abteilung Quantitative Geographie befaßt sich eine Gruppe Humanökologie mit Mensch-Umwelt-Beziehungen anhand zweier Beispiele: Räumliche Auswirkungen neuer Informationstechniken, soziale Wahrnehmung und Waldschäden.

In der Gruppe Geoinformatik befaßt man sich mit dem Einsatz von Informationssystemen zur Speicherung von geographischen Karten- und Fernerkundungsdaten sowie mit ihrer Analyse durch computergestützte Methoden.

Am Geographischen Institut der ETH ist, beginnend mit Jakob Früh, seit jeher auch die Geographie der Schweiz besonders gepflegt worden. Wesentliche Impulse wurden diesem auf die praktische Anwendung in den Bereichen Planung und Verkehr ausgerichteten Forschungszweig in jüngerer Zeit von Heinrich Gutersohn verliehen. Wie Früh widmete auch Gutersohn sein wichtigstes Werk der schweizerischen Landeskunde.

Es ist offenkundig, daß sich in der Tätigkeit der Geographischen Institute der Universität und der ETH Überschneidungen und Parallelitäten ergeben, über deren Sinn bereits seit längerem diskutiert wird. Der stete Wandel der Forschungsschwerpunkte, aber auch die räumliche Zusammenlegung der beiden Institute - sie sind in der neuen Universität Zürich-Irchel unter einem Dach vereint - lassen für die Zukunft zweifellos verstärkt Entwicklungen in einem koordinierenden Sinn erwarten.

Die Inhalte der zürcherischen akademischen Geographie sind seit dem Zweiten Weltkrieg stark von Hans Boesch geprägt worden (vgl. Portraittext). Obwohl von der Geologie herkommend - wie fast alle seine Vorgänger - legte Boesch zunehmend Gewicht auf die Wirtschafts- und Anthropogeographie. Er knüpfte damit an Vorarbeiten von Hans Wehrli in dieser Richtung an.

Mit Wehrli und Boesch gelangte das Geographische Institut der Universität auch als Ausbildungszentrum zu internationalem Ansehen, während früher angesichts des knappen Personals und der geringen Studentenzahlen die wissenschaftlich-publizistische Tätigkeit der Dozenten eher ein Übergewicht aufgewiesen hatte. Mit der Ausbildung einer großen Zahl von Fachleuten - sie stand jahrzehntelang unter dem Motto «Die Geographen ins Lehramt, die Geologen ins Öl» - wurde eine nachhaltige Verbesserung des erdwissenschaftlichen und landeskundlichen Unterrichts an unseren Schulen erzielt. Anzufügen wäre an dieser Stelle, daß wir heute wieder an einem Wendepunkt der Geographenausbildung ste- hen, wobei die neue Devise - wenigstens in bezug auf die Erdkunde - lauten könnte: «Durch mehr Theorie zu breiterer Praxis.»

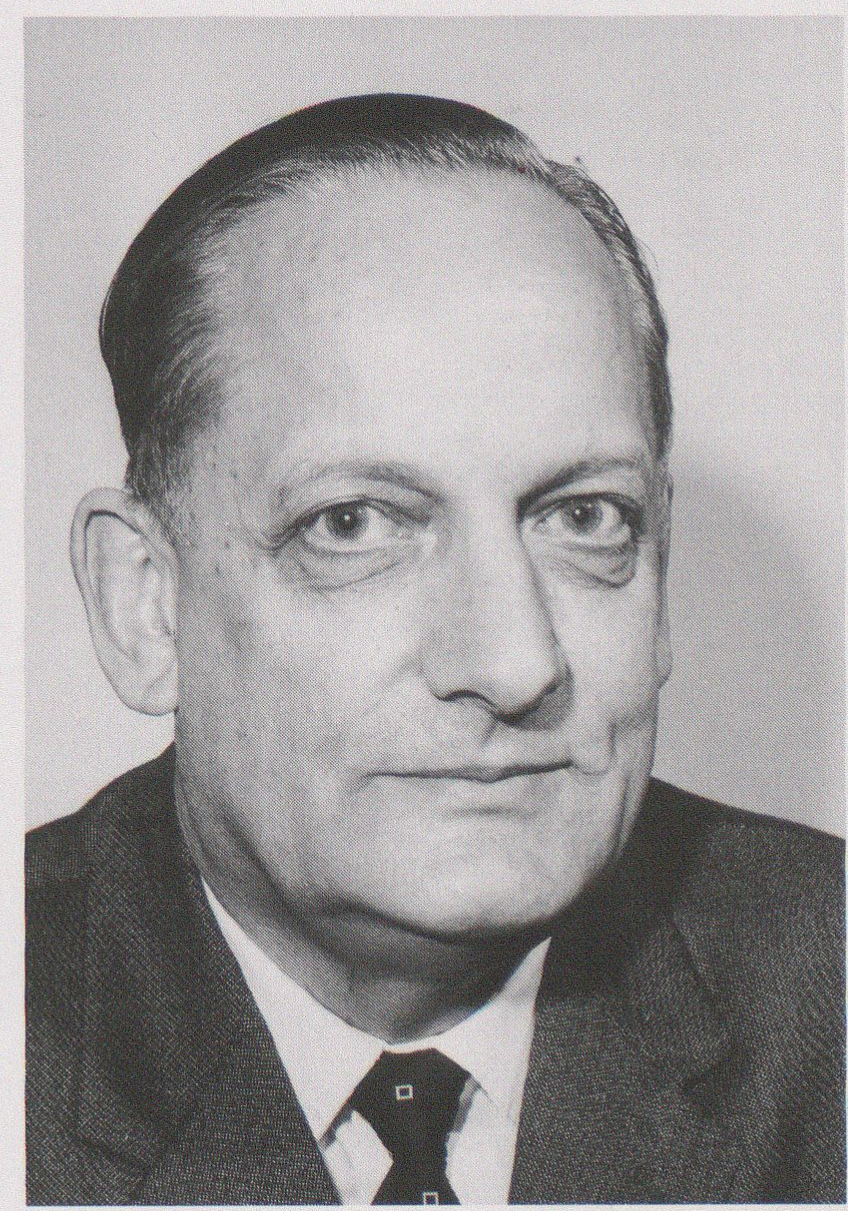

Abb. 12 Hans Boesch (1911-1978), von Zollikon (Zürich), begann seine Laufbahn als Schüler des Geologen Rudolf Staub. Auf die Tätigkeit als Erdölgeologe im Vorderen Orient folgte ein Studienaufenthalt in den USA, wo er sich unter dem Einfluß seines Lehrers van Valkenburg der Wirtschaftsgeographie zuwandte, die in seinen wissenschaftlichen Arbeiten vorrangig wurde.

1942 wurde dem erst 31jährigen Boesch vom Regierungsrat des Kantons Zürich die Leitung des Geographischen Instituts der Universität Zürich übertragen, das sich unter seiner Leitung aus bescheidensten Verhältnissen heraus zu einem heute international renommierten Institut entwickelt hat. Von 1956 bis 1968 versah er das anspruchsvolle Amt des «Secretary-Treasurer» der Internationalen Geographischen Union; zahlreich sind die Ehrungen, die ihm im Laufe der Jahre zukamen, und außerordentlich vielfältig waren seine Beziehungen zu Fachkollegen aus aller Welt.

Boesch war ein Wissenschaftler, der ein außerordentliches Wissen und Können in den verschiedensten Teilgebieten der Geographie in sich vereinigte. Deshalb entstammen Fachleute ganz unterschiedlicher Richtung seinem Kreis von Schülern. Besonders ausgeprägt war auch sein Spürsinn für die entscheidenden zukunftsträchtigen Entwicklungen der geographischen Wissenschaften.

Von 1954 bis 1962 bekleidete Boesch das Präsidentenamt der GEGZ. 


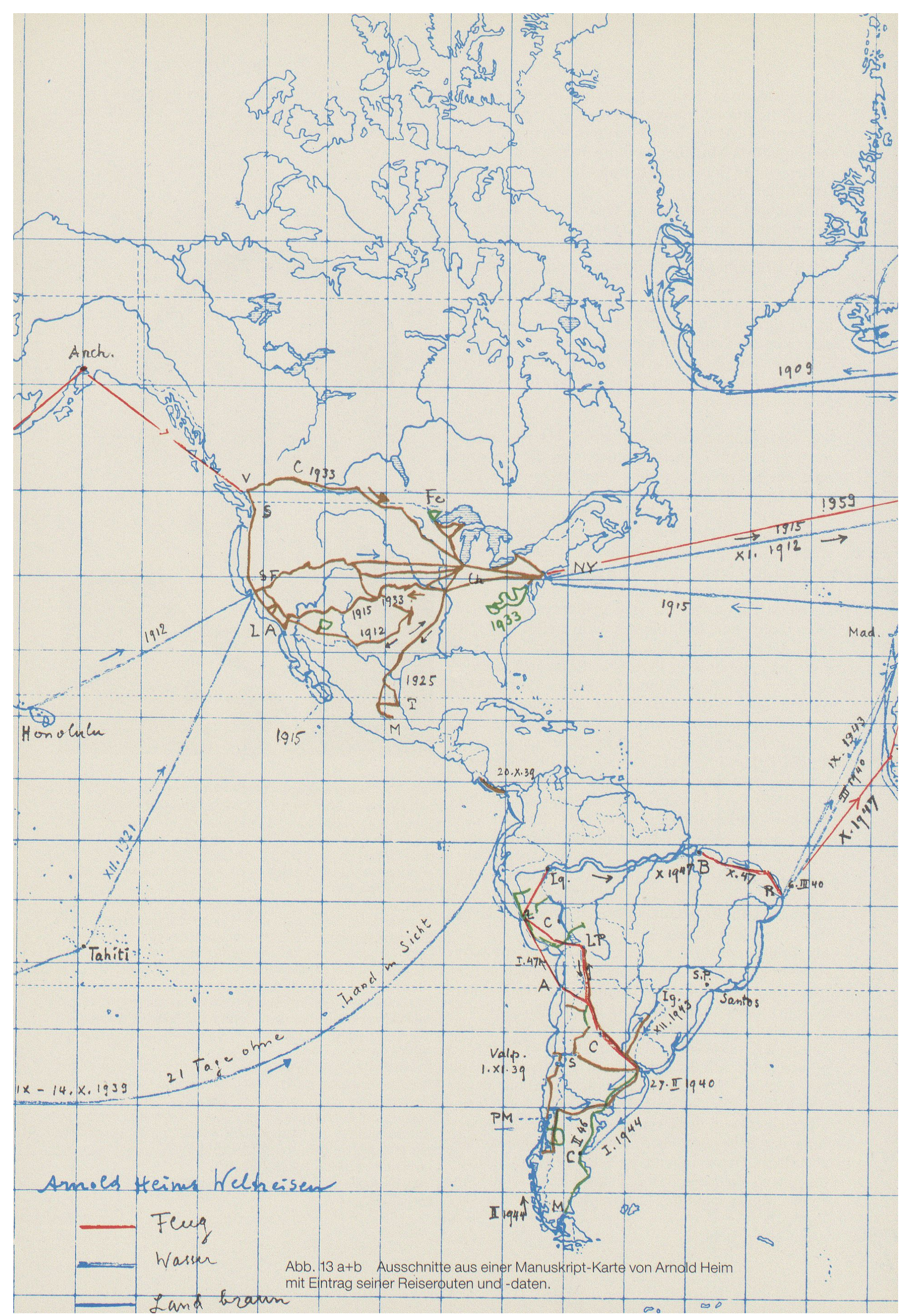


Boeschs Arbeiten fanden über seine eigenen Vorträge und diejenigen seiner zahlreichen Schüler natürlich auch Eingang in die Geographische Gesellschaft. Aufgrund einer Reise nach Arabien («NWArabien, gestern, heute und in Zukunft», 1938) befaßte er sich früh mit dem mächtigen Wirtschaftsfaktor Erdöl, wandte sich in weiteren Referaten vorerst Nord- und Mittelamerika («Birmingham, [Alabama, USA]», 1940; «Mittelamerikanische Wirtschaftslandschaften», 1950; «Chicago», 1955), später vermehrt auch Asien zu («Südasien», 1963; «Japan - Land der Kontraste», 1965; «Der See von Kathmandu - Mythologie und Wirklichkeit», 1974; u. a.). Allgemein sind in den letzten Jahrzehnten häufiger wirtschaftsgeographische Themen, etwas zögernd auch die Entwicklungsländerproblematik, Fragen des Schutzes tropischer Räume und ihrer Ressourcen, des Verhältnisses Mensch-Umwelt usw. in den Vorträgen behandelt worden. Die heute aktuelle Frage des Landschafts- und Umweltschutzes hat, auch auf das Gebiet der Schweiz bezogen, stärkere Beachtung gefunden, wobei dieser Themenkreis aus dem Bereich der angewandten Geographie hervorgegangen ist. Ein in diesem Zusammenhang grundlegender Vortrag aus dem Jahre 1942 von Ernst Winkler trägt den Titel: «Die Geographie in der schweizerischen Landesplanung». 1946 sprach der spätere Bundesrat F. T. Wahlen über "Geographie, Landesplanung und Landwirtschaft», und 1966 referierten Heinrich Gutersohn und Ernst Winkler zum Thema «Die Landesplanung und die Schweizer Landschaft der Zukunft». Bekanntlich haben Gutersohn und Winkler einen wesentlichen Beitrag zur Gründung des Instituts für Orts-, Regional- und Landesplanung geleistet, das als Stätte interdisziplinärer Forschung und der Nachdiplomausbildung in der schweizerischen Landesplanung eine führende Stellung einnimmt. Die Fachstelle ist aus der 1943 geschaffenen Zentrale für Landesplanung bzw. dem späteren Institut für Landesplanung hervorgegangen, die dem Geographischen Institut der ETH eingegliedert waren; 1961 verselbständigte es sich unter der Bezeichnung ORL-Institut.

Aus dem vielfältigen Programm der beiden letzten Jahrzehnte seien noch einige besonders gelungene Vorträge hervorgehoben: 1975 sprach der leider viel zu früh verstorbene ETH-Dozent für Geographie, Fritz Müller (Zürich), über das kanadische NorthWater-Projekt. Ein Jahr später berichtete der verdiente ehemalige Bibliothekar des Geographischen Instituts der Universität, Walter Kyburz (Zürich), unter dem Titel «Vom Elbrus an die Lena» vom Moskauer Geographenkongreß und von seinen Reisen in die Sowjetunion. W. Marschall (Bern) referierte 1977 über das «Dorfleben auf Nias» als Beispiel für einen der großen kulturökologischen Typen Indonesiens. Großen Beifall fand auch der Vortrag von Christian Kleinert (Hagen) über «Siedlung und Um-

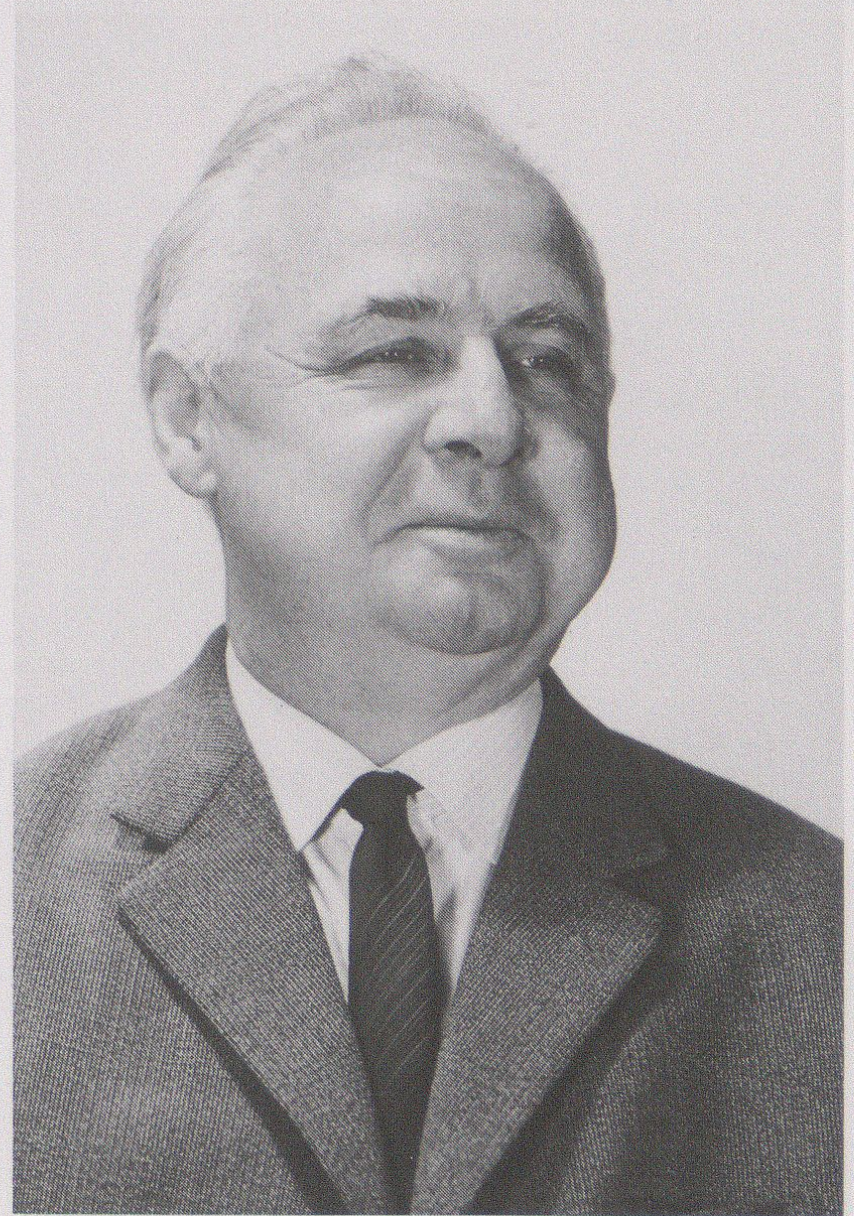

Abb. 14 Ernst Winkler (1907-1987) wählte wie viele seiner Geographenkollegen ursprünglich den Lehrerberuf. 1936 doktorierte er bei Hans Wehrli über «Veränderungen der Kulturlandschaft im zürcherischen Glattal", wo er selbst aufgewachsen war. Unter Otto Lehmann war Winkler der erste Vollassistent der ETH; 1945 habilitierte er sich an dieser Hochschule für das «Gesamtgebiet der Geographie, spez. Methodologie und Kulturgeographie», 1960 wurde er zum Extraordinarius, zehn Jahre später zum ordentlichen Professor für Landesplanung und Kulturgeographie ernannt.

Winklers besondere Stärke, die ihn bis zu einem gewissen Grad von anderen Zürcher Geographen unterschied, war seine hervorragende Kenntnis der geographischen Theorie, die auf ausgedehnten Literaturstudien beruhte. Diese Eigenschaft machte inn zum eigentlichen Geographiemethodologen Zürichs. Als großer Verehrer Alfred Hettners lag inm die ganzheitliche Landschaftsbetrachtung besonders am Herzen.

Winkler war «ein Stubengelehrter im guten Sinne» $(H$. Gutersohn), aber er hat sich auch auf dem Feld der praktischen Geographie ausgezeichnet, und zwar durch seine Mitarbeit beim Aufbau der schweizerischen Landesplanung mit ihren dazugehörigen Instituten.

Obwohl Ernst Winkler nie Präsident der GEGZ gewesen ist, hat er in der Gesellschaft durch seine langjährige Vorstandstätigkeit und seine publizistische Arbeit als Redaktor, Rezensent und Sekretär eine wichtige Rolle gespielt. 
welt im zentralen Himalaya» (1979), in welchem mit Hilfe phantastischer Bilder die traditionellen Siedlungen in Nepal in ihrer Beziehung zur natürlichen Umwelt vorgestellt wurden. Unvergeßlich bleiben ebenfalls der Vortrag des Vorstandsmitglieds Arthur Dürst (Zürich) über «Die Sinai-Halbinsel» aus demselben Vortragszyklus sowie die Referate von Bernt Glatzer (Heidelberg) über die «Nomaden in Westafghanistan» und von F. Scholz (Göttingen) zum Thema «Sultanat Oman» im folgenden Winter. In eine ganz andere Region führte an der Hauptversammlung 1981 Ernst Irnigers Vortrag «Adieu Paris?». Irniger, der für die GEGZ während Jahrzehnten vor allem durch seine Arbeit im Vorstand viel geleistet hat, erzielte damit einen ganz großen Erfolg. Mit dem Referat von Augusto Gansser (Küsnacht) unter dem Titel «Bhutan - vom Fels zum Mensch» aus dem gleichen Jahr gelangen wir bereits wieder nach Asien zurück. Gansser spannte einen großartigen Bogen von der Geologie Bhutans bis zur Lebensweise des Menschen im Gebirge. Karl Jettmar (Heidelberg) führte 1983 in einem hervorragenden Vortrag durch «Das Gästebuch der Seidenstraße», eines zentralasiatischen Handelswegs, dessen Geschichte durch Tausende von Felsbildern und datierbaren Inschriften dokumentiert ist. «Probleme des Islams in der heutigen Welt» lautete das Thema des Referats von Arnold Hottinger (Nikosia), des bekannten Nahost-Spezialisten und Islamisten (1984). Hottinger legte eine glänzende und von außergewöhnlicher Sachkenntnis zeugende Analyse des Islams, seiner aktuellen Probleme und ihrer Bewältigungsversuche in den verschiedenen Staaten vor. Wie die Mehrzahl der hier genannten Redner ist auch Karl Henking, Direktor des Zürcher Völkerkundemuseums, mit einem asiatischen Thema vor eine zahlreiche Zuhörerschaft der GEGZ getreten. Er sprach 1986 über «Kosmologische Diagramme in der Struktur von Haus und Siedlung». In seinem Vortrag wies er nach, daß Haus und Siedlung in manchen Kulturen nicht nur ökologischen und sozialen Bedürfnissen dienen, sondern auch Beziehungen zum Weltbild der betreffenden Gesellschaften aufweisen. Aus der vergangenen Vortragsperiode 1988/89 erwähnen wir die Darbietung von Peter Gerber und Heinz Lippuner (Zürich) mit dem Titel «Ich brauche keine Federn, um Indianer zu sein - Identität und Selbstbestimmung der Indianer Nordamerikas». Die zukunftsweisende, multimediale Vortragsshow zog das vielköpfige Publikum in ihren Bann; sie demonstrierte gleichzeitig, daß sich eine fesselnde, didaktisch eindrückliche Präsentation und seriöse Wissensvermittlung keineswegs gegenseitig ausschließen müssen.

Schließlich wollen wir noch zwei Vorträge aus dem Bereich der Schweizer Geographie hervorheben: Ein Höhepunkt im Veranstaltungskalender 1982/83 der GEGZ war Emil Schulthess' Präsentation seines «Swiss Panorama». Bei diesem bekannten Bild- band handelt es sich um $360^{\circ}$-Aufnahmen, aufgenommen im Helikopterschwebeflug. 1988 hielt Daniel Vischer einen Rückblick und Ausblick auf die «Gewässerkorrektionen in der Schweiz». Sein Vortrag bot eine glänzende Übersicht über die im 19. Jahrhundert begonnenen Projekte und versuchte, die Lehren aufzuzeigen, die aus der Kenntnis der damaligen Vorhaben für die Gegenwart und $\mathrm{Zu}$ kunft zu ziehen sind.

In die vierziger Jahre fällt das erste Engagement der GEGZ in einem konkreten Fall aktiven Landschaftsschutzes, nämlich der Unterstützung der Bestrebungen zum Schutze der Stammheimer Seenlandschaft, die durch eine geplante Grundwasserabsenkung in ihrem Bestand gefährdet schien. 1953 wurde die Gesellschaft tätig in der Bewegung zum Schutze der Rheinau-Landschaft. «In steigender Mitsorge ob der Überforderung der heimischen Landschaft durch die moderne Wirtschaft» (EGLI, 1964: 134) unterzeichnete sie später zusammen mit anderen Gesellschaften eine Eingabe des Zürcherischen Naturschutzbundes an die Gemeindebehörden des Kantons, die den Titel trägt: «Natur- und Landschaftsschutz als Aufgabe unserer Gemeinden». Insgesamt lassen sich für derlei Aktivitäten unseres Vereins jedoch nicht viele Beispiele finden; die GEGZ verhielt sich in ähnlichen Fällen meist recht zurückhaltend. Angesichts der Entwicklungen der jüngsten Zeit ist diese Distanziertheit natürlich zu bedauern. Welche praktischen Auswirkungen hätte das Eingreifen der GEGZ als eines ungebundenen, wissenschaftlichen Kriterien verpflichteten und langfristig denkenden Organs im einen oder anderen Fall der Landschaftsverschandelung oder der Umweltzerstörung haben können? Natürlich gilt es zu berücksichtigen, daß durch die Aktivitäten der Gesellschaft die Ansichten und Meinungen ihrer Mitglieder nicht kompromittiert werden dürfen. Trotzdem: Scheint sich im Verharren auf dem Felde der Theorie schließlich nicht auch die fehlende Praxisbezogenheit, ein Mangel an Fähigkeiten und Willen zum Engagement bei manch einem Geographen zu widerspiegeln?

Wenn also - vom normalen Veranstaltungsprogramm abgesehen - die nach außen dringenden Aktivitäten der GEGZ in den letzten fünfzig Jahren einen eher bescheidenen Umfang erreicht haben, so sind gewissermaßen hinter den Kulissen mancherlei Bestrebungen in Gang gekommen, die als wichtig und bedeutend einzustufen sind. Anknüpfend an die gesamtschweizerischen Bemühungen zur Schaffung eines geographischen Handbuchs der Schweiz, die mit der Veröffentlichung des prächtigen Werks von Jakob Früh (vgl. Portraittext) einen längst fälligen Abschluß fanden, setzten sich die GEGZ und andere schweizerische Geographische Gesellschaften seit Jahren auch für die Herausgabe einer gesamtschweizerischen geographischen Zeitschrift ein. Die Frucht der jahrzehntelangen Bemühungen 
war die 1946 geschaffene "Geographica Helvetica». Sie löste die seit 1918 publizierten «Mitteilungen» der GEGZ ab, die ihrerseits das Nachfolgeorgan der im Jahre 1900 begründeten «Jahresberichte» darstellte, ersetzte aber auch den seit 1923 erschienenen «Schweizer Geograph». Die Umstände ihrer Entstehung und der Zweck der "Geographica» bedürfen genauerer Erläuterung. Heinrich Gutersohn schrieb im Vorwort zum ersten Heft: «Mit der vorliegenden Nummer tritt die neue Zeitschrift „Geographica Helvetica” vor die Öffentlichkeit. In ihr sind zwei bisherige Publikationsreihen zusammengelegt, die „Mitteilungen der Geographisch-Ethnographischen Gesellschaft Zürich” und „Der Schweizer Geograph" des Verlages Kümmerly \& Frey, Bern. [...] „Der Schweizer Geograph” erschien erstmals 1923 als Organ des Vereins Schweizerischer Geographielehrer und der Geographischen Gesellschaft Bern, später auch des Verbandes Schweizerischer Geographischer Gesellschaften. Doch bedurfte er der kräftigen finanziellen Unterstützung des Verlages Kümmerly \& Frey, dessen jahrelange Opferbereitschaft von den Schweizer Geographen voll gewürdigt wird. [...] Die „Mitteilungen” und „Der Schweizer Geograph” bilden die Fundamente, auf denen heute die GeographischEthnographische Gesellschaft Zürich und der Geographische Verlag Kümmerly \& Frey, Bern, zuversichtlich weiterbauen, indem sie ihre Zeitschriften vereinigen. Außerdem beteiligen sich erfreulicherweise die Geographische Gesellschaft Bern und die "Société de Géographie de Genève" an der Herausgabe. Die „Geographica Helvetica” sollen an Inhalt reicher und an Umfang größer als ihre Vorgänger sein. Ihre Zielsetzung bleibt die gleiche: Veröffentlichung wissenschaftlicher geographischer und ethnologischer Abhandlungen, Berichte über Forschungsreisen, Aussprache über schulgeographische Fragen, Mitteilungen aus der praktischen Geographie, dazu laufende Orientierungen über geographische Neuigkeiten und Veranstaltungen, Zeitschriftenschau und Buchbesprechungen. Dies alles in guter und ansprechender Form darzubieten, wird erstes Bemühen des Redaktors, PD Dr. E. Winkler, sein.

Die „Geographica Helvetica” wenden sich an den Wissenschafter des In- und Auslandes. Sie wollen ihm Neues bieten, dazu aber auch die Möglichkeit geben, seine Arbeiten zu veröffentlichen. Sie wenden sich weiter an den Schulgeographen, den sie mit den Zeitproblemen des erdkundlichen Unterrichts vertraut zu machen versuchen. Sie wenden sich insbesondere auch an die Mitglieder der Geographischen Gesellschaften und an weitere Personen, welche sich für Länder, Völker und Reisen interessieren. Ihnen möge gesagt sein, daß sie mit der Unterstützung der „Geographica Helvetica” auch die erdkundliche Wissenschaft fördern. Die Geographen der Schweiz glauben, daß sie in der Nachkriegszeit mehr denn je Wesentliches zur Erkenntnis der Heimat, zum Verständnis anderer Länder und Völker und zur Förderung der völkerverbindenden Bestrebungen aller Gutgesinnten beizutragen in der Lage sind. Aber sie sind gering an Zahl und deshalb auf kräftige Hilfe einer weiteren Öffentlichkeit angewiesen» (GUTERSOHN, 1946: 1-2).

Die Gründung der «GH», an der insbesondere Hans Boesch, Heinrich Gutersohn und Ernst Winkler maßgeblich beteiligt waren, stellte einen mutigen und zukunftsweisenden Schritt dar. Damit verfügte die Schweiz erstmals über eine internationale geographische Zeitschrift hohen wissenschaftlichen Formats. In finanzieller Hinsicht allerdings war die Schaffung der «GH» ein heikles Unterfangen, das die GEGZ während Jahren über Gebühr in Beschlag nahm und viel Zeit in mancher Vorstandssitzung beanspruchte. Die Abonnementseinnahmen deckten die Kosten der Zeitschrift in vielen Jahren bei weitem nicht, und so stellte der Druck eines Jahrgang oftmals ein Abenteuer mit ungewissem Ausgang dar. Es muß an dieser Stelle hervorgehoben werden, daß die Publikation ohne die generöse Unterstützung des Berner Verlagshauses Kümmerly \& Frey zweifellos nicht überlebt hätte. Wenn die Schweizer Geographie mit der «GH» ein würdiges Aushängeschild im In- und Ausland erhalten und sich ein wichtiges wissenschaftliches Forum geschaffen hat, so bedauert das eine oder andere Mitglied der GEGZ vielleicht insgeheim den Verlust seines traditionellen Gesellschaftsorgans. Der hohe wissenschaftliche Anspruch, den die «GH» erfüllen will, bringt es mit sich, daß Laiengeographen mit ihrer Lektüre teilweise überfordert sind.

Allerdings will die Zeitschrift heute eben nicht mehr in erster Linie ein Vereinsorgan, sondern eine wissenschaftliche Publikation sein. Im Interesse des akademischen Nachwuchses, der mit ihr ein Sprachrohr für die Verbreitung wissenschaftlicher Erkenntnisse besitzt, hat sich die GEGZ als Herausgeberin und Trägerin der «GH» stark engagiert. Welche Bedeutung diese Trägerrolle innerhalb der Vereinstätigkeit aufweist, geht aus der Tatsache hervor, daß bereits mehr als die Hälfte der Mitgliederbeiträge der GEGZ für die Herausgabe der «GH» verwendet wird.

Es ist das Verdienst des früheren Gesellschaftspräsidenten und des heutigen Präsidenten der Redaktions-Kommission Ernst Spiess, Anfang der achtziger Jahre eine administrative Umstrukturierung der Zeitschrift vorgenommen zu haben. Seit jenem Zeitpunkt liegt die Redaktion in den Händen von Frau Haruko Kishimoto zusammen mit Frau Margrit Wegmann, die diese Aufgabe in sorgfältiger und umsichtiger Weise erfüllen.

Die Frage der Wissenschaftlichkeit, des wissenschaftlichen Anspruchs, die hier im Zusammenhang mit der von der GEGZ edierten Zeitschrift aufgetaucht ist, führt uns zu einem letzten Punkt, der 

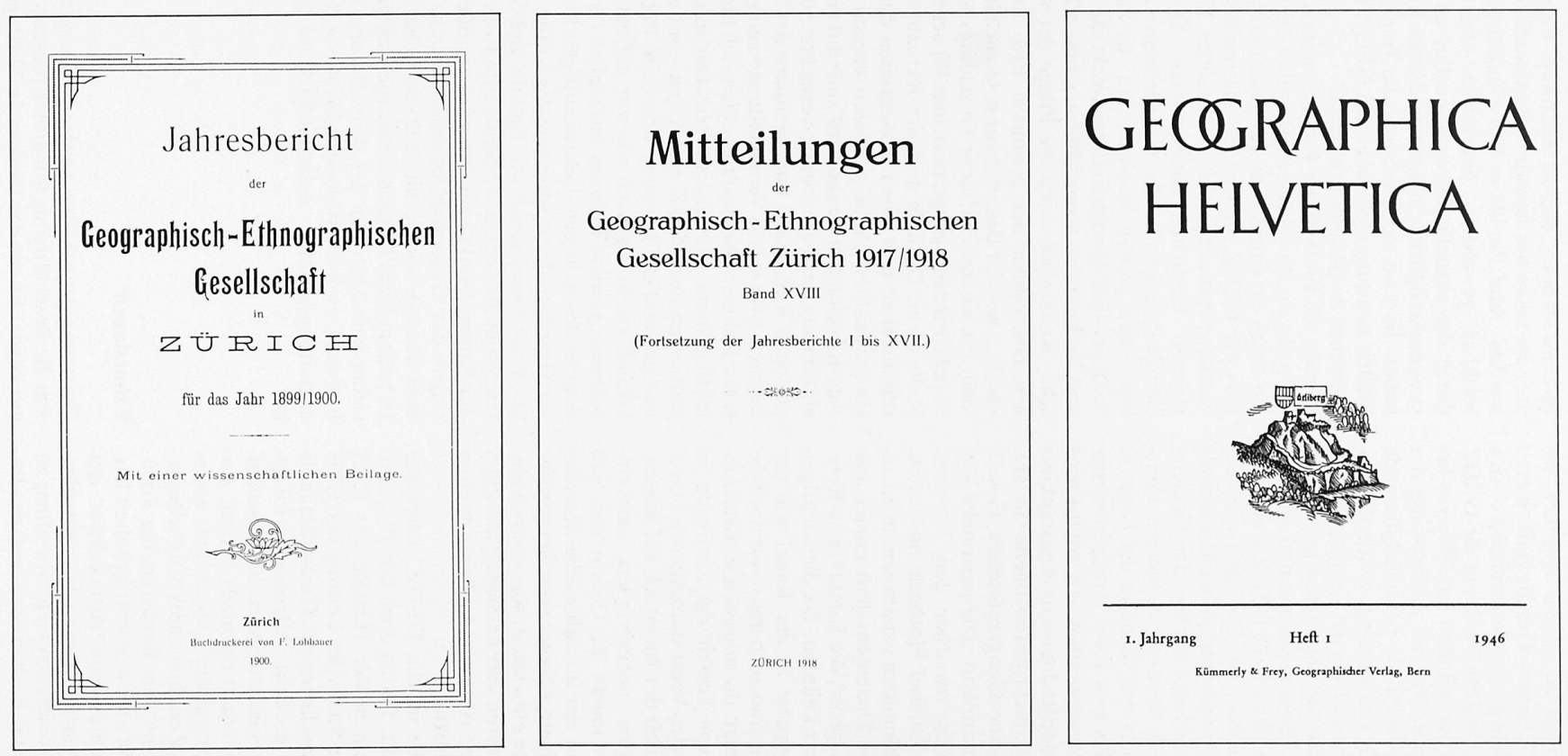
gleichzeitig auch Anlaß zu einem Ausblick ins zweite Jahrhundert unserer Gesellschaft bieten könnte. Ganz allgemein gesprochen handelt es sich hierbei um die Frage, welche Funktion die GEGZ heute und in Zukunft zu erfüllen hat. Wie wir bereits angedeutet haben, ist vom Aufschwung der Hochschulgeographie auch die heute jubilierende Gesellschaft miterfaßt und angeregt worden. Zweifellos stellen die Verbreiterung des geographischen Themenspektrums, die Spezialisierung und Vertiefung äußerst positive Phänomene dar, und es ist natürlich zu begrüßen, daß auch die GEGZ von dieser Entwicklung erfaßt worden ist. Getragen wird dieser sich rasch verbreiternde Strom der Erkenntnis von einer fast ebenso schnell wachsenden Gemeinschaft von Spezialisten. Vertreter der internationalen Fachgelehrtenschaft sind heute in der Lage, in ihren Vorträgen zu Themen jeder Art Informationen aus erster Hand auszubreiten. Allerdings wird dadurch gleichzeitig der Redner- und Autorenkreis zunehmend exklusiver, nichtprofessionelle Geographen kommen in einer Geographischen Gesellschaft immer weniger zu Wort. Die personelle Verflechtung, beispielsweise zwischen dem Vorstand der GEGZ und den Zürcher Hochschulinstituten, scheint sich darüber hinaus zu verstärken, nicht zuletzt deshalb, weil die Dozentenschaft immer ausschließlicher in der Lage ist, die Kontakte zu Referenten und Autoren zu knüpfen. Da die wichtigen wissenschaftlichen Impulse in der Regel von der Hochschule ausgehen, sind auch meist nur noch deren Angehörige befähigt, die neuesten Entwicklungen in der Vielzahl von Forschungsrichtungen zu überblicken. Wenn in den Veranstaltungen der Geographischen Gesellschaft der Anspruch auf Wissenschaftlichkeit weiterhin unvermindert aufrechterhalten werden soll, taucht die Gefahr auf, daß sich die GEGZ - und mit ihr zahlreiche ähnliche Vereinigungen - zu einem Ableger oder Sprachrohr der Hochschulinstitute entwickelt, was wahrscheinlich nicht zu einer besseren Verbundenheit zwischen den wissenschaftlichen Akteuren und dem breiten Publikum beitragen dürfte.

Bereits rein äußerlich ist die GEGZ näher zur Hochschule hingerückt, finden doch seit 1942 ihre Versammlungen in einem der Hörsäle der ETH statt. Es sei an dieser Stelle der Leitung der ETH für die großzügige Gewährung des Gastrechts in ihren Räumęn herzlich gedankt. Allerdings wird gerade durch diesen Versammlungsort die Akademisierung unserer Gesellschaft ebenfalls betont. Angesichts der Überalterung der Gesellschaft sowie der relativ langsamen Zunahme ihres Mitgliederbestandes (Tafel 1), die mit dem Wachstum der Stadtbevölkerung von Zürich nicht Schritt gehalten hat, müßte auf eine nachlassende Attraktivität der GEGZ und ihres Veranstaltungsangebots geschlossen werden. Frühere Vortragszyklen, vor allem zu Zeiten, als Reisevorträge hoch in der Gunst des Pu- blikums standen, wiesen durchwegs Besuchszahlen auf, die heute nur noch in Ausnahmefällen erreicht werden. Sind Publikum und Umfeld schwerer erreichbar geworden, übersättigt und abgelenkt durch die aktuelle Informationsflut und die Zerstreuungsmöglichkeiten des modernen Lebens oder haben die Last der Tradition, die Trägheit der zur bloßen Institution absinkenden GEGZ für eine erlahmende Ausstrahlung gesorgt?

Gerade die Freiheit der Programmgestaltung, welche nicht wie das Vorlesungsangebot der Hochschulen durch ein Curriculum festgeschrieben ist, eröffnete der GEGZ die Chance, ein breites Publikum vermehrt mit zeitgemäßen, aktuellen Themen aus vielerlei Bereichen anzusprechen. Der entsprechende Zweckartikel der Gesellschaftsstatuten läßt hier einen großen Spielraum zu. In Paragraph 2 heißt es: «Die Gesellschaft bezweckt die Förderung und Verbreitung geographischer und ethnographischer Kenntnisse sowie die Pflege der verschiedenen Disziplinen der gesamten Erd- und Völkerkunde.» Aus der Bestimmung geht auch hervor, daß nicht die wissenschaftliche Forschung, sondern die Popularisierung geographischen Wissens an erster Stelle steht. Deshalb muß der Aktualität, der Verständlichkeit und guten Präsentation der Vorträge ein großes Gewicht beigemessen werden.

Aus dem gleichen Grund wird auch auf eine Wiedereinführung der Fachabende verzichtet; die geographischen Kolloquien und Seminare der Hochschulen bieten für solche Veranstaltungen einen geeigneteren Rahmen. Keinesfalls sollen sich hingegen Effekthascherei und Oberflächlichkeit in den Veranstaltungen der GEGZ ausbreiten - solides Wissen und gedankliche Leistung sind beim Publikum der GEGZ zweifellos nach wie vor gefragt -, jedoch scheinen gewisse Indizien tatsächlich für ein Überdenken des heutigen und zukünftigen Kurses unserer Gesellschaft zu sprechen. Es würde jedes Mitglied der Gesellschaft mit Freude und Stolz erfüllen, wenn die GEGZ weiterhin ihre Rolle als «einer der Sammelpunkte zur Pflege der großen Geistesfragen der Gegenwart in unserer Stadt» wahrnehmen könnte, wie bereits 1910 festgehalten wurde. In hohem Grad hängt die Realisierung dieses Ziels sicher vom Mut, von der Weitsicht und der Offenheit des Gesellschaftsvorstandes ab, der für das Veranstaltungsangebot ausschließlich verantwortlich ist.

\section{Exkursionen}

Es ist eine der schönen Seiten der Geographie, daß sich die Beschäftigung mit dieser Wissenschaft nicht nur auf der Ebene der Theorie, im Vortragssaal oder 
in der Studierstube abspielen kann, sondern auch in der freien Natur, bei der unmittelbaren Betrachtung des Objekts. Damit gelangen wir schließlich noch zu einer wichtigen Sparte der Gesellschaftsaktivitäten, die bis jetzt kaum erwähnt worden ist, zu den Exkursionen. Grundsätzlich unternimmt die GEGZ heute pro Jahr mindestens zwei Auflüge: eine eintägige Schweizer Exkursion und eine mehrtägige Reise ins Ausland. Die erste Auslandexkursion nach dem Zweiten Weltkrieg fand im Oktober 1951 statt. Mit einem Extrazug der Südostbahn fuhren damals 51 Teilnehmer nach Tirol, Kärnten und Salzburg. Die Leitung dieser Reise hatte Erich Schwabe inne, der sich seither bei zahlreichen weiteren Gelegenheiten als Exkursionsleiter verdient gemacht hat. Als Organisator und wissenschaftlicher Reiseführer hat sich auch Emil Egli ausgezeichnet, der wie Schwabe bereits seit Jahrzehnten Exkursionen ins In- und Ausland führt. Als Reiseziele standen in den letzten Jahren beispielsweise auf dem Programm: die Region Trier-Eifel-Mosel, zwei Abschnitte der Donau von der Quelle bis in die Wachau, Holland, die Normandie, Österreich, das Westalpengebiet, das Südtirol usw.

1989 wurden zwei Jubiläumsreisen durchgeführt, deren Organisation in verdankenswerter Weise das Vorstandsmitglied Hanspeter Staedeli übernommen hat. Die erste Reise stand unter dem Motto «Nostalgie auf der Schiene und in der Luft» und hatte das Wallis zum Ziel, die zweite, eine Rundreise durch das Engadin und Tessin, führte «Von den Gletschern zu den Palmen bzw. von den Palmen zu den Gletschern». Die beiden Reisegruppen der zweiten Exkursion, die den Ausflug im gegenläufigen Sinn von Zürich aus angetreten hatten, trafen sich unterwegs im Tessin zum gemeinsamen Mittagessen.

Von aktiven Gesellschaftsmitgliedern bekommt man immer wieder zu hören, daß im Vereinsleben gerade die Exkursionen die nachhaltigsten Eindrücke und die besten Kontakte ermöglicht haben. Das Gesellschaftsleben artikuliert sich auf den Exkursionen im besonderen Maße; neben der Wissenschaft kommt auch das Menschliche zu seinem Recht, und es ist klar, daß der Zusammenhalt unter den Mitgliedern dadurch gestärkt wird. Einige Exkursionen haben wegen außergewöhnlicher Vorkommnisse allgemein geographischer, klimatischer oder menschlicher Natur noch lange zu reden gegeben, so beispielsweise eine Fahrt nach Lyon 1979 , die überschattet wurde von der Explosion einer Bombe. Wie aus den Exkursionsberichten hervorgeht, verlaufen natürlich nur wenige Reisen derart spektakulär; in den allermeisten Fällen berichten die Teilnehmer von faszinierenden Eindrücken, erholsamen Tagen und schönen menschlichen Erlebnissen.

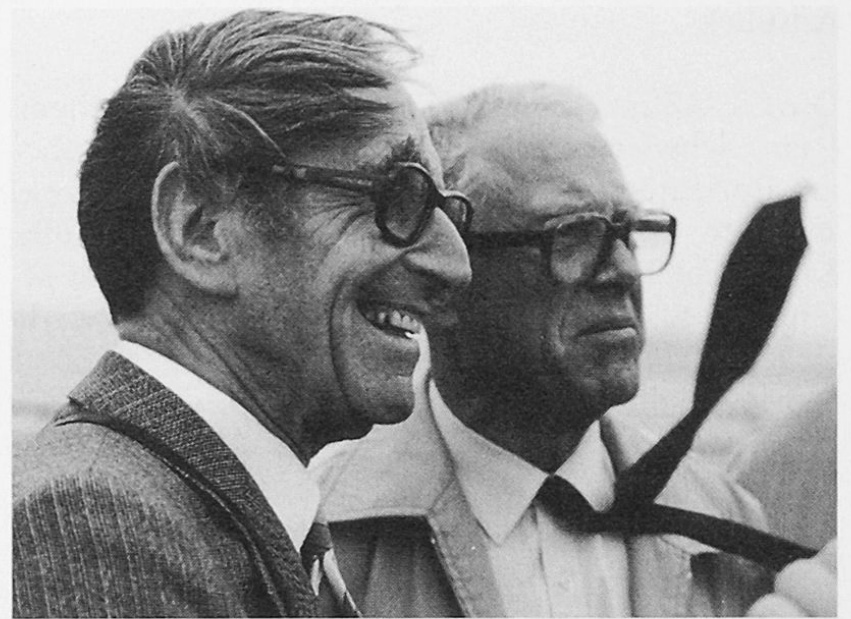

Abb. 16 Prof. Dr. Emil Egli (links), der Leiter der GEGZ-Studienreise nach Holland (16.-21. September 1985), und dipl. Ing. Josef Hanimann verfolgen im Sturm die letzten Abschlußarbeiten im Deltawerk. .

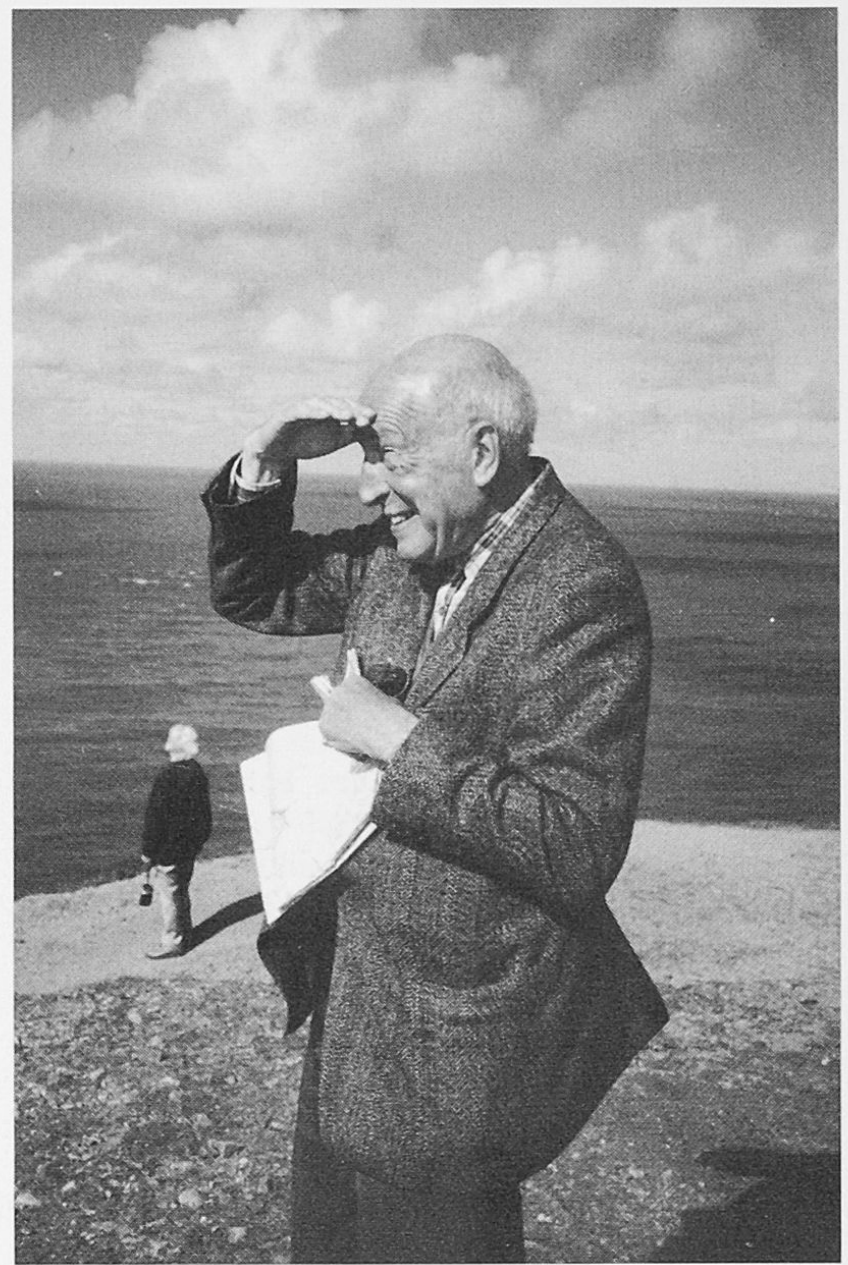

Abb. 17 Der Leiter der Exkursion in die Normandie (27. Sept.-1. Okt. 1988), Prof. Dr. Erich Schwabe, an der Küste des $\mathrm{Nez}$ de Jobourg. 


\section{Ausblick}

Die GEGZ im zweiten Jahrhundert ihres Bestehens - eine schwierige Prognose! Wollte man den früheren Berichten und Voraussagen Glauben schenken, so hätte eine «geographische Bewegung» große Kreise der Bevölkerung erfassen müssen; es ist offenkundig, daß dem heute nicht so ist. Müssen wir also realistischerweise annehmen, daß dieses Ziel Illusion bleiben wird?

Eines steht fest: Die Gesellschaftsaktivitäten werden wie bis anhin auch zukünftig auf zwei Bahnen verlaufen, und zwar in den beiden Bereichen Veranstaltungen und Sponsortätigkeit. Zu den Veranstaltungen zählen wir die.Vortragszyklen und die Exkursionen, während das Sponsoring in der finanziellen Unterstützung wissenschaftlicher Publikationen und Forschungsvorhaben und damit in der Förderung junger Wissenschaftler besteht. Offen bleibt die Frage, wie die Gewichte gelegt werden und welche Kriterien in den Gesellschaftsaktivitäten maßgebend sein sollen. Soll vermehrt auf die Breitenwirkung in der Öffentlichkeitsarbeit abgezielt werden oder hat die Propagandierung der wissenschaftlichen Forschungsarbeit Priorität? Welche Rolle wird die GEGZ beispielsweise in Zukunft hinsichtlich der Trägerschaft der "Geographica Helvetica» spielen? Die Zeitschrift hat sich bis zu einem gewissen Grad von ihrer Herausgeberin entfernt und verselbständigt, und es ist ein offenes Geheimnis, daß ihre Herstellung stark zu Buche schlägt.

Könnte die in gewisser Hinsicht notwendig gewordene Wiederbelebung der Gesellschaft durch eine Betonung ihrer Eigenständigkeit, d. h. durch eine bewußtere Abgrenzung gegenüber den Hochschulinstituten erzielt werden? Diese Abgrenzung ließe sich inhaltlich und äußerlich verstehen, denn die Gesellschaft demonstriert nicht nur durch die Auswahl ihrer Referenten bzw. Vortragsthemen, sondern auch durch ihren räumlichen Standort ihre Verbundenheit mit der Hochschule. Könnte diese Eigenständigkeit beispielsweise dadurch erreicht werden, daß die GEGZ die Rolle eines Bindeglieds zwischen der Geographie und der Ethnologie übernähme, zwischen den beiden Schwestern, die sich schon reichlich fremd geworden sind?

Der Verfasser der vorliegenden kleinen Gesellschaftsgeschichte fühlt sich nicht berufen, auf solche und andere Fragen auch Antworten zu geben; ihre Beantwortung wird vielmehr das Resultat einer gesellschaftsinternen Auseinandersetzung sein. Diese Standortbestimmung und die aufgeworfenen Fragen haben dann ihren Zweck erfüllt, wenn sie zur Diskussion über die heutige und zukünftige Funktion der Geograhisch-Ethnographischen Gesellschaft anregen und damit zu ihrer weiteren gedeihlichen Entwicklung und sinnvollen Entfaltung beitragen.

An den Schluß unserer Betrachtungen sei ein Zitat aus einer Rede des bedeutenden Zürcher Kulturgeographen Emil Egli gestellt, das uns in Zukunft als Leitlinie dienen könnte. Egli sprach 1961 an der 50-Jahr-Feier des Vereins Schweizerischer Geographielehrer in Bern über «Die Geographie in Wissenschaft und Bildung», und er hat dabei in eindrücklichen Sätzen die Besonderheit der Geographie herausgearbeitet: ihre Rolle als Mittlerin zwischen den «Earth Sciences» und den «Human Sciences», ihre einzigartige Fähigkeit zur Synthese und zur Gesamtschau, kurz Wesensmarkmale, welche uns diese Wissenschaft als besonders anziehend, vielseitig und zukunftsgerichtet erscheinen lassen:

«Die Trennung der Wissenschaften und die entwicklungsgemäß unvermeidliche, immer weitergehende, spezialisierende Aufspaltung und Verzweigung führten zum Verfall der Wissenseinheit. Die Klage darüber steigt durch unsere erste Jahrhunderthälfte empor. Es ist die übereinstimmende Klage unserer größten Denker. Es mahnten auch jene, welche in der vordersten Linie der Forschung stehn, wie C. F. von Weizsäcker 1948: „Eine spezialisierte Wissenschaft ist nicht imstande, uns ein Weltbild zu geben, das uns in der Verworrenheit unseres Daseins einen Halt böte. Daher sucht man nach der Synthese, man wünscht den großen Überblick." Niemand prangere die Spezialisierung an. [...]. Aber je kleiner die Steine eines Mosaikes sind, um so größer ist die Gefahr der Verwirrung und um so deutlicher muß also die Linienführung der Übersicht sein. Je weiter die Spezialisierung geht, um so dringender benötigen wir noch die Übersicht, die Gesamtschau. [. . .].

Jedes Fach sucht für sich nach Rundung, jedes Fach ist bestrebt, die Übersicht über sich selbst nicht zu verlieren. Und schon das ist heute oft schwierig geworden. Aber zwischen den Forschungsgebieten bleiben noch die Gräben offen. Der, ,große Überblick" bleibt wünschbar. Die einzelnen Wissenschaften können ihn nicht geben. Es braucht dafür die Sonderdisziplin, welcher das Recht zugesprochen wird, aus den Teilresultaten [...] das Gewölbe der Ganzheit zu bauen. [. . . ]. Und ist es nun nicht geradezu ein Glücksfall in der Geschichte der Wissenschaften, daß in diesen Jahrzehnten, da der Ruf nach Überblick, nach Gesamtheit immer lauter wird, die Geographie freier und reifer vor ihrer Sendung steht? Freier durch die Abspaltung selbständig gewordener Randdisziplinen; reifer, weil in ihre zentrale Aufgabe endgültig hineingewachsen und weil die Stoffsammlung der Spezialwissenschaften reicher zur erd-menschlichen Synthese zur Verfügung steht.

So kann denn die Geographie mithelfen, „Disharmonien zu beseitigen". Denn ihre Kraft und ihre Aufgabe in Bildung und Wissenschaft ist die Verbindung. Das ist gelegentlich als ihr Verhängnis gedeutet worden. Es ist ihre Berufung und unser Glück» (EGLI, 1961 [1975]: 184-8). 


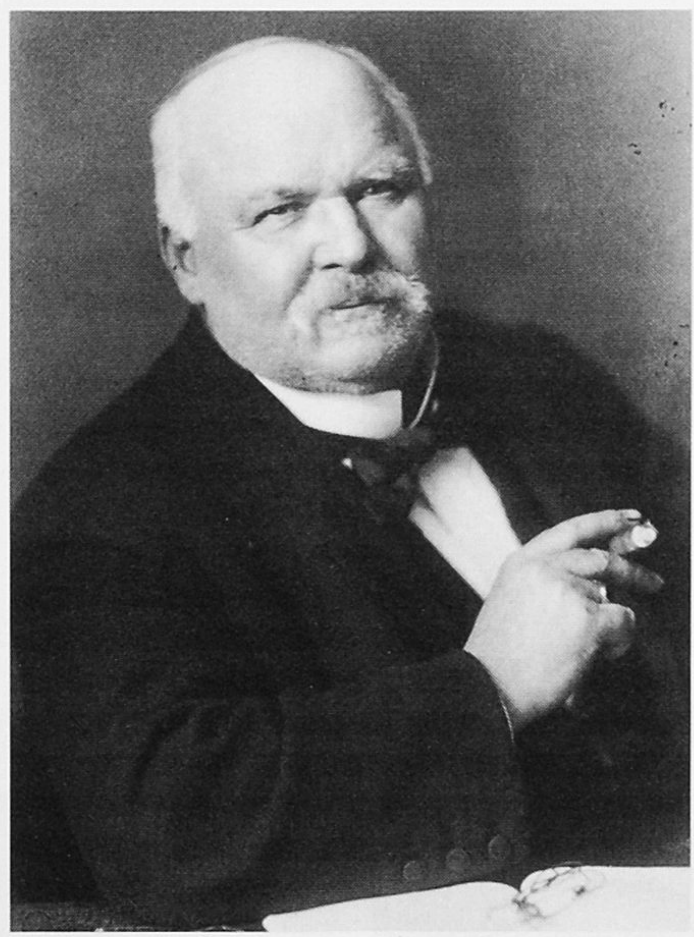

1899-1901, 1903-1914

Dr. Conrad Keller (1848-1930)

Professor für Zoologie an der Universität Zürich und an der ETH

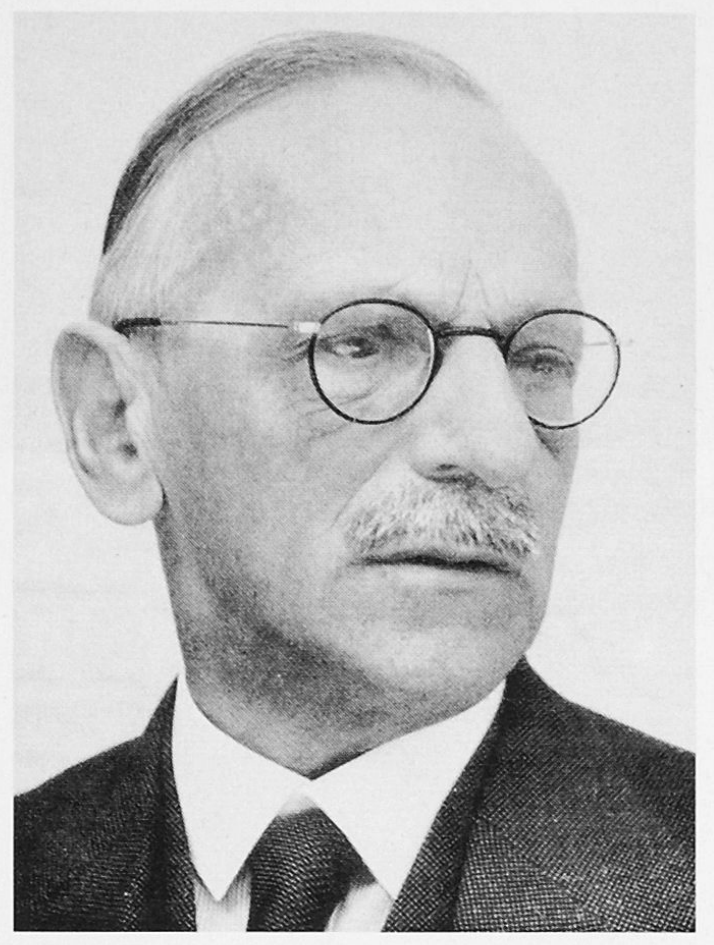

$1914-1930$

Dr. Hans Wehrli (1871-1945)

Professor für Geographie und Ethnographie an der Universität Zürich

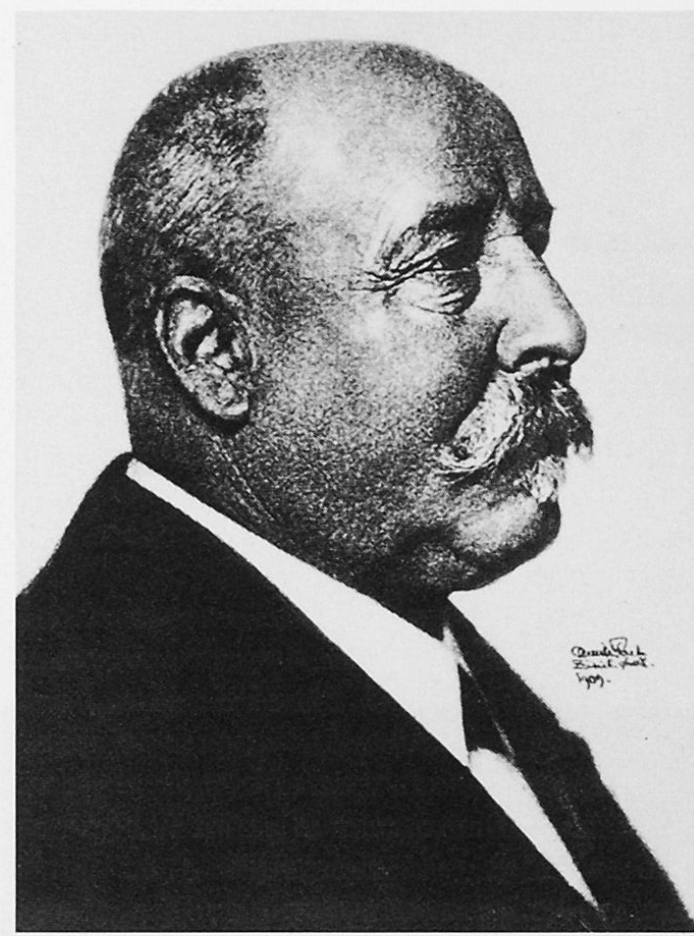

$1901-1903$

Dr. Ulrich Meister (1838-1917)

Zürcher Stadtforstmeister, Politiker, Oberst

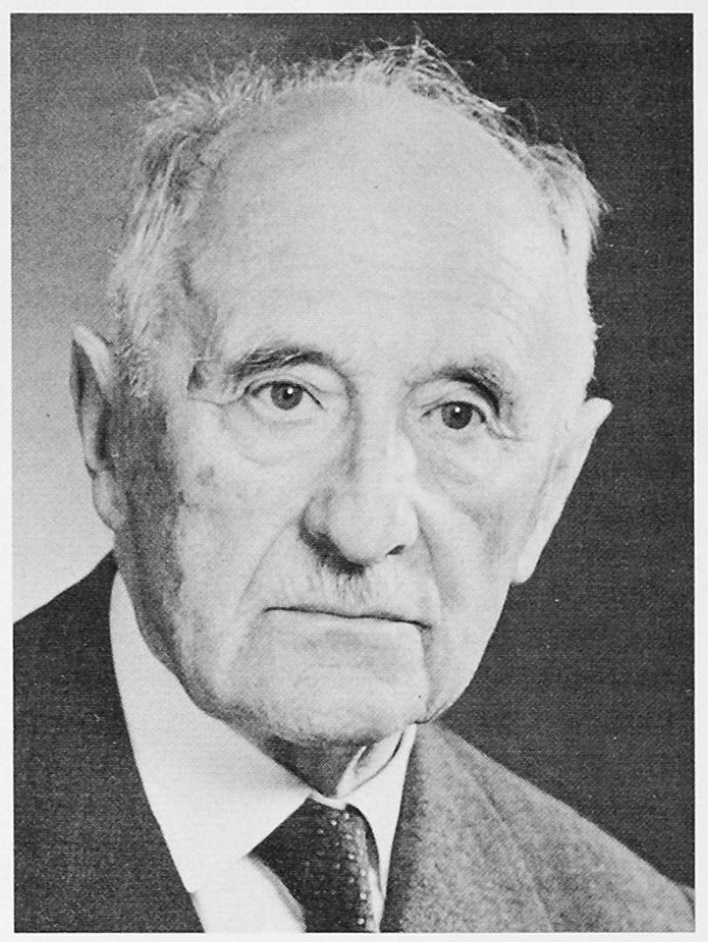

$1930-1936$

Dr. Otto Schlaginhaufen (1879-1973)

Professor für Anthropologie an der Universität Zürich 


\section{$1936-1940$}

Dr. h. c. Eduard Imhof (1895-1986)

Professor für Kartographie an der ETH

(Siehe S. 132, Abb. 7)

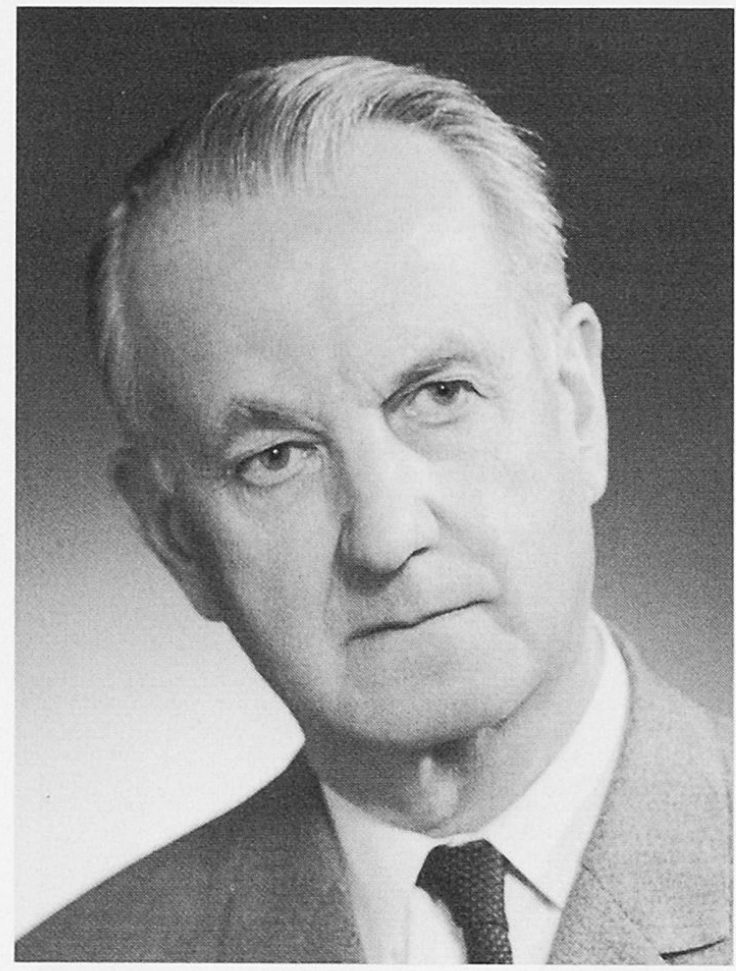

$1942-1948$

Dr. Heinrich Gutersohn (geb. 1899)

Professor für Geographie an der ETH
$1940-1942$

Dr. Otto Flückiger (1881-1942)

Professor für Geographie an der Universität Zürich

(Siehe S. 131, Abb. 6)

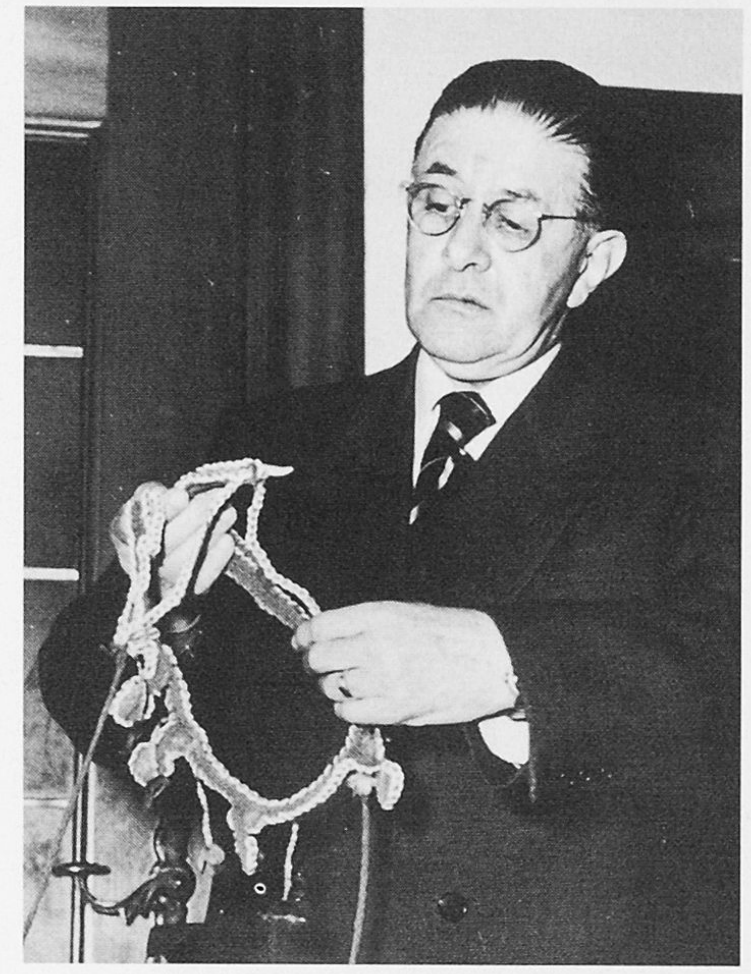

1948-1954

Dr. Alfred Steinmann (1892-1974)

Professor für Völkerkunde an der Universität Zürich

1954-1962

Dr. Hans Boesch (1911-1978)

Professor für Geographie an der Universität Zürich

(Siehe S. 139, Abb. 12) 


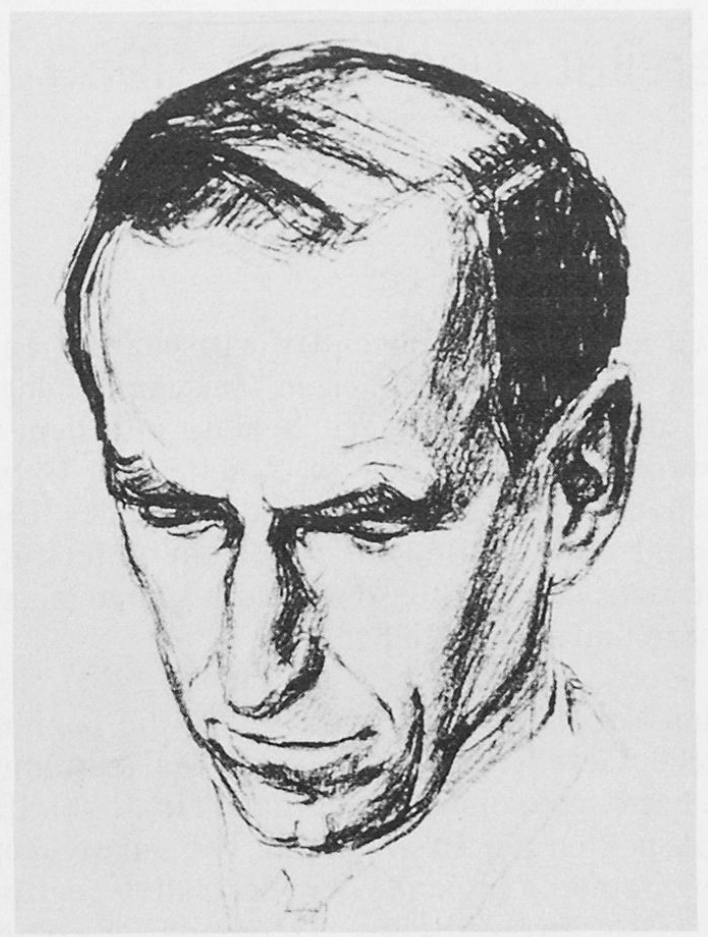

1962-1973

Dr. Emil Egli (geb. 1905)

Professor für Geographie an der Kantonsschule, Dozent an den beiden Zürcher Hochschulen

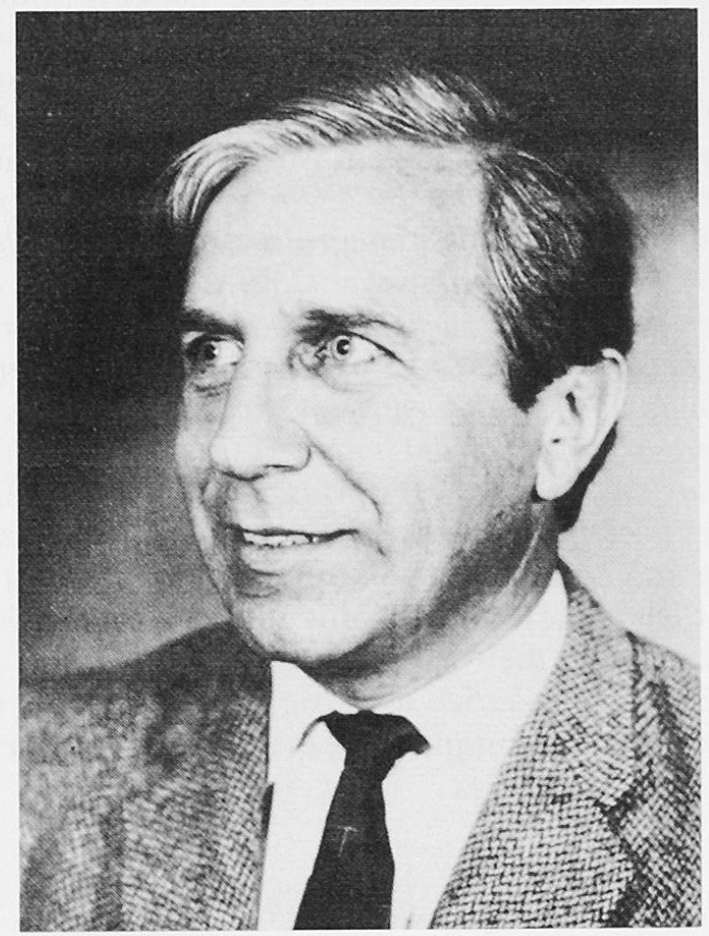

1980

Dr. Fritz Müller (1926-1980)

Professor für Geographie an der ETH

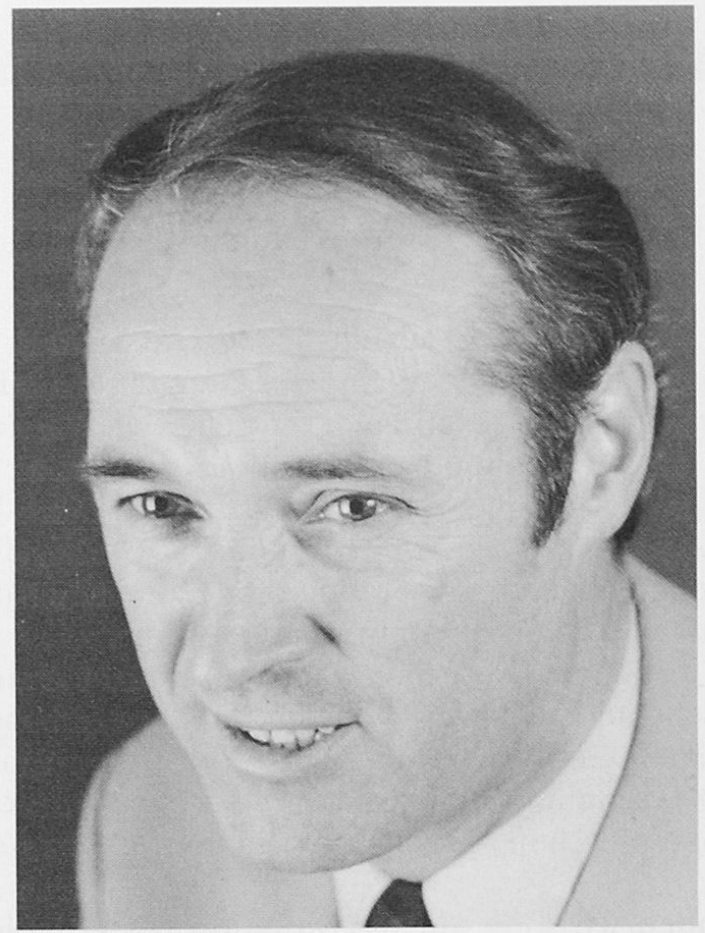

$1973-1980 / 1981$

Ernst Spieß (geb. 1930)

Professor für Kartographie an der ETH

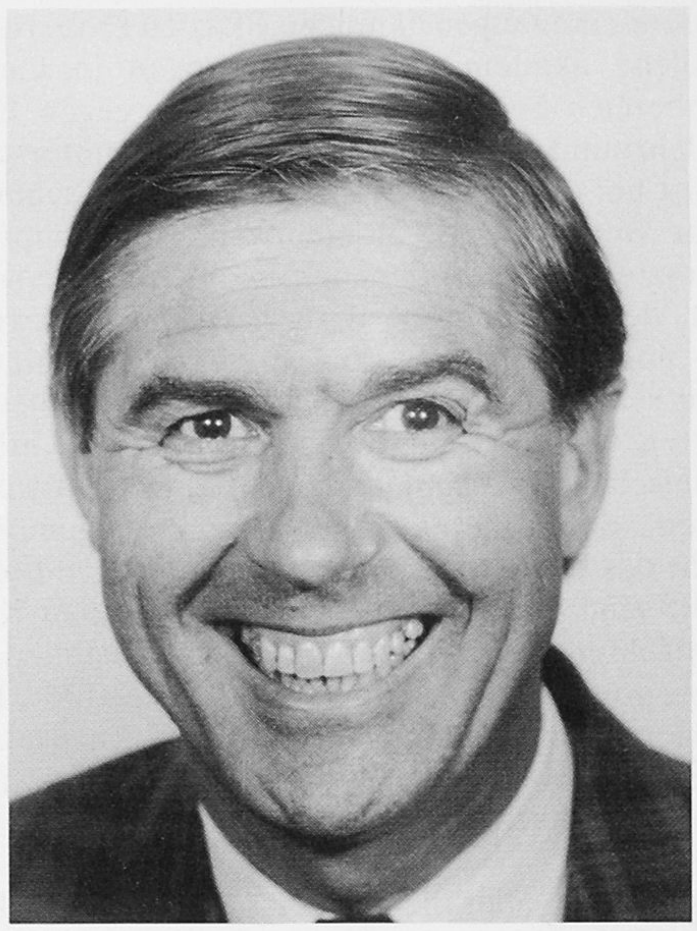

Seit 1981

Dr. Harold Haefner (geb. 1933)

Professor für Geographie an Universität Zürich 